\title{
A SIMPLIFIED PROCEDURE FOR MAJOR THOROUGHFARE PLANNING IN SMALL URBAN AREAS
}

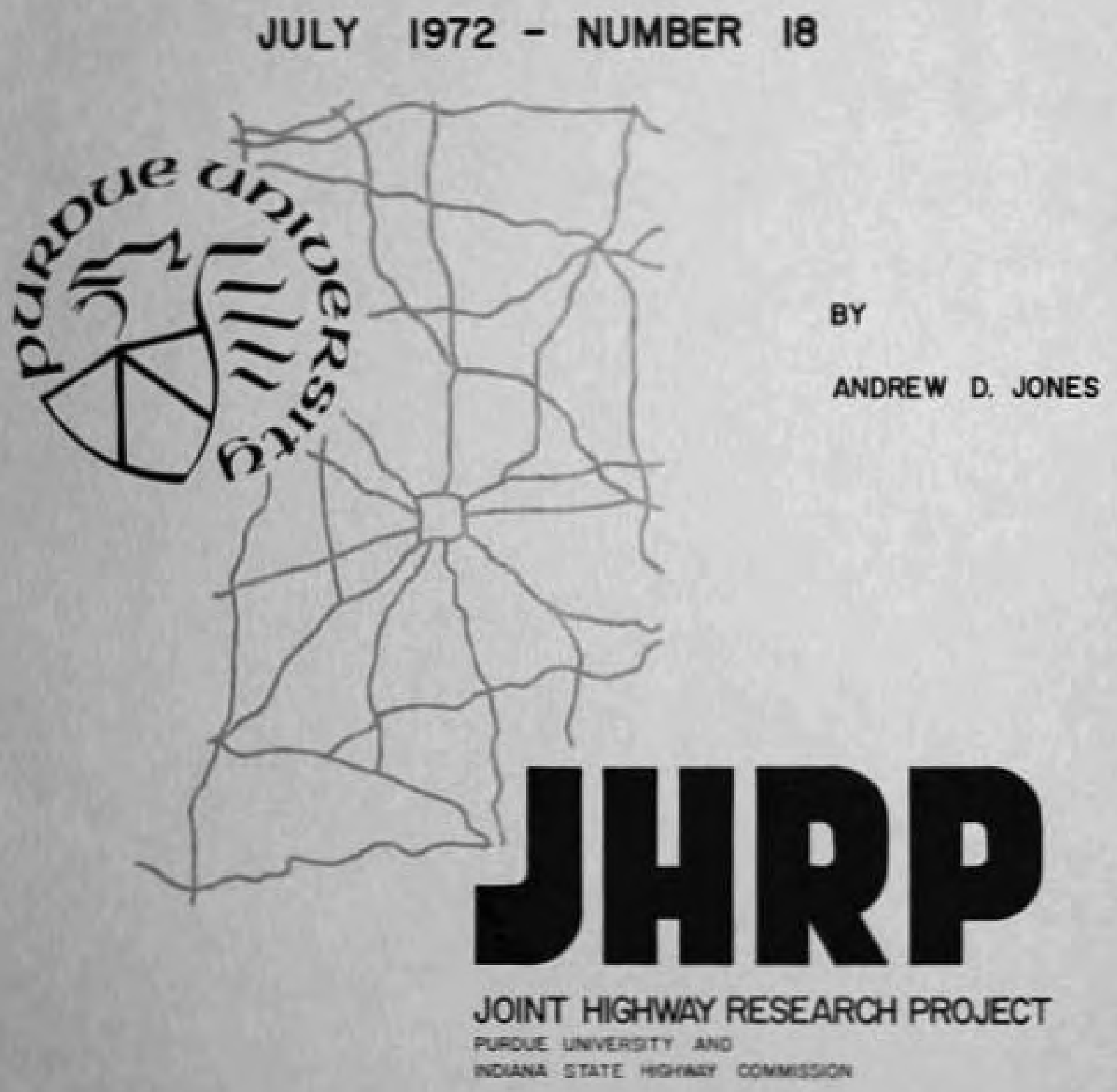




\section{Interim Report}

A SIMPLIFIED PROCEDURE FOR MAJOR THOROUGHFARE PLANNING

\section{IN SMALL URBAN AREAS}

TO: J. F. McLaughlin, Director

Joint Highway Research Project

FROM: H. L. Michael, Associate Director Joint Highway Research Project
July 26,1972

Project: C-36-69D

File: $\quad 3-7-4$

The Interim Report attached is submitted for acceptance as partial fulfillment of the objectives of Part V, "Alternate Planning Process for Small Cities", of the HPR Part I Research Study "An Investigation of Major Aspects of the Urban

Transportation Planning Process". The Report has been prepared by Andrew D. Jones, Graduate Instructor in Research, under the direction of Professor W. L. Grecco.

The Report documents research on refinement of previously developed corridor growth factor models for developing future estimates of internal traffic in small urban areas and on the development of regression models for trip data normally obtained at external cordon surveys. The developed procedures are adequate for the accuracy necessary for major thoroughfare planning in small urban areas. The feasibility of the complete procedure is demonstrated in Columbus, Indiana. The procedures developed permit adequate planning at lower cost, in more rapid time, and at a level of sophistication that will permit application by personnel available in small communities.

The Report is presented for acceptance. It will also be forwarded for review, comment and acceptance by ISHC and FHWA.

Respectfully submitted,

HLM:ms

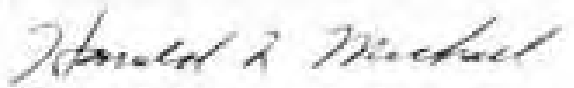

Harold L. Michael

Associate Director

cc: W.L. Dolch

R.L. Eskew

W.H. Goetz

W.L. Grecco

M.J. Gutzwiller

G.K. Hallock
R. H. Harrel1

M. L. Hayes

C. W. Love 11

G. W. Marks

R. D. Miles

J. W. Miller
C. F. Scholer

M. B. Scott

J. A. Spooner

N. W. Steinkamp

H. R. J. Walsh

E. J. Yoder 


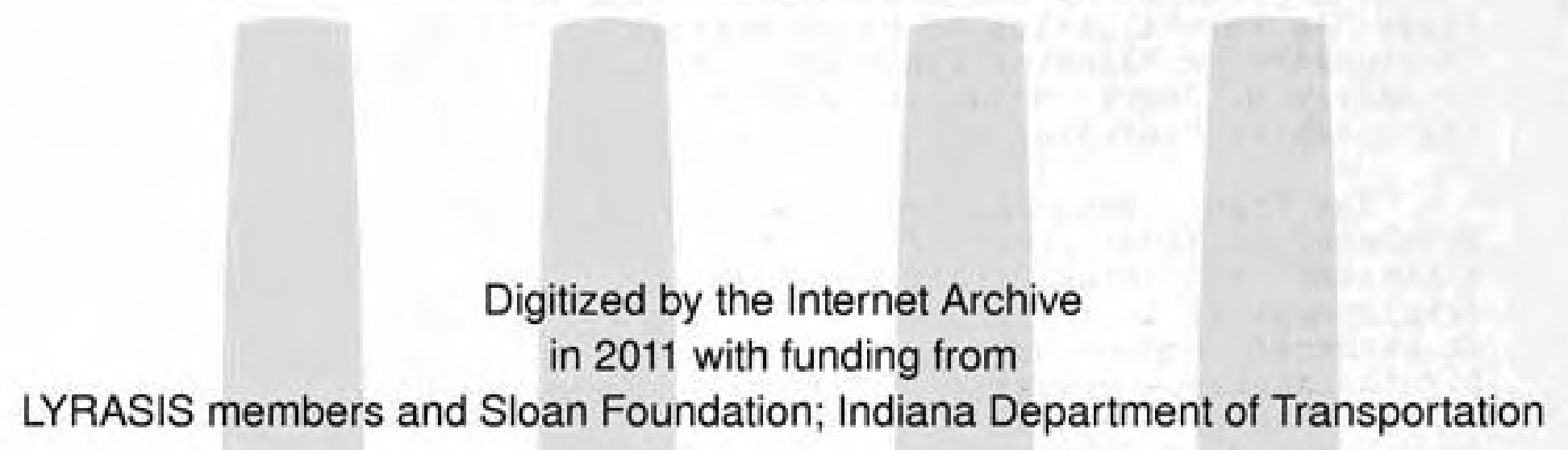

http://www.archive.org/details/simplifiedproced00jone 
Interim Report

A SIMPLIFIED PROCEDURE FOR MAJOR THOROUGHFARE PLANNING IN SMALL URBAN AREAS

by

Andrew D. Jones

Graduate Instructor in Research

Joint Highway Research Project

Project No.: C-36-69D

File No.: 3-7-4

Prepared as Part of an Investigation

Conducted by

Joint Highway Research Project

Engineering Experiment Station

Purdue University

In cooperation with the

Indiana State Highway Commission

and the

U.S. Department of Transportation

Federal Highway Administration

The opinions, findings and conclusions expressed in this publication are those of the authors and not necessarily those of the Federal Highway Administration. 


\section{ACKNOWLEDGEMENTS}

The author wishes to express his sincere appreciation to all those who have assisted him during this project.

The author is particularly indebted to Dell and Rosadel Butcher for their encouragement and assistance.

The author takes this opportunity to express his appreciation to Professor William L. Grecco for his guidance, understanding and generous assistance throughout the project; to Professor Harold L. Michael for his recomendations, assistance and review of the manuscript; to Professor Virgil L. Anderson, Department of Mathematics and Statistics, for his advice and review of the data analysis and manuscript; and to Professor Robert D. Miles, for his review of the manuscript.

Acknowledgement of the assistance provided during the data collection in Columbus is made to Thomas Chastain, Bill Connor and John West.

Sponsorship of the project by the Joint Highway Research Project and the Indiana State Highway Commission is also gratefully acknowledged.

Finally, but definitely not least, the author expresses his gratitude to his wife Norene and son Randal for their encouragement, assistance and understanding throughout the project. 
TABLE OF CONTENTS

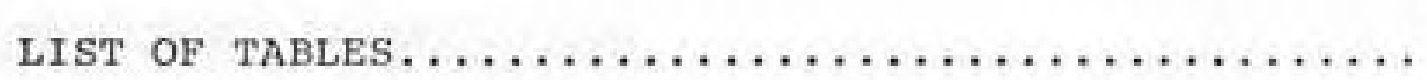

Page

LIST OF FIGURES $\ldots \ldots \ldots \ldots \ldots \ldots \ldots \ldots \ldots \ldots \ldots \ldots \ldots \ldots \ldots \ldots$

ABSTRACT . . . . . . . . . . . . . . . .

INTRODUCTION $\ldots \ldots \ldots \ldots \ldots \ldots \ldots \ldots \ldots \ldots \ldots \ldots \ldots \ldots \ldots \ldots \ldots$

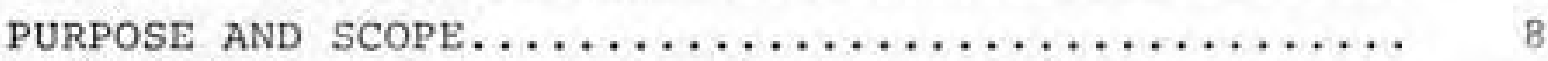

REVIEW OF LITERATURE. . . . . . . . $\ldots \ldots \ldots \ldots \ldots$

CONCEPTUALIZATION OF A SIMPLIFIED PLANNING

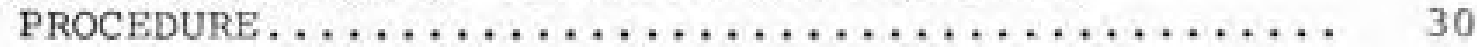

Corridor Identification................ 32

External Traffic.................... 33

Distribution of Trips Between External Stations.. 35

Distribution of External Trips Within The

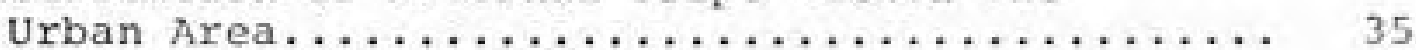

Developing a Growth Factor............... 36

Plan Evaluation...................... 38

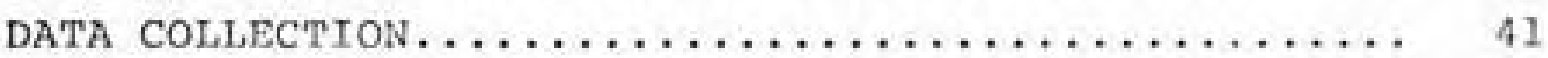

Data Collection: Lafayette - West Lafayette..... 41

Employment........................ 41

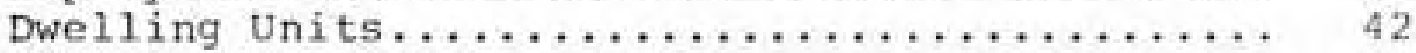

1952 Traffic Data....................... 43

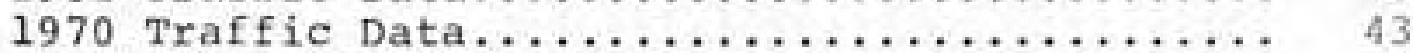

Automobile Registration................ 46

Data Collection: Columbus................. 46

Dwelling Units..................... 46

1960 and 1970 Traffic Data............. 47

Automobile Registration............... 47

Employment....................... 47

Street Inventory .................. 47

Miscellaneous Data.................... 48

Data Collection - External Models........... 48

TESTING THE CORRIDOR GROWTH FACTOR TECHNIQUE IN

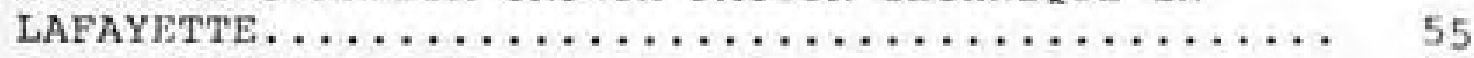

Conclusions on The Lafayette Check.......... 73

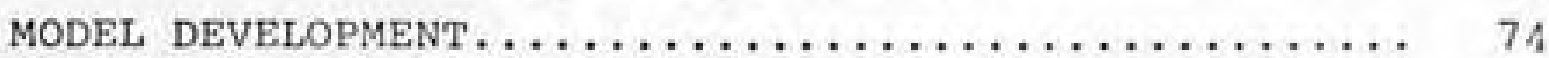

Regression Models................... 74 
Stepwise Regression. . . . . . . Page

Direct Models.................... 84

Distribution of Total External Volumes Among

External stations..................... 85

Distribution of External-Internal Volumes to

Stations........................ 86

Forecasting External Volumes............. 89

Determining Fxternal-External Volumes......... 94

External-Internal Traffic to CBD ........... 94

COLUMBUS FEASIBILITY DEMONSTRATION ............. 99

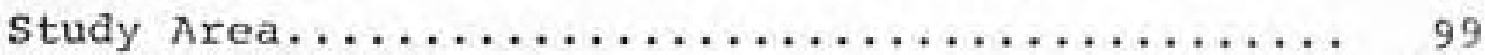

External Cordon...................... 100

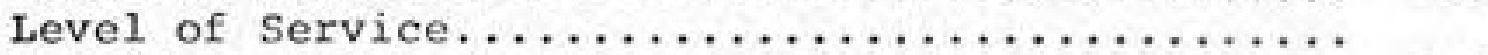

Corridors and Major Thoroughfares........... 101

Calibration Procedure...................... 105

External Traffic....................... 105

Internal Traffic.................. 106

Conclusions......................... 111

SUMMARY AND CONCLUSIONS $\ldots \ldots \ldots \ldots \ldots \ldots \ldots \ldots \ldots, 112$

RECOMMENDATIONS FOR FURTHER RESEARCH $\ldots \ldots \ldots \ldots \ldots, 116$

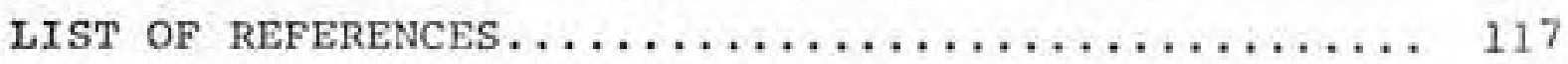

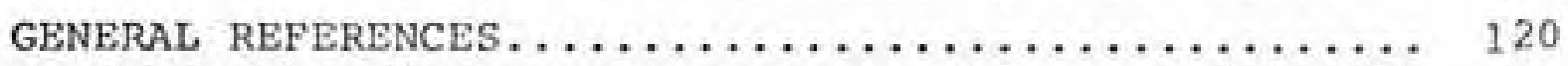

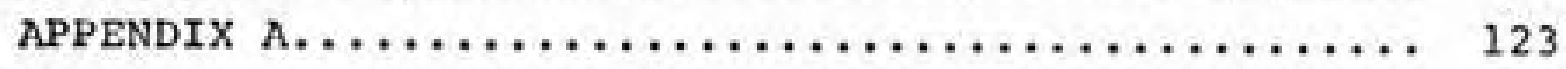

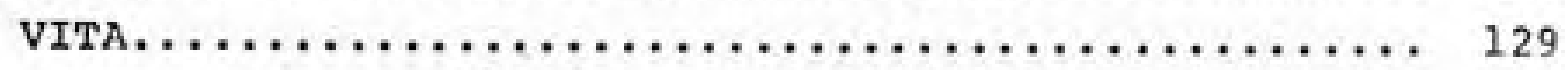


LIST OF TABLES

Table

Page

1 Cities Included in study............... 49

2 Auto Driver Linked Trips By Purpose......... 62

3 Radial Corridors - Lafayette - Near Central

Area............................. 65

4 Radial Corridors - Lafayette - nidpoint of

Corridor ........................... 66

5 Lafayette - Circumferential Routes.......... 67

6 Adjusted Volumes - West Lafayette........... 69

7 Radial Corridors - Lafayette - Near Central

Area.............................. 70

8 Lafayette External Cordon Stations.......... 71

9 Distribution of External Traffic Anong Stations. 87

10 External Volume vs. External - Internal

Volume Mode1 ..................... 50

11 Check on Growth Factor Based on County Vehicle

12 City Data - Percent of External-Internal Trips

with CBD and Frame Destinations and Percent

of Total Employment in $\mathrm{CBD}$ and Frante....... 96

13 Columbus - External Cordon stations.......... 107

14 Radial Corridors - Columbus - Near Central

Area............................ 110

Appendix

Table

1 A 1952 Lafayette Corridor Data.............. 12 A

2A 1970 Lafayette Corridor Data............... 125

3A 1964 West Lafayete Data................. 126

$4 \mathrm{~A} 1960$ Colubbus Corriclor Data.............. 127

5A 1970 Columbus Corridor Data............... 128 
LIST OF PIGURES

Figure

Page

$1 \quad 1952$ Traffic Volumes - Lafayette........... 44

$2 \quad 1970$ Traffic Volumes - Lafayette.......... 45

3 Location of cities in Data Set........... 50

4 Greater Lafayette Urban Area Location

in Indiana...................... 56

$5 \quad 1964$ Traffic Volunes - $\mathbf{w}$. Lafayette......... 5t:

6 Corridors - Lafayette ................. 59

7 Corridors - Lafayette.................. 60

8 Average Corridor Error vs. Parameter Sets.... 64

9 Percent of Total External Crossings at

Corcion Station in Base Year vs. Percent

External Crossings at Cordon Crossing in

Present Year......................... 88

10 Percent of Total External Crossings at Cordon

Station va. Percent External-Internal Cronsings

at Cordon station.................. 91

11 County Vehicle Registration Increase as Growth Factor for External Trips................

12 Percent External-Internal Cordon Crossings with Destinations in CBD and Frame vs. Percent Total Employed in CBD and Frame.............

13 Greater Columbus Urban Area Location in Indiana 102

14 Corridors-Columbus.................... 103

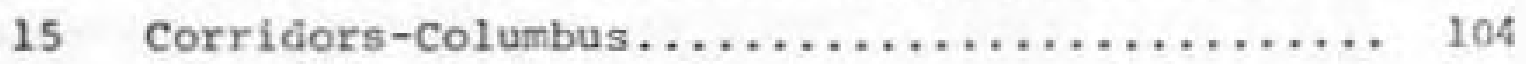


ABSTRACT

Jones, Andrew Delaney, Ph.D., Purdue University, August 1972. Simplified Procedure for Najor Thoroughfare Planning in Small Urban Areas. Najor Professor: Hililata L. Grecco.

The purpose of the research project was to develop a simplified procedure for major thoroughfare planning in small urban areas. Previously developed corridor grouth factor models for developing future estinates of internal traffic in small urban areas were tested, modificd and refined using Lafayette, Indiana data.

Regression models to provide data ustally obtained by use of external cordon surveys were doveloped. External survey reports from thirty-six cities in fourteen states, ranging in population from ten thousand to ninety thousand, provided the majority of the data utilized. Alternate procedures for providing the external survey information, based on use of historical data from the subject city, were also developed.

The completed procedure provides forecasted traffic volumes within the accuracy necessary for major thoroughfare planning in small urban areas at lower cost and with a level of sophistication that will permit application by personnel usually available in small communities.

The feasibility of the complete procedure for providing the required traffic volume for major thoroughfare planning in snall urban areas was demonstrated in Columbus, Indiana. 
INTRODUCTION

The President of the United States, John F. Kennedy, in his message to The Congress of The United States, April 5, 1962, formally recognized the vital part adequate well planned transportation facilities play in our everyday lives in all areas of the United States by stating that an efficient and dynamic transportation system is vital to our domestic economic growth, productivity, and proyress. The President further emphasized in his address the basic objectives of the transportation systems of the nation by stating the following:

"The basic objective of our Nation's transportation system must be to assure the availability of the fast, safe, and economical transportation services needed in a growing and changing economy to move people and goods, without waste or discrimination, in response to private and public demands at tice lowest cost consistent with health, convenience, national security, and other broad public objectives."

The President in this address also requested legislation that would provide for adequate transportation planning in the major cities of the nation. The final legislation passed by Congress providing for transportation planning under the auspices of the Federal Aid Highway Act of 1962, as a matter of practicality, limited the required transportation planning to areas commonly designated as standard metropolitan statistical areas. This definition basically means an area containing a central city or cities of 50,000 or more population.

The Federal Mid Highway Act of 1962 states the following: 
"It is declared to be in the national interest to encourage and promote the development of transportation systems embracing various modes of transport in a manner that will serve the State and local communities efficiently and effectively . . After July 1, 1965, the Secretary shall not approve under section 105 of this title any program for projects in any urban area of more than fifty thousand population unless he finds that such projects are based on a continuing comprehensive transportation planning process carried on cooperatively by State and local communities in conformance with the objectives stated in this section." (27)*

A comprehensive, continuing, cooperative planning process was therefore to be required in each of the SuSA's in the United states. However, traffic problems and congestion are not unique to these cities that qualify as SuSh's but are present in varying degrees in all citics. In the satne legislation the necessity and advisability of planning in cities of 5,000 to 50,000 population was also recognized but, due to the tremendous task already imposed by the required planning, planning in these areas was not made compulsory. It is in. such small areas that the procedures developed and contained herein are intended to apply.

The continuing planning process developed as provided by Federal Aid Highway Act of 1962 was very precise and detailed in the stated requirements. A complete land use inventory, an inventory of existing physical facilities, an inventory of population and economic information, a review of existing zoning and subdivision regulation ordinances, an inventory of parking facilities and usage, and a complete inventory and study of all other aspects pertaining to or connected with existing traffic was required. In addition to requiring the detailed inventories, the manner in which this information would be obtained was

\footnotetext{
* Numbers in parentheses refer to entries in the List of References.
} 
carefully outlined. A home interview origin-destination survey and an external cordon survey were specific requirements. The total sample size or percent of the existing dwelling units in the area to be interviewed varied with the size of the city. The overall study design was directed toward producing statistically sound information on trip making for the entire area. The external cordon survey was designed to determine the number of trips with their origin or destination outside the study area and crossing the cordon line on a daily basis. With the information from the external survey and other collected data, forecasts of future traffic volumes can be made and total future trip generation by traffic zone within the study area determined. Through the use of computers, these future trips are distributed between the various traffic zones and finally the total trips between zones are assigned to a mathematical representation of the major arterial network. Through this process the planners are able to determine the segments of the transportation system requiring either improvement or the planning and development of complete new segments to handle forccasted traffic for the target year in the community. This is accomplished by comparing the assigned traffic to the existing capacity of the individual segments of the system. Techniques specifically designed to accomplish the same objectives for the smaller urban areas as for these larger studies have not been developed. In general, especially in the 25,000 to 50,000 population range, it has been the practice to assume that the same studies and depth of detail as used in the larger areas were an absolute necessity. This of course means that in smaller urban areas, to ensure statistically sound sampling, a much higher overall sample percentage is necessary for the home interview origin-destination survey. In addition, a staff to successfully complete a transportation study 
requires highly qualified professional and technical personnel. The required professional staff for a small urban area will be almost as large as a staff for a larger urban area. The end result is that even if a competent staff were available to complete a transportation study for a small urban area, the cost will be much higher on a per capita basis then for a large urban area. The National Committee on Urban Transportation gives the following cost figures for the data collection phases of the external cordon and home-interview studies (5):

Metropolitan

Population

50,000 to 150,000

150,000 to 300,000

300,000 to 500,000

500,000 to $1,000,000$
Data Collection

Cost

$\$ 30,000-85,000$

$68,000-135,000$

$85,000-150,000$

$112,000-225,000$
Per Capita

\begin{tabular}{ll} 
Cost \\
\hline$\$ \quad .60$ \\
.45 \\
.30 \\
.22
\end{tabular}

A recent $H R B$ report entitled "Data Requirements for Metropolitan Transportation Planning" (7), reviewed the primary data collection costs for five transportation studies conducted in Buffalo, Chicago, Milwakkee, Tucson, and Wilmington, reporting that this cost ranged from $\$ 0.22$ to $\$ 0.86$ per capita and averaging $\$ 0.52$ per capita. The $\$ 0.22$ figure was for Chicago and the $\$ 0.86$ figure was for Tucson, indicating the trend toward a cost increase with a decrease in city size.

There are two transportation studies currently in progress in Indiana that provide current estimates for the total cost of such studies. The estimated total costs for the two studies currently under way in Indiana is approximately $\$ 1,000,000$ for Evansville (population approximately 250,000$)$ and $\$ 575,000$ for Lafayette (population - approximately 109,000), which results in overall total study costs per capita of approximately $\$ 4.00$ and $\$ 5.25$. This also indicates the increasing per capita cost accompanying the decrease in city size. 
An additional major disadvantage of the detailed procedures followed in larger areas is the length of time required to complete such a comprehensive study. The initial data collection phase of a study will usually require a minimum of two years when using established procedures in any urban area. In addition, to attain the maximum benefits from such studies they should be reviewed and updated every five years as a minimum.

In the smaller urban areas of 5,000 to 50,000 population there are always many existing minor transportation problems. These will become greater as the area yrows and auto registrations increase. These problems can be alleviated by proper planning in the majority of cases even though such planning is not presently required by Federal legislation.

For the purposes of this study a small urban area will be defined as a geographically separate urban arca. The size will be limited to less than 100,000 population. Public transportation in such areas usually is nonexistant or at best provides transportation for a small portion of the population, therefore study procedures for this area will not be included.

A simplified planning procedure for major thoroughfare planning, developed and designed specifically to satisfy the requirements of small urban areas, is needed. The procedure must be easily applied by the type of personnel usually available at the municipal level of government, must require a small budget, and must produce results with the degree of accuracy necessary for sound thoroughfare planning.

The utilization of the existing city personncl would accomplish a multipurpose objective. First, the completion of the study by the local people would enhance the possiblity of developing the all important continuing planning process. Second, this type of procedure would 
permit maximum efficiency and economy, allowing city personnel to complete the required data collection during normal slack periods in their regular routine. Third, and possibly most important, the involved personnel will gain an overall knowledge of the community and the traffic and transportation problems that could not be accomplished through any amount of training. The problem was approached with the above criteria as a guide.

D.K. French $(10)$, a Purdue Graduate, recently completed a research study utilizing data that is readily available in small areas to develop simple models for deriving internal-internal traffic volumes on arterial streets in small urban areas. At his point in time he felt that the external cordon survey would still be required to provide external volumes to be used in conjunction with his developed models to provide total volumes. This procedure was a considerable improvement over the generally accepted techniques but it still left the small urban area faced with the necessity for the expertise and funds necessary to complete an external cordon survey and assemble the information into a useable package.

French used three independent variables in his models that required collection of data. These variables were dwelling units, retail and total employment per corridor. The procedure also required the delineation of traffic corridors, establishing the limits of the central business district and its environments and determining an external cordon line. The existing traffic volumes at each intersection of a major arterial with the corridor boundary was also required. All the required information for the above models is readily available in all areas or easily obtainable from uncontrolled aerial photography such as flown by the U. S. Department of Agriculture, and other sources such as the state employment office, etc. 
This study was directod specifically to development of models to satisfactorily duplicate information normally obtained from external cordon surveys. The procedure utilized readily available data from completed external survey study reports to develop detailed models and application procedures for using these models to obtain future traffic volumes. The study also consisted of using this information to complete a thoroughfare study and plan for a small urban area. Constraints established were that the procedure would not require the use of a computer and that the required transportation expertise of personnel be minimal. For the purposes of major thoroughfare planning in small urban areas investigations of causal relationships between variables used in the models was not considered necessary. 
PURPOSE AND SCOPE

The purpose of this project was to develop a simplificd procedure for major thoroughfare planning in small urban areas.

The scope or basic parts of the research undertalen and described herein were three fold as follows:

1. The research project used data from external survey reports of numerous cities in the $5-100,000$ population range to develop models for replicating those portions of the external survey data required in the "corridor growth method" of forecasting traffic.

2. The methodology developed by French for estimating future traffic demand by "corridor growth factors" in a small urban area was tested using 1970 Lafayette data (10). A complete review of the method, including evaluation of the variables and their weights, was accomplished with the explicit purpose being to improve and simplify the overall procedure.

3. The feasibility of the models and detailed procedures proposed for use in major thoroughfare planning in small urban areas (as developed under items one and two above) was demonstrated in columbus, Indiana.

A data set consistine of variables obtained frou external cordon survey or planning reports from 36 cities in 14 states; with city size varying from 5,000-100,000 population was used in the regression procedures to develop the models for predicting external cordon traffic volumes. The information was limited to reports of studies or surveys of the cities dated 2960 or later. 
The Lafayette area data wereobtained from the Greater Lafayette Area Transportation and Development Study, The Indiana state Highway Commission and by ground surveys.

The Columbus, Indiana data were obtained through personal contact with area representatives, on the ground surveys and aerial photography.

A prime consideration throughout the project was to retain simplicity of methodology while ensuring adequate accuracy for the thoroughfare planning process. 


\section{REVIEW OF LITERATURE}

The literature review portion of this report will not attempt to exhaust or report in detail the information available from the many references on transportation planning because of the depth of knowledge that exists at this point in time on the subject. Attention will instead be directed to presenting the general requirements of the transportation planning process, documenting the modified requirements for planning in small urban areas being recommended, discussing a selected group of reporte dealing with research conducted in the arca of developing simplified planning and modeling procedures, presenting a review of information establishing the corridor analysis of traffic as an accepted procedure, and finally, presenting a brief documentation of information on external traffic composition to provide the basis for the theory behind the development of models for forecasting the external traffic information contained in this project.

A brief review of the use of aerial photogrametric techniques in conducting of transportation studies will also be presented.

Within the last few years more attention is being given to developing transportation planning techniques for application in the smaller cities, specifically those of less than 50,000 population. This re-evaluation of techniques has been the result of a number of factors as follows :

1. The planning emphasis on those cities of 50,000 and over population and the techniques required by them have required the expenditure of extremely large sums of money. 
2. These same transportation studies have utilizcd a large percentage of the available professionals that are qualified in these areas of endeavor.

As the planning processes in these larger transportation studies reach their peak effort and taper off into what is commonly known as the continuing process, more and morc of the people charged with the responsibility for maintaining adequate transportation facilities in all cities look to the requirements of the smaller urban areas. These administrators are faced with the dilenma of providing adequate transportation planning for these areas with a minimum of funds and personnel available for the purpose. Thus the impetus to stimulate development of new technigues specifically designed for such areas (utilizing where possible the data that have been collected on travel patterns and travel characteristics in the larger citiesl and depending more on models based on this available information rathor than additional surveys.

Some of the states that are active in these areas and have published reports on their research are Georgia, Virginia, Minnesota, Missouri and North Carolina. In these states it may be generally stated that the technigues used for pilot or research studies for simplified procedures involve utilization of data on travel characteristics from other completed transportation studies that used the home interview origin-destination survey technique for data collection. Regression models werc developed based on knowledge of interaction of variables gained from the previous studies and by using these nodels and collecting a minimum amount of data, traffic volumes were obtained. By forecasting future values for the independent variables and using the models, target year traffic volumes, permitting proper planning of major thoroughfares for the areas involved, were derived. 
The Federal Aid Highway Act of 1962 outlined ten specific areas for data collection and analysis in the transportation planning process as follows:

1. Population study and forecast

2. Economic study and forecast

3. Land use study and forecast

4. Transportation facilities

5. Travel patterns

6. Terminal and transfer facilities

7. Traffic enginecring features

8. Community controls

9. Financial resources

10. Community value factors

The methods suggested for collecting the data were presented in a series of reports called procedure manuals, published by the Public Administration Service (5). Stated in general terms, an urban transportation planning process required the inventory of existing facilities including the capability to handle traffic, both present and future, data collection to determine travel patterns and characteristics of trip makers, traffic forecasts for a target year, assignment to the existing facilities, identification of deficient network segments and development, and testing and evaluation of alternate future plans.

As a means of determining existing traffic patterns and providing a basis for forecasting future traffic volumes in an urban area the home interview origin destination survey was recommended and is generally used. The home interview origin destination study consists of interviewing a statistical sample of the trip makers in the urban area and expanding the trip information to represent the total existing trip patterns. By forecasting variables such as population, employment, etc., future trip patterns and volumes are derived. The sample rate used for the home interview study varies from twenty 
percent of the households for cities under 50,000 population to four percent for those of over 1,000,000, population. In conjunction with the home interview origin dostination survey an external cordon survey and truck and taxi survey are usually conducted. The purpose of the external corcion survey is to determine the number of trips to the area with origins and/or destinations outside the intensive study area. The external survey is conducted by stopping and interviewing a percentage of the total traffic at each external cordon station, and then expanding the data to represent the total volume. In these surveys information is obtained regarding trip purposes for all trips, the point of origin, the destination. In the home intervicw study - information was obtained to identify the type dvelling unit interviewed, the time of day all trips from that houschold are made, number of passengers in the vehicle, ctc.

The established procedure outlined above nocessarily requires substantial financing. The cost of obtaining the required information as given by the thational Comittce on Urban Transportation is 600 per capita for citics with population ranges from 50,000 to 150,000 , down to $22 \mathrm{C} p \in=\mathrm{I}$ capita for those cities ranging from 500,000 to $1,000,000$ population (5). Later figures given in 1170 special peport 120 (7) give per capita costs for prinary data collections for Buffalo, New York as $43 \mathrm{c}$ with this cost representing thirty six percent of the overall study cost. For Chicago the costs given are $22 \%$ per capita, ropresenting an expenditure of twenty eight percent of the total study cost for data collection. For Milwaukee the equivalent figures are $36 \%$ and thirty porcent respectivoly. In the Tucson and Wilmington studies the figures are $86 C$ and thirty eight percent and $73 \mathrm{c}$ and twenty five percent respectively. This indicates an average cost of $52 \mathrm{c}$ per capita for data collection with approximately thirty one percent of the total study cost devoted to the data 
collection phase. In the above cases the cities involved were all large cities but the trend of higher per capita costs as the city size decreases is readily apparent by comparison.

Research projects have been underway since the initiation of transportation planning in the early $1950 \mathrm{~s}$ investigating ways of reducing the data collection requirements and cost for transportation studies. Many of the efforts were directed towards attempts to utilize alternate means for conducting the home interview study such as telephone interviewing, mail questionnaires, and telephone and television type interviews. It is generally accepted that although these methods, due to their lower cost, allow obtaining a much larger sample, they also probably introduce bias in the sample. This is especially true if the individuals are required to return the questionnaires on their own initiative (5) (11).

Research has also been directed towards reducing the overall costs of transportation studies by developing techniques based on the assumption that travel patterns and travel characteristics from city to city do not vary sufficiently to require a complete home intorvicw origin destination survey. Some of the methods that have been developed needed an extremely smali interview sample as a statistical check to verify that the trip characteristics in the study city do not vary substantially from trip characteristics in other areas. Trip generation characteristics and values from other studies are used to develop existing total trip and distribution between zones in the study city. The gravity model is generally used for the distribution of the trips. This procedure is explained in detail in a Bureau of Public Roads (BPR) report and has been modified many times since in other projects (28). Basically the gravity model utilizes the following mathematical relationship: 


$$
T_{i-j}=\frac{P_{i} A_{j}{ }^{P}\left(t_{i-j}\right)^{K} \sum_{x=1}^{n} A_{x}{ }^{F}\left(t_{i-x}\right){ }^{K}(i-x)}{\left.{ }^{n}\right)}
$$

where

$$
\begin{aligned}
& \begin{aligned}
\mathrm{T}_{i-j}= & \text { trips produced in zone } i \text { and attracted } \\
& \text { to zone } j .
\end{aligned} \\
& \mathrm{P}_{i} \quad=\text { trips produced by zone } i \text {. } \\
& \mathrm{A}_{j} \quad=\text { trips attracted by zone } j \text {. } \\
& \left.F_{\left(t_{i-j}\right.}\right)=\text { empirically derived traveltime factor } \\
& \text { which expresses the average arcawide } \\
& \text { effect of spatial separation on trip } \\
& \text { interchange between zones which are } \\
& t_{i-j} \text { apart. This factor is equal to } \frac{1}{t^{1}} \\
& \text { where } \mathrm{n} \text { would vary according to the } \\
& \text { value of } t \text {. } \\
& \mathrm{x}_{i-j}=\mathrm{a} \text { specific zone-to-zone adjustment } \\
& \text { factor to allow for the incorporation of } \\
& \text { the effect on travel patterns of defined } \\
& \text { social or economic linkages not other- } \\
& \text { wise accounted for in the gravity model } \\
& \text { formulation. }
\end{aligned}
$$

The gravity model technique of trip distribution, unless a very small number of traffic zones are used, requires a computer for application; therefore, it may be considered basically a method for a larger urban area study to use.

The Federal Highway Administration, among others, has recognized the need for transportation planning in the smaller urban areas; however, until recently little actual guidance has been given to the procedures to be followed.

The Federal Highway Administration in a recent directive entitled "Proposed Addition to Regional Guidance and Policy Manual-Urban Transportation Planning in Areas Under 50,000 
in Population" states the following:

"The purpose of this directive is to provide guidance in determining the level of planning necessary to evaluate transportation system improvements required to handle future traffic demands in urban areas of less than 50,000 population. In vicw of increasingly heavy demands on public funds it is the policy of this region that the intensity of planning in small areas be the minimun comensurate with the magnitude of transportation problems. Transportation needs of a given place are in turn dependent upon the character of the area, that is, its growth rate, econonic and geographical characteristics, etc."

The proposed addition outlines the subject areas in small urban areas requiring review, data collection and analysis as follows:

1. Population trends

2. Economic development trends

3. Land use development trends

4. Geographical and topographical constraints

5. Bypass routes

6. Transportation network continuity

7. Limits and duration of congestion

An additional comment is given, "In general, detailed data gathering efforts such as home interviewing are discouraged as are computerized forecasting models unless it can be shown that they are necessary".

Further detail is given on the depth of recommended study as follows:

"In the event that a more intensive study is deemed necessary, the following guidelines may be considered in developing an areawide planning program:

1. Areas under 25,000 population

A. Population study and forecast

B. Economic study and forecast

C. Land use study and forecast

D. Traffic engincering study

E. Linited parking study

F. Volume count progran

G. Special generator study (Optional) 
H. External cordon O-D study on major routes (Optional)

I. Screenline survey (Optional)

J. Major thoroughfare plan based upon land use plan including forecast of travel.

2. Areas between 25,000 and 49,999

Elenents A - F above, Plus

G. Special generater study

H. External cordon $0-D$ study on major routes

I. Screenline survey (Ootional)

J. Internal travel synthesis (Optiona1)

K. Major thoroughfare plan based upon land use plan including forecast of travel."

Generally all research projects in the states which are active in developing new methods for snall areas follow the same pattern. Regression modeling techniques are used to devolop models for predicting internal traffic volumes and patterns, and in all projects reviewed, an external cordon survey in accordance with the Federal Highway Asministration recommendations was completed.

Winchester, Kentucky is an area with a study recently completed using thirty two traffic analysis zones for the city of 16,502 people (29). Traffic volume counts were taken at locations throughout the study area and an external cordon survey was completed. A land use inventory and dwelling unit survey was also completed within the study area and employment figures were compiled. The study design for winchester provided for synthesis of the internal travel information. The development of the models involved a critical review of information from other studies with similar population and socio-economic characteristics. These socio-economic characteristics were used as input for the study. The traffic models were then adjusted until the existing traffic volumes in the study were satisfactorily reproduced. For the synthesis, three transportation studies were used for basic information including Austin, Minnesota; Albertlea, Minnesota; and Madisonville, Kentucky. Internal trip data were developed for winchester for home-based work. productions and attractions, home-based non-work productions 
and attractions and non-home based productions and attractions. Only two independent variables, population and total employment, were necessary in the regression models. Distribution of the trips was accomplished using standard gravity model techniques. The consultants engaged in the study and the Kentucky Department of Highways was completely satisfied with the accuracy of the results obtained.

Georgia Highway Department personnel have done extensivo research in the area of developing methods for synthesizing internal-internal trips in small urban areas (2) (3). Their technique, as in all others reviewed, still recommends a complete external cordon survey. In the work done in Georgia, the procedures are based on the assumptions that the multi-variant relationships determining productions and attractions for trips for any analysis zone are similar for all urban areas within the range of population of 5,000 to 45,000 , and that the distribution of internal trips by a gravity method is valid for any size urban area in the sane population range. This permits using the same set of factors to represent spatial separation and facilitates trip distribution in any small urban area with minor adjustments. The Georgia research study used information from two completed comprehensive transportation studics to develop models for use in a third city. The output from the study included eight different trip models including home based work productions and attractions, home-based non-work productions and attractions, non-home based productions and attractions and total trip production and total trip attractions for each survey zone. The nodels required as independent variables the number of personaluse motor vehicles garaged in the zone, civilian labor in each zone, total employment in each zone, number of squore feet, in thousands, of retail sales building occupancy in each zone, school enrollment by zone and the number of 
square feet, in thousands, of office use building occupancy in each zone. The traffic volumes produced by the models were considered satisfactory for thoroughfare planning in small urban areas.

Personnel in North Carolina havealso done research in the area of synthesizing trips for small urban areas (19). Information to be collected for each traffic survey zone wastpopulation by race and housing condition, number of dwelling units by race and housing condition, employment divided into seven categories, and dwelling unit trip generation rates by race and by housing condition, either from a small sample home interview origin destination survey or developed from origin destination surveys conducted in other areas. They stressed in their brief report that the average family income should also be considered when selecting the trip production rate to be used. Regression models were developed to produce the required trip generation values. Gravity techniques were used for the trip distribution between survey zones. A complete external cordon survey was considered necessary with the technique developed.

Jefferies and Carter (16) investigated simplified techniques for developing transportation plans in smali urban areas. The basic data collection and studies that they consider necessary for transportation planning in any area include:

1. sample selection study

2. home interview study

3. truck and taxi survey

4. external survey

5. data summary through trip tables

6. screen line survey

other inventories:

1. street inventory

2. capacity study

3. sign and signal inventory 


\section{4. traffic counts}

5. accident study

They also list analysis and projection as follows:

1. trip generation analysis

2. trip generation projection

3. trip distribution and model calibration

4. assignment of future trips to existing notwork

The research objective was to investigate simplified techniques for developing transportation plans in small urban areas. The data were from six cities of less than 200,000 population where a "gravity model" type study had recently been completed. Home interview origin-destination and external cordon surveys provided the basic trip characteristics. Regression analysis was used to develop prediction models for trip generaticn by traffic zones for each of the urban areas. Data for the selected indopendent variables were then combined to develop one model for predicting daily home-based vehicle work trips per dwelling unit produced per zone.

The variables were the $\log _{10}$ automobiles owned per dwelling unit, the total stuay area population divided by total square miles of developed land within the study area, the total dwelling units within the study area divicied by the total square miles of developed land within the study area, and finally, the percent of developed area in residential land use. One conclusion stated in the report was as follows:

\footnotetext{
"It is feasible to develop an equation to predict vehicle work trip production $i_{n}$ smaller urban areas without conducting an extenstive origin and destination study. These values are sufficiently accurate for planning purposes" (16).
}

A study dealing with testing the gravity model technique is Sioux Falls, South Dakota(4).The study area population was 62,000 . The study investigated the minimum amount of data required in a small urban area and was conducted in 
1963 (4). A standard home interview origin destination survey was used for checking the developed models. The study determined that, in the city tested, a data check consisting of six hundred home interview samples, combined with information from other completed home interview origindestination surveys and from a standard external cordon survey, could be combined satisfactorily to produce the input data for the gravity model technique. The report further concluded that three purpose trip stratification of home-based work, nonwork and nonhome-based trips werc sufficient for small urban areas.

B. J. Sexton in a recent publication discussed Kentucky's approach to transportation planning in small urban areas (24). Kentucky generally follows the established criteria stated below in small urban area studies:

1. A physical inventory of the existing arterial and highway system is completed.

2. Traffic volume counts and speed and delay studies are conducted.

3. Capacity of the existing system is calculated.

4. An external cordon survey is conducted.

5. Internal travel estimates are obtained by phone, post card or hone interviews, establishing a sample of 500 dwelling units which is satisfactory for trip generation and distribution models.

6. Trip purposes are limited to home-based work, home based other, non-home-based and internal external trips. For areas of less than 16,000 population, it is suggested that a single purpose model may suffice.

7. Land use or development data are collected by internal survey zones. 
Trip generation rates for vehicle trips are "borrowed" from origin-destination surveys of other areas. With the forecasted future values for land use or development characteristics of the zones and the trip generation rates, total future trip ends by survey zone can be estimated. The report states that the following basic types of inventories by traffic zone are still necessary.

1. Dwelling units

2. Population

3. Employment

Numerous reports of research in the area of synthesizing urban traffic have beenpublished by the Joint Highway Research Project at Purdue University (JHRP) , A disscussion of several of these projects which are considered pertinent to the subject of development of simplified procedures for transportation and thoroughfare planning for small urban areas will be presented hercinafter.

A report entitled "Development of Travel Patterns in Major Urban Areas" (23) deals with synthesis of travel patterns for urban areas. Utilizing home interview origin destination survey information from fourteen large United States cities, the researcher developed regression nodels for internal trip generations and attractions by survey zones, for the entire study area and for the central business district. In addition a model was developed for predicting the ratio of external-external and cxternalinternal vehicle trips to total vehicle trips, and the ratio of internal-external trips to total vehicle trips. The independent variables investigated during the multiple regression analysis were population, areas, population densities, auto ownership, public transportation usage, income, occupation, school enrollment, workers, automolile usage, location of employment, value of residences and various interaction terms. The developed models were considered satisfactory for prediction of the various response variables. 
The JHRP report entitled "An Evaluation of Methods for Updating Origin and Destination Studies" reported on a research project that evaluated the various trip end prediction models in use (1i).In addition, commonly used trip distribution models were reviewed. Regression analysis was used to develop three regression equations for prediction of zonal trips in Lafayette. Indiana. The resulting models utilized automobiles per acre as independent variables for prediction of zone trips for residential zones. The number of commercial establishments per acre was the only independent variable used for the trip prediction model for commercial zones. The trip prediction modol for industrial zones used employees per acre and industrial establishments per acre as independent variables. The predicted zonal trips thus derived compared to the 1952 actual inventoried trips resulted in a growth factor for use in trip generation calculations. The research project utilizod the developed models to predict trips per zone for a period of time from 1952 to 1964 to provide a model checl: and then used the gravity method for distribution of the forccasted trips. The predicted volumes on a natural scroen line (Wabash River) conpared within acceptable limits to the actual counted volumes. The report concluded that regression analysis appeared to yield reasonable data for trip prediction.

Shunk, in a JHRP report entitled "The Journey to work: A Singular Basis for Travel pattern Surveys" (25) describes a research project investigating the feasibility of using the pattern of work trips to represent the total pattern of trips in an urban area. In addition, the possibility of using peak hour trips to represent traffic for full day was explored. The purpose of the study was to find an alternative method of reproducing travel patterns in an urban area without the use of the usual home interview origin destination survey. The report concluded that a high deqree 
of variation in total trips can be explained by the vork purpose trip. This procedure establishes the feasibility of determining the total trip patterns in urban areas by the review of employer records and/or interviews with drivers at their place of employment, reducing the time and cost of obtaining trip information when compared to the traditional home intervicw survey.

A JHRP report by Ricks, "A Synthesis of Urban Trave1 Patterns in Metropolitan Lafayette, Indiana" (20) described a project that applied eight regression models, previously developed by Schuster, to the Lafayette - West tafayette area to check their applicability to a small urljan area. The models estimated total vehicle trips in a study area, the ratio of local vehicle trips to internal vehicle trips, the vehicle trips to and from central busincss district, intrazonal central business district (CDD) trips, vehicle trips trips generated and attracted by a zone, vehicle trips between a zone, and the CBD and interzonal vehicle trips.

The conclusions reached by the rescarcher wore that the models were developed from data from larger cities and the range did not include the size of the investigated study area causing the results to be lcss than desirable. Other comments were that the models were extromely sensitive to the study area size and density and that the indopendent variables required information that may not be availahle in cities not classed as SMSN's.

The"corridor growth factor"tochnique of traffic forecasting was thoroughly discussed by French in his JHRp report (10). Some of the information contained and referenced in his report will be repeated here to provide a complete documentation without additional references being required.

The basic concepts involved in the "corridor growth factor" method of traffic forecasting are simple. Small urban areas have relatively few major traffic generators. 
Usually the central business district, a major shopping conter or two, a few industrial locations and possibly a special generator such as a university, constitute the major traffic generators in a community. The major traffic movements in the area are mainly contained within relativoly narrow bands, with each band composed of one or nore major streets radiating outward from the $\mathrm{CBD}$ to existing major external highway routes. The American Association of state Highway officials (AMSHO) policy (1) states the following:

"In a particular quadrant or wedge from the center of an urban area, a rather centrally located radial route connecting with a rural trunk highway usually will-be the dominant arterial highway."

Harland Bartholomew and Associates, in their manual entitled "Procedural outlines for Major Thoroughfare Planning" (13), recommend a sophisticated type of corridor analysis for planning purposes.

In the 1963 Corpus Christi, Texas (approximate population of 200,000 ) Transportation Study (26) the study personnel utilized the corridor analysis approach to determine transportation system deficiencies. The study procedure included the home interview origin-destination and external cordon surveys to collect information on the travel characteristics of the trip makers in the 269 traffic survey zones used in the study. Computer facilities at Texas A \& $\mathrm{M}$ University were used for trip distribution and trip assignments to a mathematical representation of the arterial street system. It was the considered opinion of the staff that, even with the sophisticated procedures outlined above, analysis and development of alternative systems by corridor would provide the necessary flexibility in the planning process to negate early olsolescence.

The above comments substantiate that the "traffic corridor concept"is generally recognized by professionals engaged in the planning process. Utilization of the concept is relatively sinple, especially if undertaken by 
personnel intimately familiar with the study arca. Initial identification of the traffic corridors and major traffic generators can be based entirely on knowlecge of the area and the subsequent delineation of corridor boundaries completed and verified by a study of existing traffic volumes, aérial photographs, etc.

The "corridor growth factor" method as developed by French requires as independent variables; the number of dwelling units, the total employment and the retail employment by corridor (10). French's work indicated the three parameters were sufficient to forccast future trips by corridors. The number of total employees was used to represent work and business trips while the number of retail employees was used to represent shopping and social recreation trips. The total number of dwelling units was used to represent home and other residential trips. $\mathrm{N}$ external cordon survey, to permit separation of external trips into components of external-external and externalinternal trips for forecasting purposes, was recommended. Future land uses and activities by corridor, with the accompaning future dwelling units and number of total and retail employees, were required for future traffic volutno forccasting. The increments, in each of the parameters are converted into growth factors for expansion of existing volume data. French expanded external traffic by using growth factors based on forecasted growth in motor vehicle registrations.

There have been numerous studies analysing the traffic crossing external cordons in various size cities. AASHO and BPR publications include tables based on such studies indicating the composition of traffic approaching various sizes of cities. J. D. Carroll, Jr., completed an extensivo study on the subject in the mid $50^{\prime} \mathrm{s}$ in Michigan revicving data from a large number of external surveys in various sizes of cities and investigating selected independent 
variables for replicative and predictive models. Burch substantiated in a study involving five cities (varying from 16,500 population to 125,000 population) that traffic interchange between cities could be replicated using the gravity model concept (6).

Pollard and Guyton in their report entitled " $A$ Modified Growth Factor Trip Distribution Procedure" (20) discussed a method for forecasting future traffic in cities in the 50,000 to 500,000 population range. The authors state that modificd growth factors that use factor components of population increase, vehicle registration increase and vehicle use increase may be used to satisfactorily expand traffic volumes. It was also stated that recognition fuust be given to a "saturation" limit of the number of vehicles per capita that can be expected in the forecast year. The technique presented in the report involved the use of a computer for trip distribution in the urban areas.

Schuster found in his study of data from fourteen cities varying from 72,365 to 627,525 population that the ratio of external vehicle trips per day to the total vehicle trips per day in a city could be satisfactorily reproduced with a replicative model using the transportation study population and the transportation study area in square miles as independent variables (23).

Personnel of North Carolina University and the State Highway Commission completed a research project in the late 1950's investigating the "interactance" between five independent cities and towns varying in population from 16,500 to 125,000 (6). The model developed to fit the basic data was $\mathrm{T}=0.4 \mathrm{~m}^{2}+4.9 \mathrm{~m}+160$, with" $\mathrm{T}$ " representing the number of weekday trips starting in City $\Lambda$ and ending in City $B$, and with" $\mathrm{m}$ "representing the square root of the product of the population of City A and City B divided by the square of the travel distance between their centroids. The report stated that the accuracy was best when distances 
were less than 50 miles. The report also stated that trips from surrounding counties could be satisfactorily predicted in the same manner, utilizing a "dominant" sizeable city as the centroid for the calculation.

The above studies that investigated the relationships between various parameters and the number of external trips to urban areas indicate that such trips are a function of independent variables such as the city size, the proxinity and size of adjacent cities, character of the hintorland of the city, whether urban or rural, etc. The nNswo Policy (1) indicates the final destination of trips approaching a city vary with the city size with fifty one percent of approaching trips in eities of under 5,000 population destined to the city. For cities in the 500,000 to $1,000,000$ population range this figure is expressed as ninety two percent.

The successful use of aerial photography and photogrammetric techniques for traffic surveys, land use and street inventory and parking studies is well knotan. The Southeastern Wisconsin Regional Planning Comission (8) used aerial photographs for the inventory of existing land uses in the study. Their opinion of the procedure is quoted as follows:

"In retrospect, the use of aerial photographic interpretation to complete the existing land use inventory, as outlined herein, proved to be a wise decision. The method of inventory afforded the Commission staff an accurate and complete picture of the existing land uses in the Region at a minimum cost."

A technical paper by Bruce E. Howlott (15) discussed the feasibility of aerial photography for comparison of urban growth and changes in urban areas. The author made the following statement: 


\begin{abstract}
"From land use measurements the quantitative aspects of land use changes can be determined and compared with changes in other key growth indices. Aerial photographs provide a firm basis for allocating land use forecasts and for checking their accuracy through periodic aerial resurveys."
\end{abstract}

Jones, in his report entitled "The Uses of Rerial Photography in Urban Transportation Studies" (17), given limited distribution to Texas Transportation Studies concluded that "The use of aerial photography for urban transportation studies is practical and can reduce the cost of the study.

Aerial photography can be used for data collection for a majority of the elements of an urban transportation study."

Full scale applications of photogrametric techniques in the continuing phases of transportation and major thoroughfare planning are still being studied with procedure refinements being developed. 
CONCEPTUALIZATION OF A STMPLIFIED PLANNING PROCEDURE

In the larger urban areas the shear magnitude of the component parts of the transportation system and interactions of the many attracting forces or traffic generators make the problem impossible for the planners to mentally visualize. The only practical procedure necessitates a step by step planning process that includes data collection, assimilation and summarizing of the data with the use of computers. In this manner the individual-components may each be carefully analyzed separately and then combined in any selected manner for analysis of alternate systems. However, this type of costly procedure does not seem necessary for smaller urban areas.

The majority of the small urban areas in this country have followed a modified sector and concentric circle growth pattern. The central business district represents the major traffic generator in the community and traffic corridors radiate outward from this center. Major shopping centers, if they exist, are usually located on existing arterial streets and their size, even though they may be substantial, do not compare to the size of the central area, therefore their influence is subsidiary to the central arca.

The traffic corridor concept of thoroughfare planning is not new. In fact, many transportation planners still feel this approach to the solution of the problem of providing an adequate transportation system is superior to a zone by zone analysis oven in this day of third generation computers. Using the corridor technique requires that both the capacity of the available thoroughfares and the forecasted future traffic volumes be determined by corridor. The 
traffic corridor concept is accopted in principle by all planners who utilize computer capacity-restrained-traffic assignment packages in transportation planning. This particular theory of assignment provides for a reduction in link speed when the assigned volume reaches a predetermined level, with this level being based on the level of service concept of capacity. The reduction in link speed forces computation of new zone to zone minimum paths or trees and new assignment of trips. This effectively distributes trips over a number of arterial streets serving the same basic traffic movement and provides in essence a corridor assignment.

This approach is very sensible. Why shouldn't the strects that serve as major arterials and handle the majority of the traffic today be effectively and economically reinforced by parallel arterials in the same corridor that are lightly traveled today but available when future capacity is required. In many cascs the reasons for traffic preference for one arterial over another in a corricior may be a slight travel time difference or other factor that can be readily rectified or which becomes non-existant as volumes increase.

French in his research report, carefully outlined the basic concept of the "corridor growth factor" for expanding present traffic volumes to represent future traffic volumes (10). Future desire or demand traffic volumes are necessary for each corridor to permit planning for improvements to handle the demand within the time constraint established. French found this future traffic volume could be obtained by multiplying the existing traffic vlumes by a growth factor. The growth factor was based on growth of the "activities" in the corridor. Comparison of the streets capacities to forecasted volumes can then provide an estimate of capacity deficiencies. This procedure can be substituted for the distribution and assignment modols used in large studies. 
The entire procedure is predicated on the assumption that the existing travel patterns in the community will remain stable over time. This is considered a reasonable assumption. It can be noted that even in the very large cities the basic travel patterns remain substantially the same except for circuitous travel over routes provided by controlled access facilities that tend to encourage such travel. In the small cities the growth is usually an extension along present patterns. To disrupt or change the basic travel patterns in a small city would require the elimination of a large portion of the existing strect network. This is not likely to occur.

\section{Corridor Identification}

A corridor may be defined as an area between traffic divides and representing the area producing trips served by the one or more basically parallel major streets in the area. The orientation of the corridor in small urban areas would be basically oriented toward the central area because of its predominance as a generator. With a knowledge of the local travel habits, supplemented by aerial photographs, street classifications, land use maps, and a traffic volume map, the corridor limits may be determined. The corridor boundary should be equidistant between arterials unless physical constraints dictate otherwise. Corridors may overlap with separate corridors identified on circumferential or cross routes.

To select corridors first requires delineation of the central area. This central area would include the CBD or core and would generally include the "frame" of the CBD. Specifically, the central area would begin at the point where radial corridors and the arterial streets serving the corridors merge and lose their individual identity. Usually the merging movement would be served by cross routes bordering the $C B D$ providing for disbursement of traffic to the scattered destinations. 


\section{External Traffic}

Traffic entering small cities is composed of varying percentages of external-internal and external-external traffic. Generally, the composition and magnitude of this traffic is determined by an external cordon survey. These surveys are time consuming and relatively expensive. Studics of external traffic have shown that the external-internal trips are made by the suburbanites who commute to work and their families who produce additional shopping, business and recreation trips. The external-external trips arc a function primarily of interaction between the city involved and surrounding cities or population centers and sometimes it may include interaction between larger cities on either side of the subject city with resulting trips through the area.

There should be two separate feasible proceduros to follow for determining the total external traffic and the components of extcrnal-external and external-internal traffic necessary for the simplified procedure for mojor thoroughfare planning. The procedure to follow will be determined by the availability of information as follows:

1. An external cordon survey study report for the area from a past year is avajiable.

2. Traffic volumes from a past year at the cordon stations are the only available information.

With an external survey report available the procedure should be greatly simplified. A growth factor based on the increase in vehicle registration should be adequate for forecasting to the future. A calibration period using a growth factor based on five to ten years should provide a check on the accuracy of the procedure.

Traffic surveys indicate a high correlation between trips and the number of registered vehicles in an area. It should be possible to expand the total external traffic volume crossing the cordon line of a city by application of 
a single growth factor developed using the increase in total vehicle registration in the county. In the $1950 \mathrm{~s}$ and early 1960's growth factors usually combined several components such as population, vehicle registration and automobile usage to arrive at a modified growth factor. This was necessary because the ratio of automobiles to people and the usage of the individual automobile was increasing. These trends are approaching a plateau, remaining stable over time, therefore it should be possible to use the simple single component growth factor based on vehicle registration to expand the external volumes in small urban areas. Theoretically the percentage split: between the two components of external traffic at each station should remain constant through time because of the stability of travel patterns. The percentage of external traffic destined to the central area should also remin constant; however, employment of the central area should provide a better indicator that would reflect any shift in retail business and the accompanying trips to suburban locations during the interim period from the study date to the present. The procedure using past external reports, would be preferred to other type models because the unique character of the area would be reflected therein.

If an external survey report is not available the following procedure should provide adequate accurate information for planning. The external trip information should be subject to regression modeling. In this application certain assumptions must be made in addition to those necessary for regression modeling as follows:

1. The city must exist as a separate entity, i.e., not as a suburb of a larger city.

2. A major military establishment or similar trip attractor must not be in the area immediately outside the city.

3. The city must not be located on an international border. 
Models should be developed using total external traffic volume and extemal-external traffic volume as response variables. This would permit flexibility in the model application to fit any unusual conditions in the specific study area.

Distribution of the Trips Between External Stations The same stability of travel utilized as the foundation for internal growth factors should also be applicable to the external trips patterns in an area. Our cities are not new, they have been developing for years, therefore it is reasonable to assume that growth patterns, both in the city and in the immediate surrounding ared, are a continuation of historical trends except in a fow isolated cases. The present percentage of total traffic crossing the cordon line at a station should therefore also be an accurate estimate of the percentage of the forecasted traffic that can be expected to exist at the station. If the split between external-internal and external-external traffic is known it should also remain constant over a reasonable forecast period, therefore the percentage of each component of the external traffic at a cordon station will be a known factor.

If an external survey study report is available the necessary information on the split can be obtaincd directly from the report on the area. Where a report is not available the percentage split between external-external and externalinternal traffic should be subject to the regression modeling outlined previously.

Distribution of External Trips Within the Urban Arca

Extensive studies by the Bureau of Public roads, now known as the Federal Highway Administration, indicated a high percentage of external trips are destined to the central area of small urban areas (12). The approximate 
percentages given were twenty five percent to the CBD and twenty five percent to the immediate adjacent area for cities of approximately 25,000 population. Employment has been shown to be highly correlated to trip making, therefore it should be possible to approximate the volume of traffic destined to the central area of a city by determining the ratio of $C B D$ employment to the total city employment. Considering the initial relative magnitude of external traffic to internal traffic, if volumes on the order of twenty five to fifty percent are destinted to the central area, it should not be necessary to distribute the remaining external trips. The remainder can be reasonably assumed to distribute evenly over the area in most cases.

If a major traffic generator is located in an area the chances are that it wi 11 locate as follows:

1. On an existing arterial

2. In the outlying corridor area

This location procedure would mean that traffic destined to this generator would flow opposite to the usual peak load and could reasonably be assumed to create no problem only to balance the distribution of traffic flow.

\section{Developing a Growth Factor}

A growth factor for each corridor must be established to forecast growth of internal traffic. The factor must adequately represent the growth of all "activities" in the corridor. Corridors commonly contain an agglomeration of land uses, each having a differont trip generation rate, therefore, a method of weighting these rates is necossary. The growth factor must reflect the increase, present to target year, of each land use.

The method established to handle the weighting of trip attractiveness of variousland uses was to use the percentage of total linked-trips by linked-trip purpose. This information was obtained from a review of available origindestination study reports. Trip purpose may be related to 
land uses or other parameters to obtain a relative trip attractiveness. Examination of the existing percentages for each type of linked-trip purpose for auto driver trips for various size cities provided the means for determining percentages for use in the procedure.

Parameters, easily measured and forecastable, to indicate trip purposes are required. The acres of each type of land have been used in many studies for this purpose but: the problem inherent with this parameter, varying densities of development, etc., make it undesirable.

The total number of employees within the unit of study appear to be a good indicator for work and busincss trips and were used for the study. This information is available from several sources and is usually listed by business establishments and can be forccasted satisfactorily.

Home trips can be determined using the number of dwe lling units per corridor.

Shopping trips may be determined by using the total number of retail employees. The number of retail employees by corridor can be obtained easiest concurrently with collection of the number of total employecs necessary for work trips.

Social-rccreation trips to clubs, theaters, resicential areas etc., are difficult to represent with any single parameter due to their diversity. The three parameters used for work and business, home and shopping trips can be assumed to represent these trips without a separate parameter.

Previous research has indicated that these three parameters were adequate to represent the total trips. This project therefore used total employees to represent work and business-linked trips by corridor, the number of retail employees were used for shopping-linice trips and the number of dwelling units were used for home-linked trips and other trips to residential areas. The original research 
established the percentage of total trips to be represented by each parameter as follows; total employces - forty percent, retail employees - fifteen percent, and dwelling units - forty five percent. To establish the exact percentages would require some form of origin-destination survey not considered necessary for this procedure. Using completed origin-destination study data from similar size cities permits selection of reasonable values.

The previously developed procedure established relative trip production rates for the three parameters in the study area in the following manner. The relative average trip production rate per employee would be established by dividing the percent of the total trips to be represented by that parameter by the total employees in the study area. The same procedure would be followed for the remaining parameters. These rates are assuned to remain constant over time and are used in both the base and target year. The procedure for developing a growth rate by corridor was as follows:

1. The relative trip rates by each parameter are multiplied by the quantity of the parameter in the corridor for the base year and the products are totaled.

2. The procedure is repeated for the target year using forecasted quantities of the parameters.

3. The ratio of the target year sum to the base year sum is the corridor growth factor.

4. The corridor growth factor multiplied by the base year traffic volume in the corridor gives the forecasted or design volume for the corridor.

\section{Plan Evaluation}

The evaluation procedures for alternate plans are well documented by many references such as the National Committee on Urban Transportation (10). The evaluation is simplified 
because mass transit will be non-existent or will contribute little to the solution of the transportation problems in small urban areas. In the smaller urban areas, frecway networks are seldom warzanted. This leaves improvements to the existing system as the primary solution to traffic problems. The street capacity calculations themselves should provide clues as to where additional needed capacity can be provided with minimum expenditures. 'The Policy' and Procedure Nemorandum 21-18, U. S. Department of Transportation, Federal llighway Administration, dated May 13, 1971, for the TOPICS program provides a good guide for methods of upgrading existing facilities.

All traffic assignment procedures require engincering judgement. This simplified procedure requires the sarie judgement in the application. There will be only a fow existing parallel arterial streets to kandle the corricior traffic and it can be assune that traffic can be divided between these streets. Major arterials should always have four moving lanes which should be sufficient in most cases to handle arterial traffic in small urban arcas. It should be remembered that re-evaluation of the plan will be simple under the proposed procedure, therefore catn be easily and quickly repeated any time any substantial variations in forecasted traffic volumes are noted.

The usual procedure for major thoroughfare planning is to make an overall twenty year forecast with five year step or incremental forecasts to provide information for establishing project construction priorities and for capital improvement programs. The simplified procedure should not be an exception to this procedure, quite the contrary, this is one of the strong points of the method. Simplicity and minimum personnel requirements permit reevaluation on short notice as area development dictates. When unexpected new development occurs a re-cvaluation can be quickly accomplished to check proposed plans and provide 
information for modifications if necessary. The five year incremental forecasts will also preclude errors due to large growth factors.

The "best" plan is that plan that satisfies the people of the community and satisfactorily handles the traffic. Utilizing the simplified procedure described herein adequate information will be developed to provide direction to those charged with the responsibility of developing a plan but it is not intended as "the" cookbook solution. Judgement and assistance of those in the arca is not only helpful but is an absolute necessity when developing a plan that will serve the purpose and be acceptable to those it affects. 
DATA COLLECTION

Project data collection will be discussed for the three separate phases as follows: Lafayette - west Lafayette; Columbus; external models.

\section{Data Collection: Lafayette - West Lafaycte}

The 1952 Lafayettc data for testing the corridor growth factor were obtained from the files for the original research. The sources used are outlined below.

\section{Employment}

Employment data for both 1952 and 1970 were obtained from reports of the Indiana Employment Securities Division. In 1952 only those employers having more than eight employees were required to register with the Employnient Division. To make the data comparable for both years all employers with less than eight employees were deleted from the data for 1970 .

Telephone directories were obtained for both years. The address of each employer listed by the Employment Division was obtained from the telephone directory. This permitted location of the employees by each corridor. Many employers, such as food stores, had several branches and the total number of employees branches except in cases where store managers provided better information.

There were employers, such as U.S. Postal Service and the hospitals, that were not listed in the data. Additional information on such firms was obtained from the chamber of Commerce and personal contact with the respective firms. 
Telephone calls were made to the two large hospitals and a mental institution to obtain employment data. Employment for Purdue University was obtained through personal correspondence with the comptroller's office.

Retail employees were tabulated simultaneously with the total employees in each corridor. Retail establishments were established to be those having Standard Industrial Classification codes of 5250 to 5460 and 5540 to 5990. This range included all retail stores, restaurants, taverns and service stations.

Employment data are presented in Appendix A, Tables $1 \mathrm{~A}$ and $2 \mathrm{~A}$.

Dwelling Units

The number of dwelling units in 1952 was obtained from the Lafayette City Directory and aerial photogräphs. The city directory provided information within the city limit of Lafayette and West Lafayette. Each address and each apartment unit was counted as one dwelling unit. The houses outside the city limits were counted from available 1955 aerial photographs. The difference between 1955 and 1952 was consicaered insignificant. The 1970 dwelling unit data were obtained from computer tabulations compiled by traffic zones and sub-zones for the Greater Lafayette Area Transportation and Development Study (GLATDS). In those areas where a further breakdown was required then was provided by the tabulation, available infra-red aerial color photographs,at a scale of $1: 120,000$, were used with an adjustable magnifier (Bausch and Lomb Macroscope) used at the thirty power magnification, to obtain a further breakdown of the number of dwelling units to correspond with the corridor boundary. Some discomfort was experienced when working with this extremely small scale of photos although the required information was obtained. 
The dwelling unit data for 1964 were obtained by direct count on $l^{\prime \prime}=400^{\circ}$ scale 1963 aerial photographs of the West Lafayette area. Stereoscope glasses providing a four power magnification were utilized. This procedure was completely satisfactory.

These data are presented in Table $3 A$.

\section{Traffic Data}

In 1952 the Indiana State Highway Commission conducted a post card origin-destination survey and an cxternal cordon interview survey. The 1952 ADT volumes obtained from the report are shown in Figure 1.

The external cordon line used in 1952 included only the 1952 development. A new line was established to include the 1967 development and was also used for 1970 . The movement of this line affected only two external stations; SR 43 and SR 25 South. The additional 1952 development in the expanded area was included by moving the cordon line. Corresponding reductions were made in 1952 external-internal traffic at the new external stations.

The external traffic was displayed in the above mentioned report in the form of desire lines from external stations to internal zones or to other external stations. From these desire lines, the amount of external-external and external-internal traffic using each major street was established.

\section{Traffic Data}

The 1970 ADT volumes were primarily obtained from GLATDS and the Indiana State Highway Commission. Additional required counts were obtained by the researcher utilizing pneumatic tube traffic volume recorders. This information is shown in Figure 2 . 


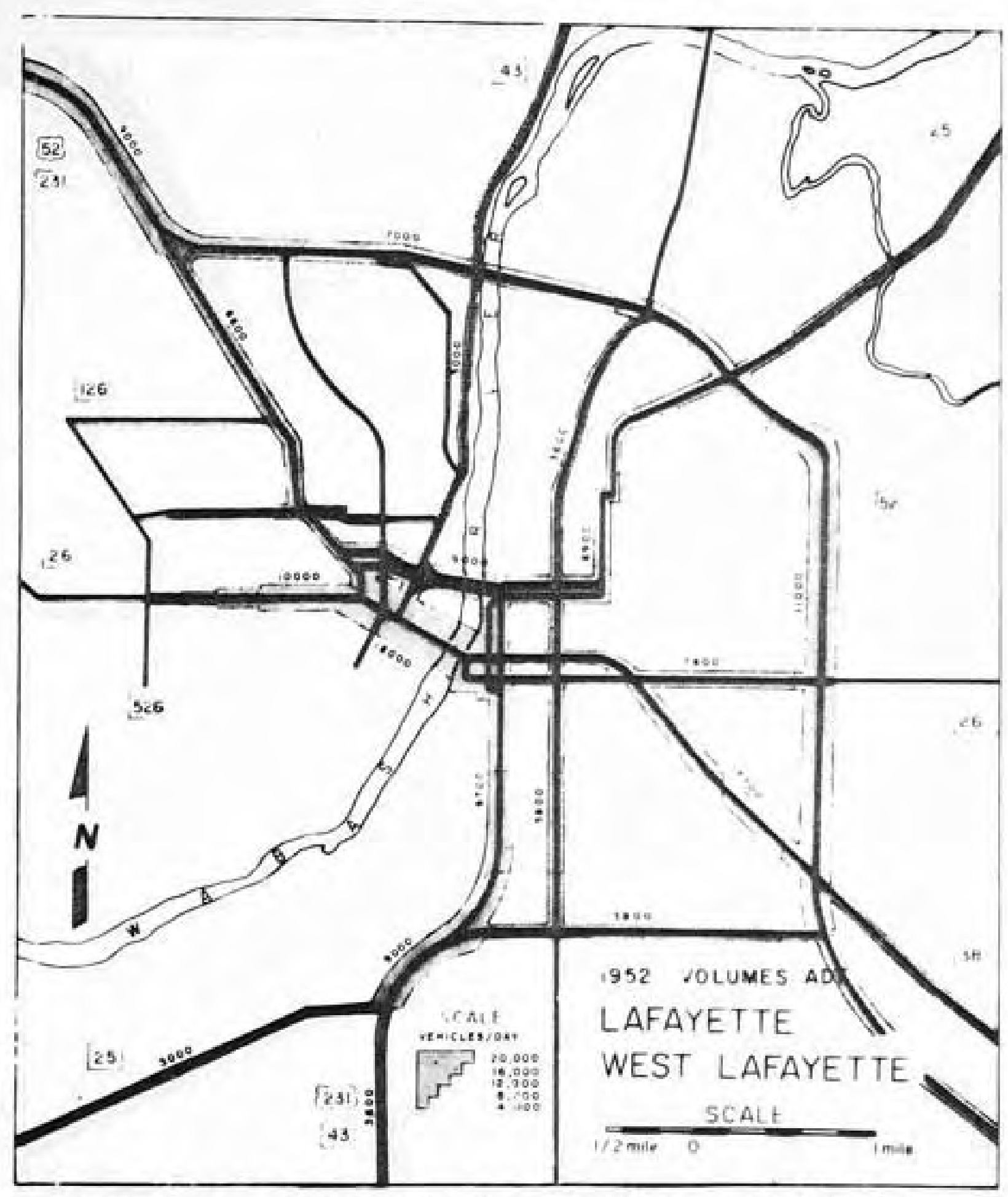

FIQURE I. 1952 TRAFFIC VOLUMES - LAFAYETTE 


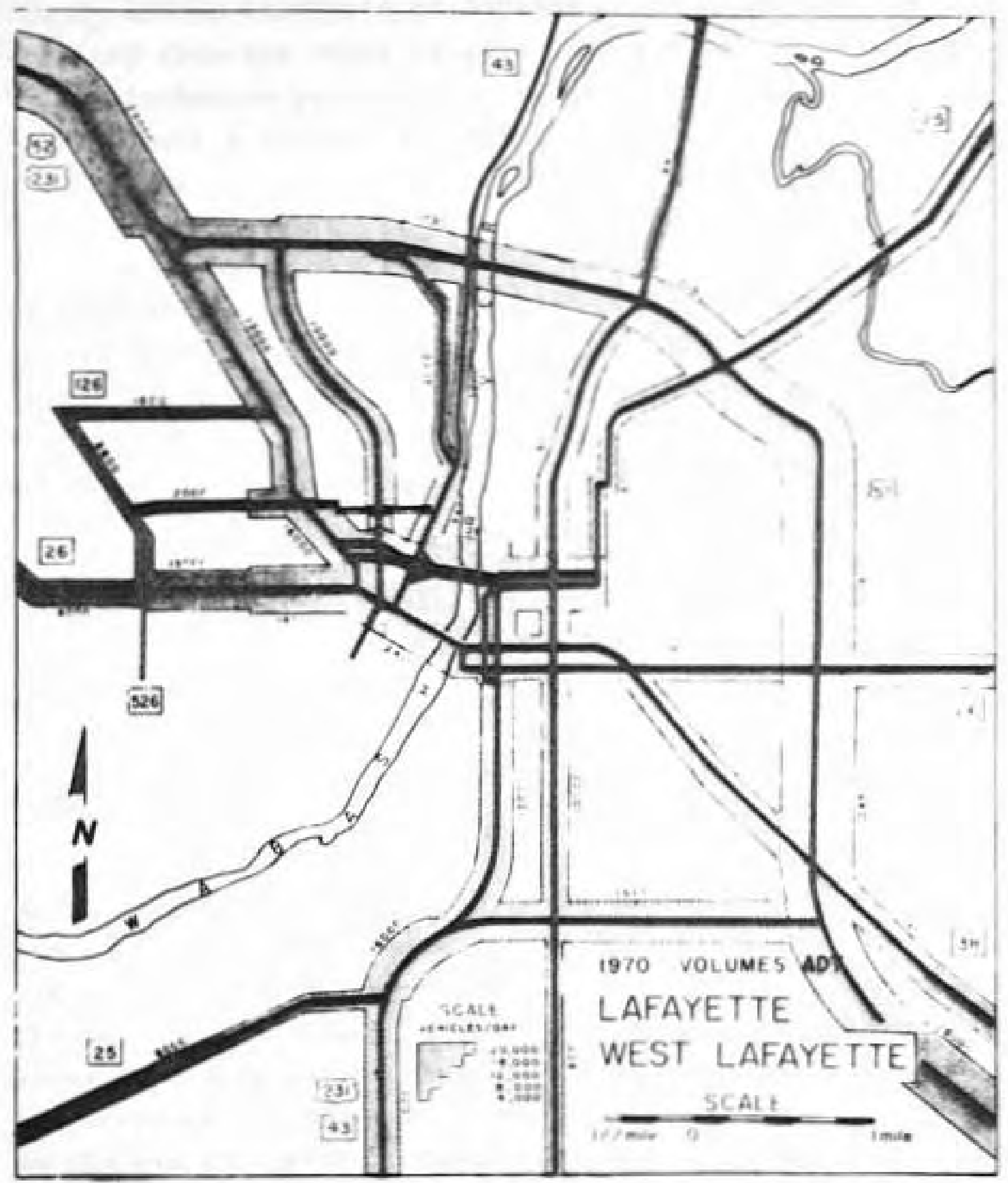

PIOUnE 2. 1970 TRAFFIC VOLUMES - LAFAYETTE 
Automobile Registration

The number of automobiles registered in Tippecanoe County and in the state of Indiana in 1952 and 1970 were obtained from the Motor Vehicle Division in Indianapolis. This information provided the means of calculating the growth factors for the external traffic.

\section{Data Collection - Columbus}

Data sources for the procedure feasibility demonstration in columbus, Indiana are presented below. Aerial photography prints on a scale of $1 "=400$ ' for Columbus for the years of 1960 and 1969 were obtained from the Indiana state Highway Commission to facilitate corridor identification, dwelling unit counts, physical street and traffic control inventory, as well as to assist in location of employment and commercial centers. A four inch diameter reading glass and four power stereoscope glasses and a Gurley Rapid Comparator were the items used in various portions of the data collection from the aerial photographs.

\section{Dwelling Units}

A topographic base map of Columbus, color coded to match the master copy of the June, 1970, existing land use map in the office of the Director of Planning, was prepared. Using this land use map and the aerial photos, the number of individual dwelling units were determined by zones that were established to permit later assimilation by corridors. Multi-family dwellings were also identified on the map and on the ground checks provided the number of dwelling units for each. This information was tabulated and summarized by corridor for both 1960 and 1969. The difference between 1969 and 1970 was considered to be insignificant. 
1960 and 1970 Traffic Data

Traffic volumes on some of the major thoroughfares for 1960 were obtained from the Indiana State Highway Commission. Volumes on all the major thoroughfares at screenline locations for 1970 were obtained from the Columbus City Engineer's office and the Indiana State Highway Conmission.

\section{Automobile Registration}

The motor vehicle registration figures for 1960 and 1970. were obtained from the Motor Vehicle Division, Indianapolis.

\section{Employment}

Employment data for 1970 for Columbus was obtained from information assembled by the Indiana Employment Securities Division.

The 1970 telephone directory provided addresses for the majority of employers listed. This facilitated tabulation and summary by the designated corridors, hs in the Lafayette data, if several branches of a grocery store chain existed, then the total employees were equally divided between branches. Phone calls were made to the larger companies with several locations, obtaining a breakdown by location in this manner. The same retail breakdown code was used in columbus and in Lafayette.

\section{Street Inventory}

It was necessary on recently completed construction projects to determine street widths, number of lanes, whether strect section was curbed, etc. This information was obtained directly from the $1 "=400^{\prime}$ aerial photographs with the aid of a Gurley Rapid Comparator. Random checks in the field indicated the accuracy of these measurements to be in the range of \pm 1 foot in the width of the street. 


\section{Miscellaneous Data}

A list of publications reviewed and/or copies obtained for past Columbus studies dealing with population, economic data, employment, planning and future projections is included in the List of References. This information was assembled, reviewed and where necessary the forecasts were revised and/or extended to the target year.

Topographic maps provided by the office of the City Engineer, prepared from 1969 aerial photography, proved useful for the street inventory.

As in all studies, it is not only necessary but absolutely essential that past work by other professionals be used as the base from which to begin new work. This study was no different. The street classifications previously established by DeLeuw, Cather and Associates, Chicago, served as the starting point (9). The city plan Commission Master Plan, dated 1965 was also used extensively throughout the study.

\section{Data Collection - External Modols}

To provide basic data for the independent variables to be used in the regression modeling for external traffic data, twenty states were contacted by letter asking for external survey or complete transportation study reports for cities between five thousand and one-hundred thousand population. Nineteen states responded favorably. The final data set consisted of thirty-six cities from fourteen states and included study area populations ranging from eleven thousand two hundred to eighty-five thousand three hundred. These cities are listed in Table 1 with the locations shown in Figure 3 . Information on size and distance to surrounding communities and counties was obtained from a 1970 Rand Mcllally Road Atlas. 
Table I Cities Included in Study

\begin{tabular}{|c|c|c|c|}
\hline City & State & City Pop. $\left(\times 10^{3}\right)$ & Study Pop. $\left(\times 10^{3}\right)$ \\
\hline Moberly & Missouri & 13.4 & 13.4 \\
\hline Lancaster & Ohio & 32.9 & 32.9 \\
\hline Bellefontaine & Ohio & 11.3 & 11.3 \\
\hline Urbana & Ohio & 11.2 & 112 \\
\hline Xenia & Ohio & 25.4 & 25.4 \\
\hline Tiffin & Ohio & 21.6 & 21.6 \\
\hline Circleville & Ohio . & 11.7 & 11.7 \\
\hline Greenville & Ohio & 12.4 & 12.4 \\
\hline Mount Vernon & Ohio & 13,4 & 13.4 \\
\hline Alpena & Michigan & 14.7 & 17.2 \\
\hline Bay City & Michrgan & 49.1 & 82.3 \\
\hline Glas gow & Kentucky & 10.9 & 13.0 \\
\hline Richmond & Kentucky & 12.5 & 12.5 \\
\hline Bowling Green & Kentucky & 30.5 & 33.2 \\
\hline Frankfort & Kentucky & 18.0 & 22.9 \\
\hline Owensboro & Kentucky & 42.5 & 42.5 \\
\hline Elizabethton & Tennessee & 10.1 & 19.7 \\
\hline Henderson & North Carolina & 12.7 & 20.4 \\
\hline Kingston & North Carolina & 24.8 & 49.0 \\
\hline Jacksonvilie & North Carolina & 15,7 & 30.6 \\
\hline Lumberton & North Carolina & 15.3 & 20.4 \\
\hline Sanford & North Carolina & 11.7 & 16.5 \\
\hline Hays & Kansas & 14. 0 & 14. 0 \\
\hline Independence & Kansas & 11.5 & 11.5 \\
\hline Pittsburg & Kansas & 18.7 & 18.7 \\
\hline Borger & Texas & 13.9 & 13.9 \\
\hline Bay City & Texas & 12.0 & 12.0 \\
\hline Brownwood & Texas & 16.3 & 16.3 \\
\hline Big Spring & Texas & 28.2 & 28.2 \\
\hline Blytheville & Arkansas & 28.3 & 28.3 \\
\hline Pulaski & Virginia & 11.0 & 13.3 \\
\hline Tuscallosa & Alabama & 61.9 & 73.2 \\
\hline Gainsville & Georgia & 15,4 & 21.4 \\
\hline Boise & Idaho & 75.0 & 85.3 \\
\hline Billings & Montana & 61.6 & 62.0 \\
\hline Great Falls & Montana & 60.0 & 74,7 \\
\hline
\end{tabular}




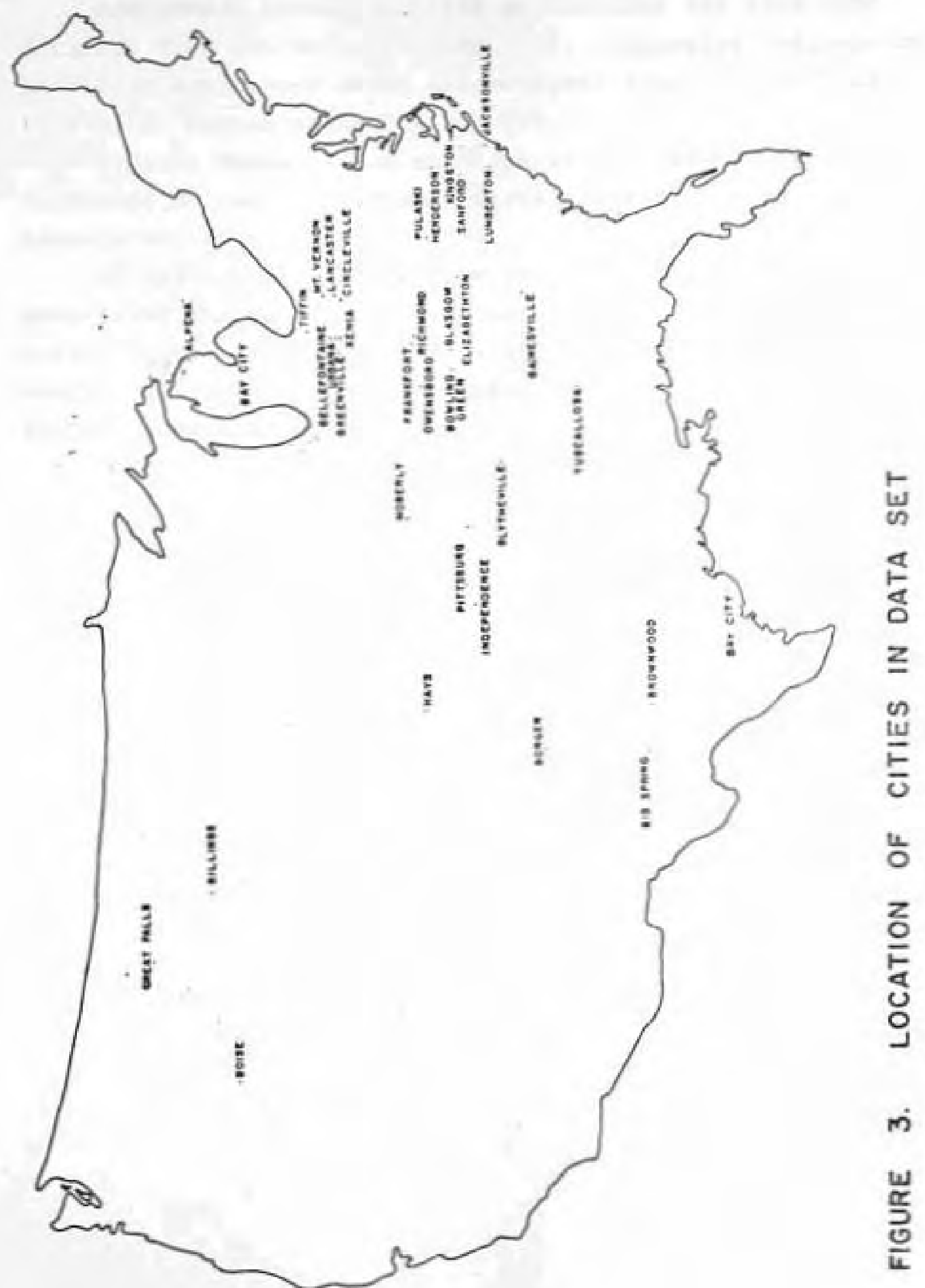


Additional county and city populations for 1960 were obtained from the World Almanac (18). Extensive information including employment data, was obtained from the 1960 and 1970 U. S. Bureau of Census reports.

Vehicle registration data for several states was furnished by representatives of the Federal Highway Administration.

In addition to the reports from the thirty-six cities comprising the regression data set, additional city survey reports were utilized as information sources for other comparisons. The additional cities are listed in the section where they are used. 
TESTING THE CORRIDOR GROWTH FACTOR TECHNIQUE IN LAFAYETTE

To properly evaluate the growth factor technique of traffic forecasting requires establishing standards for acceptance. One method of evaluating traffic forecasting techniques is to determine the percentage error of the predicted volume versus the actual volume. This would mean ignoring the entire objective and purpose of the procedure for which the predicted volumes are to be usod. The standard of acceptance for this project was established as the point where the predicted volume was within the range of accuracy that would allow a planner or designer to determine the correct number of lanes, proper location of improvements and proper relative construction priorities for inprovements to the major thoroughfare system of a sinall urban area. In reviewing this report and the described procedure, the reader must not lose sight of the basic advantagos and the design constraints for this procedure. It is simple, economical to use, and can be effectively utilized by personnel possessing a minimum of expertise in transportation planning. In short, it is intended to be as simple and inexpensive as possible while still providing the required information.

Major thoroughfare capacities for planning purposes are based on the 1965 Highway Capacity Manual (14). Using the manual, certain ranges of service volumes for the Lafayette check were obtained for a thoroughfare assuming the following:

1. A level of service - "C"

2. Population of city $-75,000$ 
3. Peak hour factor - .85

4. Directional split - 60-40

5. Peak hour volume - ten percent of $\mathrm{ADT}$

6. $\mathrm{G} / \mathrm{C}-.45$

7. Lane width $-10-12$ feet

8. No parking

9. Twenty percent turns

Using the above assumptions, considered reasonable for the Lafayette area, gives the following capacity ranges for major thoroughfares.

4 lane thoroughfare $-12,000-15,000$ vehicles per day

4 lane with left turn lanes - 15,000 - 19,000 vehicles per day

6 lane thoroughfare $-19,000-23,000$ vehicles per day

This indicates that an estimated volume with an error of approximately four thousand vehicles per day, for volumes under nineteen thousand, will not change the basic design of the street. If the estimated volume forecasted during the planning study is just under fifteen thousand vehicles per day for a street which has four lanes, twelve feet wide, no improvements will be recommended. If the volume for the target year actually is between fifteen thousand vehicles per day and nineteen thousand vehicies per day, then some widening may be needed at critical intersections to incorporate left turn lanes. At non-critical intersections, additional green time may be available from the cross-street to accomodate the additional volumes. It is apparent from these figures that the underestimation of future traffic by four thousand vehicles per day of volumes below nineteen thousand would not create a traffic problem for the target year. Over estimation would not involve significant over design unless the estimated volume exceeds approximately nineteen thousand vehicles per day. 
The streets on the major thoroughfare system in any urban area should be designed and constructed to four lane minimum standards according to the recommendations of the National Committee on Urban Transportation. Volumes in the range below the basic capacity of a four lane facility therefore do not affect the design in any manner.

The initial phase of the project involved testing the methodology developed by French for estimating future traffic demand by use of "corridor growth factors" (10). The procedure had been originally tested using 1967 data. The availability of data from GLATDS study provided an opportunity to review the procedure utilizing the current data and to incorporate refinements and/or improvements in the corridor growth factor models.

The procedure involved comparison of forecasted corridor volumes, derived by applying 1952-1970 growth factors to the 1952 base year data, to the actual observed 19.70 corridor traffic volumes. Values for the parameters for the 1952 base year were utilized from the earlier research. The 1970 values for each corridor for each of the three parameters of dwelling units, total employment and retail employment were obtained. Dwelling unit information was provided by computer tabulations by traffic sub-zones for GLATDS. The GLATDS study also provided the majority of the traffic volume observations for 1970, with the remainder of the volumes proviced by the Indiana state Highway Commission or by counts made by the researcher utilizing the pneumatic tube counters. Employment data was reduced from tabulations produced by the Indiana Employment Securities Division. Using this information and following the procedure described below, growth factors for each corridor were computed. The relative trip production rate was established for each parameter as follows: 
Relative trip $=$ Percent represented by parameter Production rate $=\frac{\text { Number of parameter units in arca }}{\text { Nuts }}$ Example: A study area contains twenty thousand dwelling units and the planner elects to use forty percent as the percentage of the total trips to be represented by the dwelling unit parameter. The relative trip production rate per dwelling unit would be as follows:

$$
\text { Relative trips }=\frac{.40}{20,000}=2.0 \times 10^{-5}
$$

The same procedure is followed for the other parafleters. The same rates are then used for both the base year and the forecast or target year.

The external traffic was projected from the 1952 base year to 1970 using the growth factor based on vehicle registration increase.

The external traffic growth factor, except for U.S. 52, was derived from the increase in vehicle registration in Tippecanoe County. For U.S. 52, carrying a large percentage of regional and state wide trips, a growth factor based on the increase in vehicle registration for the State of Indiana was used.

The Greater Lafayette Urban Area location is shown on Figure 4. The area can be described as a typical small city experiencing a steady growth during the period from 1952 to 1970. The 1952 population was approxinately forty-nine thousand. In 1970 the U.S. Census figure for the combined population of Lafayette - West Lafayette was seventy-nine thousand one hundred eighteen. The growth has been predominantly in the south portion of Lafayette and in West Lafayette, north of Purdue University.

Purdue University presents the major non-typical feature of the community. The student housing and general travel characteristics of the student population precluded using the same growth factor for the Purdue University corridor as for the rest of the area. A growth factor 


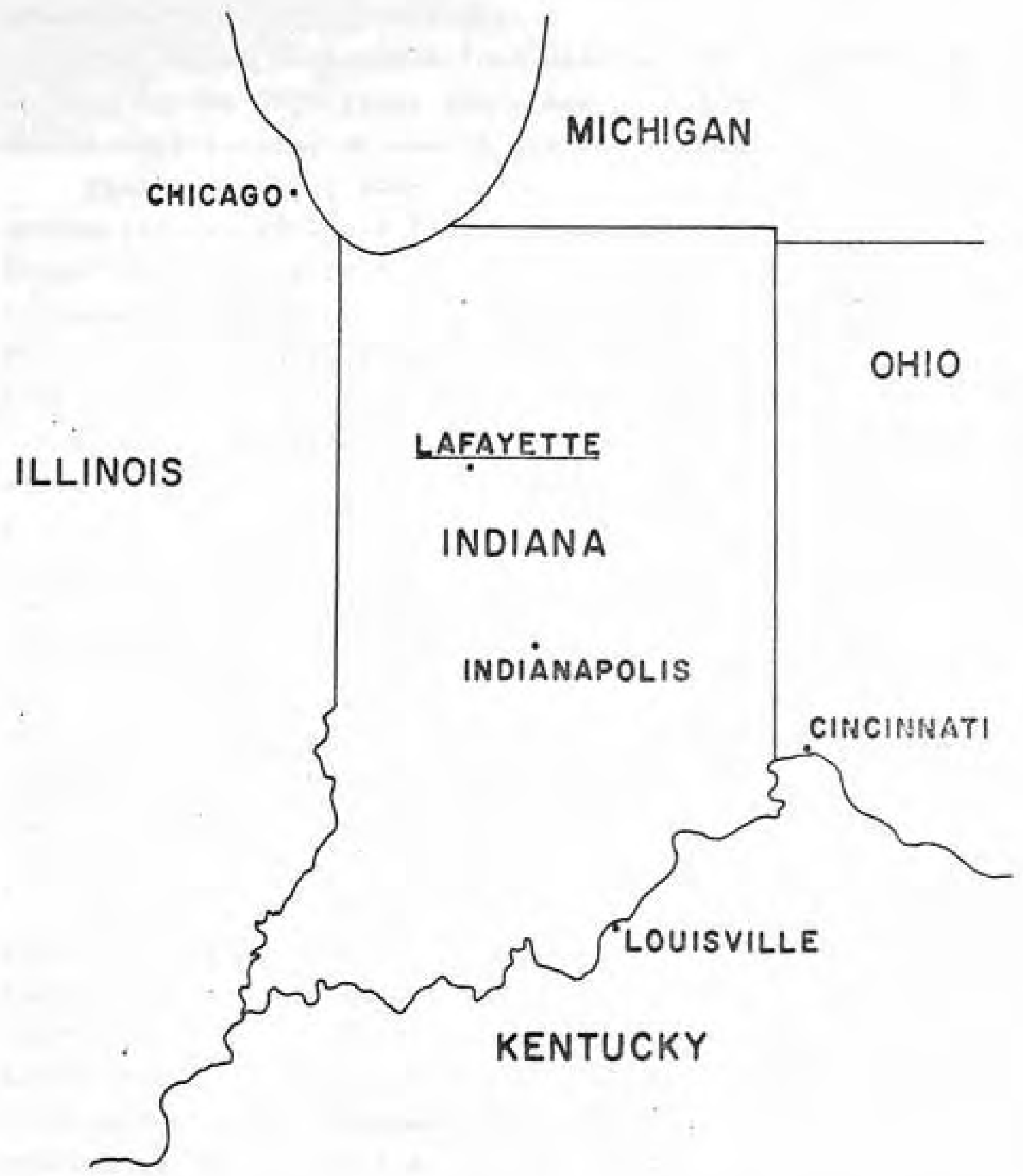

FIGURE 4. GREATER LAFAYETTE URBAN AREA LOCATION IN INDIANA 
based on the Purdue employee increase was used for the growth factor in this corridor.

The street classifications used in 1967 were the same as used in the 1970 study therefore no change in the corridor classifications or boundaries was necessary.

There were only three major changes in the street system between 1952 and 1970. A new bridge, the Harrison Street Bridge, was built connecting Union and Salem Streets in Lafayette to Wiggins and Fowler Streets in West Lafayette. The two sets of streets were made a one-way pair. Third Street was extended from Brown Street to Union Street and converted with Fourth Street into a one-way pair extending south to Alabama. Eighteenth Street was extended from Kossuth to South street and became an arterial while Sixteenth street was converted into a local street. Other improvements did not change the function of the arterial street network:

The corridor boundaries established in the original research were accepted initially; however, the researcher later found it necessary to change the corridor limits in the West Lafayette area. The original corridors are shown in Figures 6 and 7 .

Twelve principal radial corridors were originally established with two of these (nine and ten) overlapping. Corridor eleven was established to estimate Teal Road traffic volumes. Corridors four, five and six were used to estimate U.S. 52 Bypass volumes in eastern Lafayette, and corridors nine and twelve were used for U.S. 52 Bypass volumes in West Lafayette. Corridors four, five, six, seven, eight, nine and twelve were used to estimate the volumes on the Bypass Bridge across the Wabash River.

The author found it necessary to make adjustments in the West Lafayette area. To isolate the source of the large error in the forecasted traffic volumes for corridors nine and ten for the forecast period 1952 to 1970 , another 


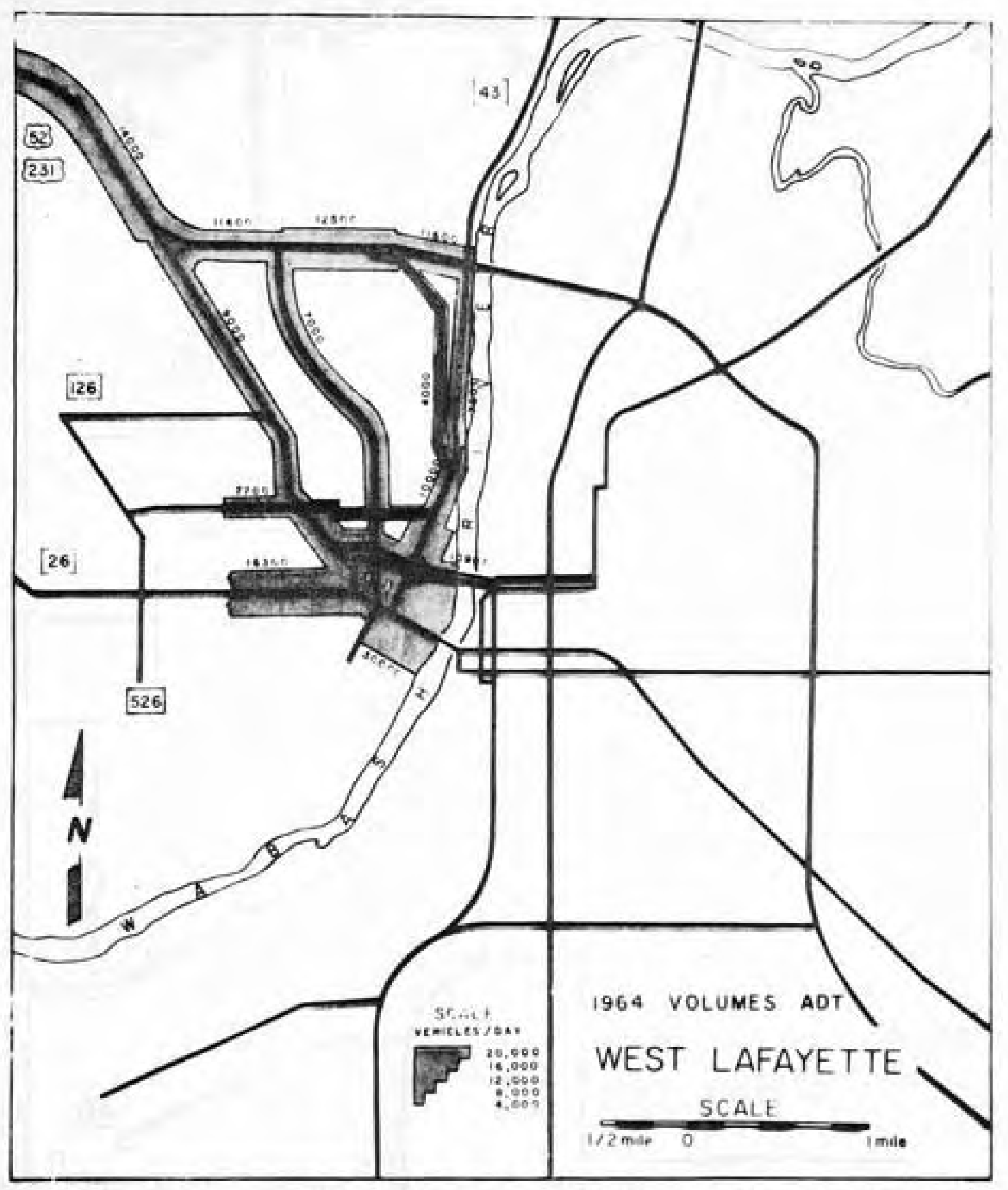

FIGURE 5. I964 TRAFFIC VOLUMES - W. LAFAYETTE 


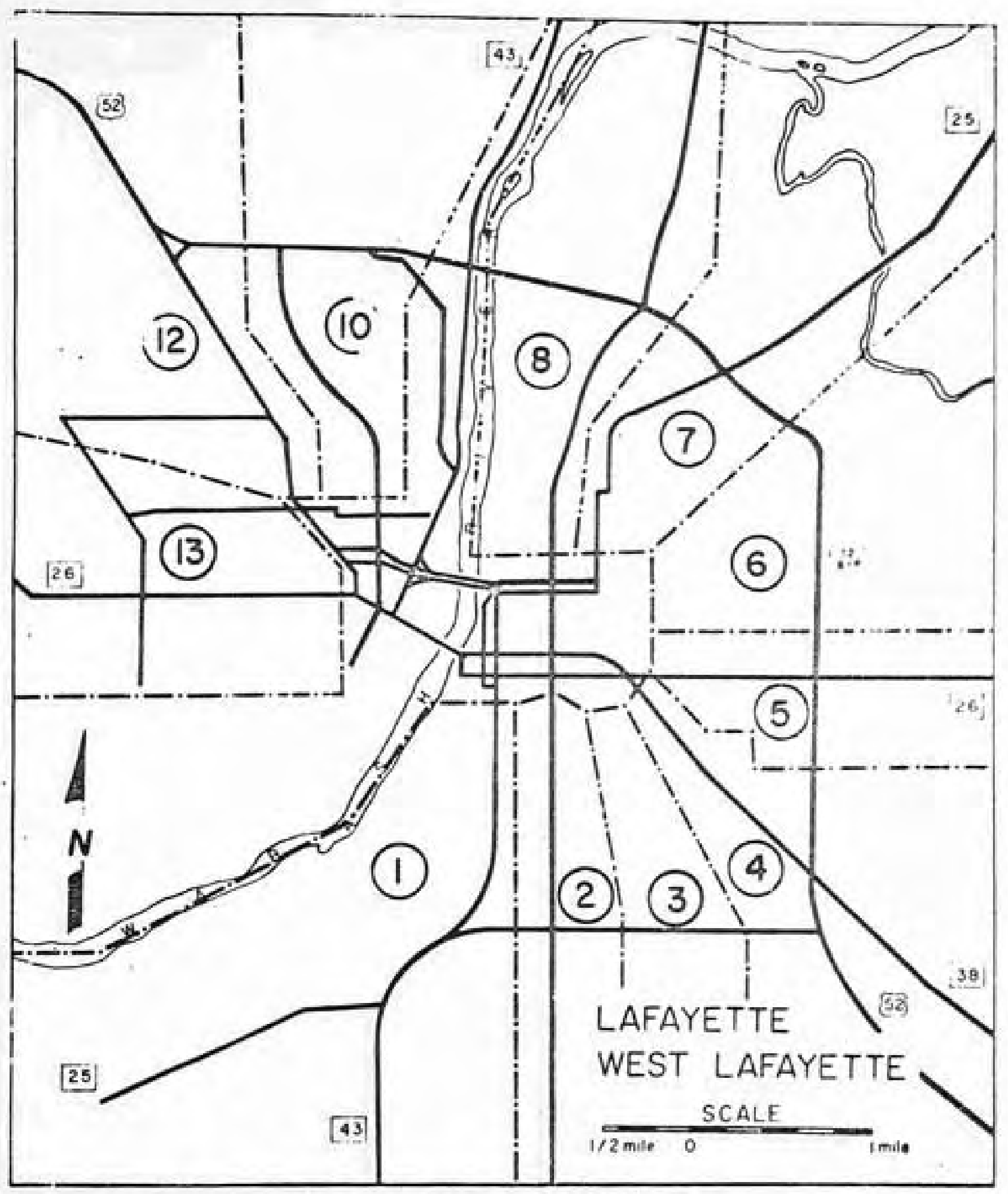

FIGURE 6. CORRIDORS - LAFAYETTE 


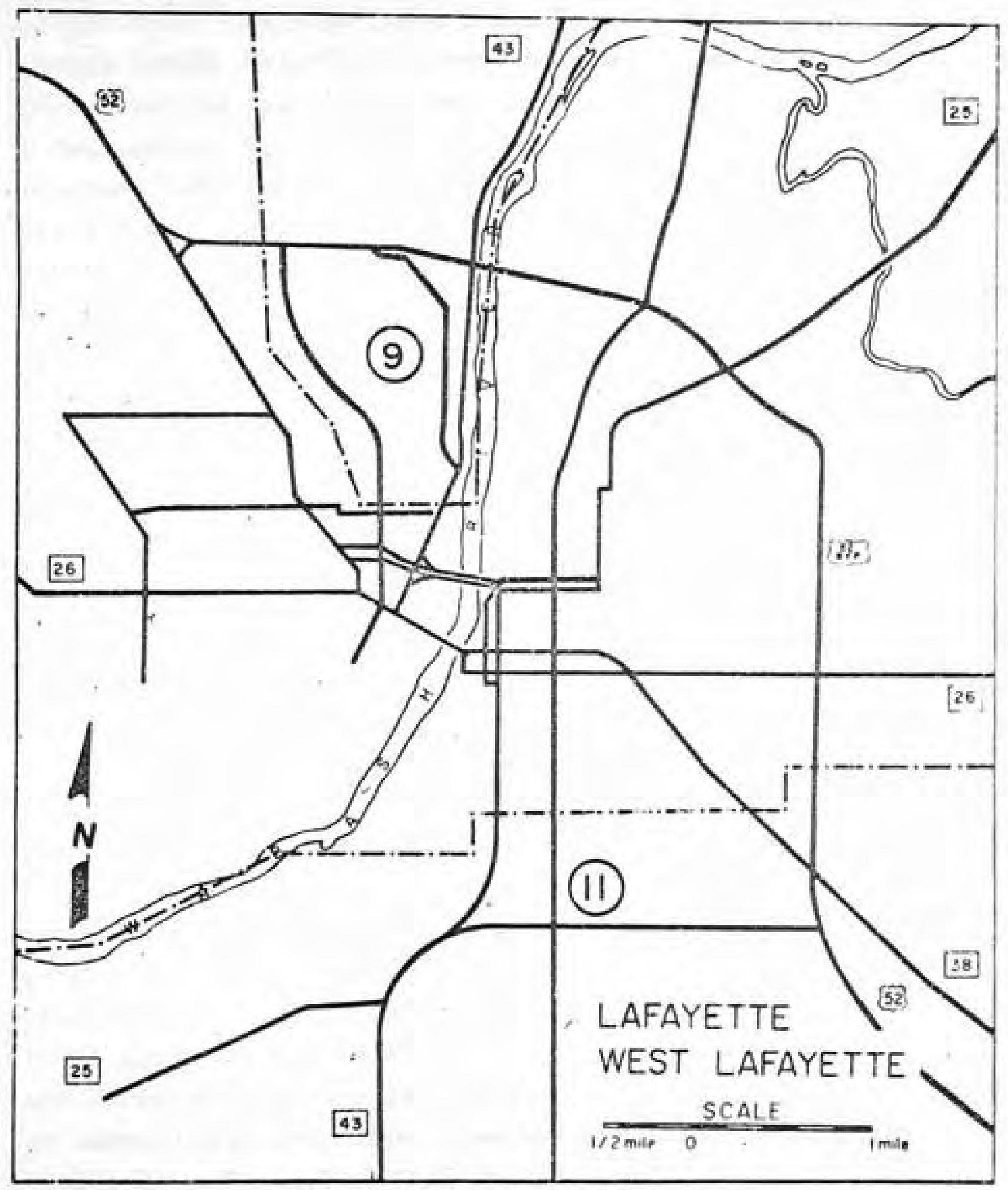

FIGURE 7. CORRIDORS - LAFAYETTE 
base year, 1964, was utilized. The growth factors for 1964 to 1970 for corridors nine, ten, eleven and twelve were calculated. The same data sources and same procedures for growth factor calculation were utilized for 1964 except that existing traffic volumes (Figure 5) were obtained from a JHRP Report by Rude (22). The same percertage split of external-external and internal-external as existed in 1952 was assumed for 1964. The corridor growth factors were determined for the same corridors as established originally and in addition a further overall check combined corriclors nine; ten, eleven and twelve. The narrow total width of the corridors at the south boundary, limited by Purdue University to the west and the Wabash River to the east, indicated that possibly the area should be considered as one corridor served by several arterials.

An additional refinement was also investigated during this phase of the project. The percentage of the total trips considered to be represented by each of the thrce parameters of dwelling unit, total employment, and retajl employment represents a judgement decision that can be decided in several, ways. The original researcher used a percentage for each parameter that best fitted the reported percentages of trips based on trip-destination by trip purpose in a number of cities. Using this procedure throughout the original investigation satisfactory results were obtained. It was felt this factor should be further investigated. The percentage of total trips, based on the total percentage of linked trips for home, work, business and shopping purposes was determined. This was accomplished by sumarizing data from several transportation studies (Table 2). The percentage of total trips represented by the home-linked trips, work-linked trips, business-linked trips and shopping-linked trips were calculated. Using the same procedure as the original researcher the home-linked trips were assumied to be represented by using dwelling units 


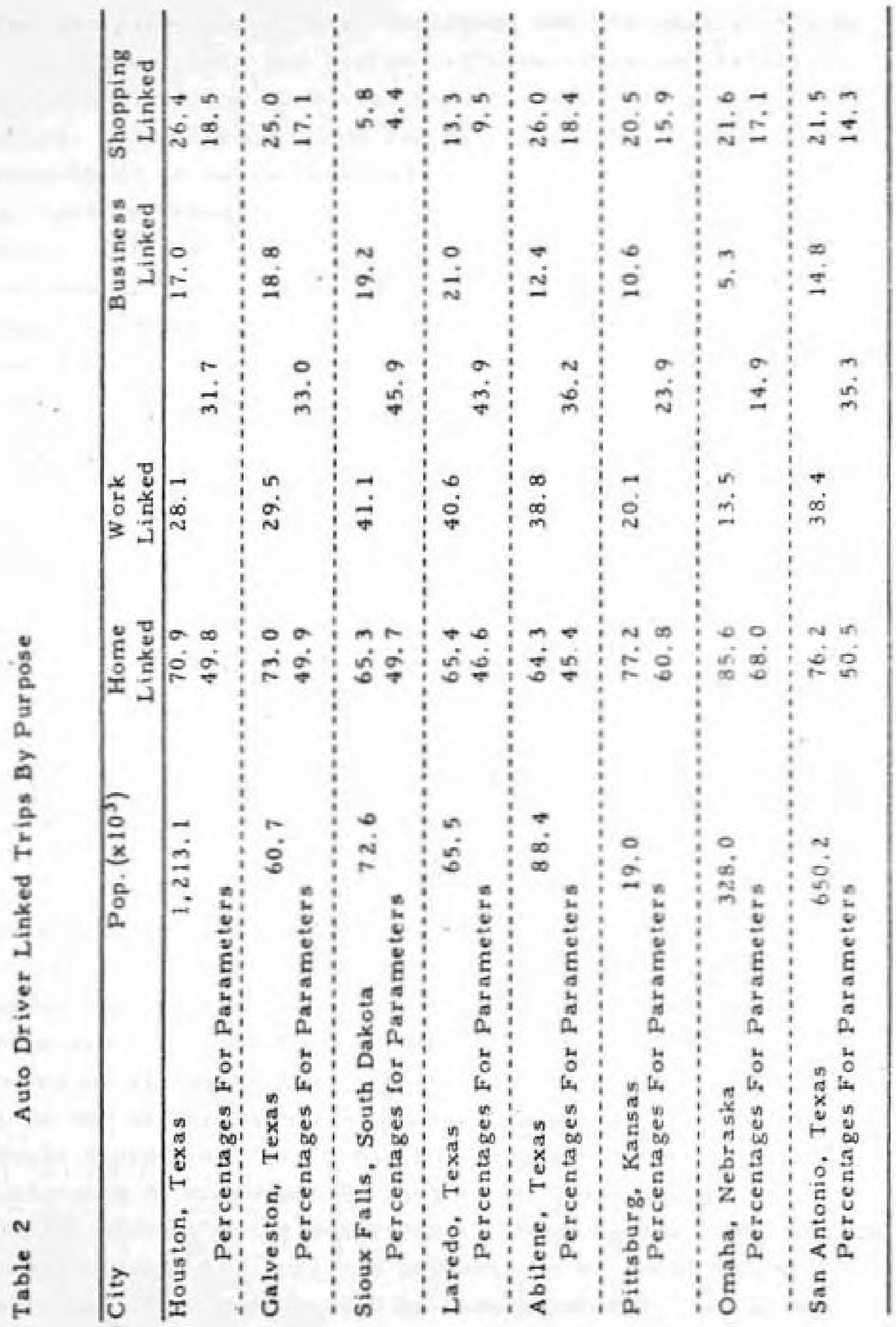


for the parameter. Total employees was the parameter used to represent work and business-linked trips and retail employees was the parameter used to represent shopping-linked trips. Social-recreation and miscellaneous trips are also considered to be represented by the above three parareters without additional calculation. This procedure indicated a split of fifty, thirty-five and fifteen percent for the percentage of the trips to be represented by dwelling units, total employees and retail employees respectively. A computer program was used to provide forecasted volumes by corridor in Lafayette for each of fifty set: of valurs for the three parameters. A plot of the results of the celculations is shown in Figure 8, plotting the various sets against the average corridor traffic volume orror. The plots generally indicate a reduced error as the percentage of total trips represented by the dwelling unit paraneter increases up to approximately sixty percent. The results become erratic beyond this point. Further investigation would be necessary to establish the exact method to establish these parameters; however, the studies used for this determination also indicate that in small urban areas the percentages may differ from large urban areas. As new information becomes available this can be better determined.

The resulting traffic volume comparisons for the principal radial corridors, utilizing the above outlined procedure, are presented in Tables 3 and 4 . Table 3 presents the comparison of the Lafayette-west Lafayette 1970 forecasted volumes to the existing 1970 volumes by radial corridor at the central area screenline. Table 4 makes the same comparison at the approximate midpoint of each corridor. Table 5 presents the comparison of the volumes on the Lafayette circumferential routes, on Teal Road and on the Wabash River-U.S. 52 screenline. These tables represent the results using the original percentages of total trips selected to be represented by each parameter. Volumes 


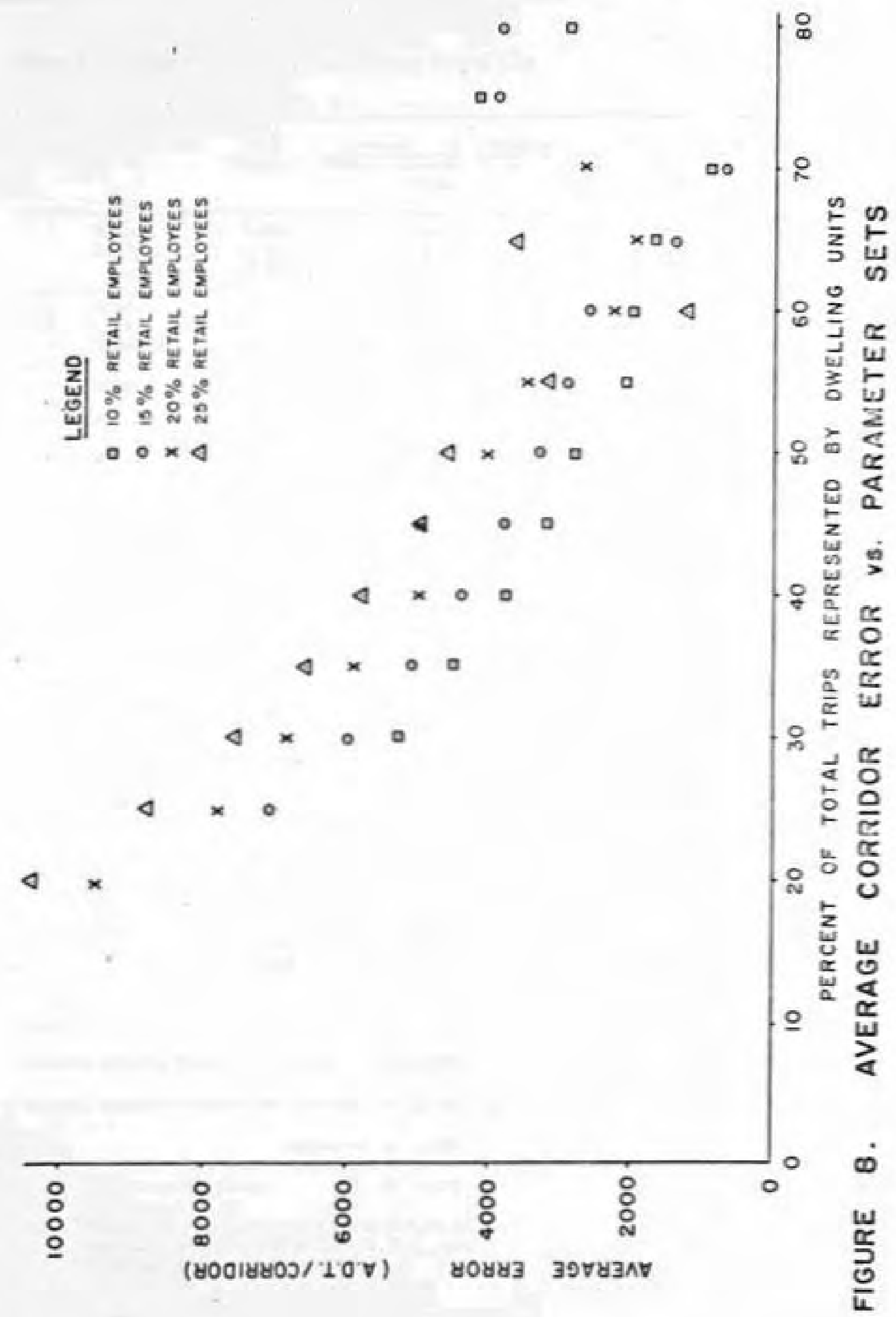


Table 3

Radial Corridors - Lafayetle - Near Central Area

\begin{tabular}{|c|c|c|c|c|c|c|c|c|c|}
\hline \multirow[t]{2}{*}{ Corrider } & \multirow[t]{2}{*}{ Streets } & \multirow{2}{*}{$\begin{array}{c}1952 \\
\text { Volume }\end{array}$} & \multicolumn{2}{|c|}{ Internal } & \multicolumn{2}{|c|}{ Fexternal } & \multirow{2}{*}{$\begin{array}{c}\text { Estimated } \\
1470 \\
\text { Volume }\end{array}$} & \multirow{2}{*}{$\begin{array}{l}\text { Actual } \\
1970 \\
\text { Volune }\end{array}$} & \multirow{2}{*}{$\begin{array}{c}\text { Corridor } \\
\text { Errot }\end{array}$} \\
\hline & & & Volsime & $\begin{array}{l}\text { Grawth } \\
\text { Factor }\end{array}$ & Vatume & $\begin{array}{l}\text { Crowth } \\
\text { Factor }\end{array}$ & & & \\
\hline \multirow[t]{2}{*}{1} & Wabssh & 3,530 & 3,530 & 2.22 & . & . & 7,837 & 6,000 & \\
\hline & Third $t$ Fourts & $\frac{8,740}{12,270}$ & 5,440 & 2.22 & 3, 300 & 19 & $\frac{18,347}{26.148}$ & $\frac{18,400}{24,400}$ & 1. 784 \\
\hline 2 & Nintb & 3.760 & 3,760 & 2.53 & . & + & 9.513 & 10,100 & $\begin{array}{c}\text { - Set } \\
\text { - }\end{array}$ \\
\hline & $\ldots \ldots \ldots$ & $\ldots . .$. & $\ldots . . . .$. & ......... & $\ldots . .$. & $\ldots$ & ............ & and & $\ldots \ldots$ \\
\hline 3 & Eighteenth & 2.850 & 2,850 & 3.57 & $\cdot$ & - & 10,175 & 11.100 & $=925$ \\
\hline \multicolumn{2}{|r|}{ 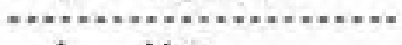 } & 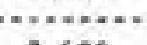 & 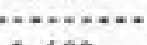 & $\ldots$ & $\therefore \ldots$ & (n......... & $\ldots+\ldots$ & 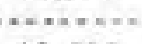 & $\ldots+\cdots$ \\
\hline & Main & 7,690 & 5.690 & 1.96 & 2,000 & 1.9 & 14,952 & 10.500 & 4.452 \\
\hline 5 & South & 7,370 & 5, 870 & 2.03 & 1,500 & 1.9 & 14,766 & 12,000 & 2.766 \\
\hline \multirow{4}{*}{6} & & & & & $\ldots \ldots$ & $\cdots$ & $\ldots+n$ & .......... & $\ldots$ \\
\hline & Union & 3,630 & 3.630 & 3.97 & - & - & 14,411 & 10,509 & \\
\hline & Elmwood & 1.660 & 1,660 & 3.97 & - & - & 6,340 & 12.000 & \\
\hline & & 3.290 & & & & & 21,001 & $22,56 \pi$ & $-1,4,4$ \\
\hline \multirow[t]{3}{*}{7} & Eighteenth & 2.950 & 2.450 & 1.09 & 500 & 1. 9 & 3.621 & $6, H 04$ & \\
\hline & Fourteenth & 6.950 & 5,450 & 1.09 & 1.500 & 1.9 & B. 741 & 3.564 & \\
\hline & & 9.900 & & & & & $\sqrt{12, \sqrt{42}}$ & $\overline{12,306}$ & 112 \\
\hline \multirow[t]{3}{*}{8} & Ninth & 3,010 & 2,710 & 1.50 & 300 & 1.9 & 4,635 & 7. 0 tom & \\
\hline & Canal & 3,650 & 2,950 & 1.50 & 700 & 1.9 & 5.745 & 7. 6 atits & \\
\hline & & 6.660 & & & & & T0. 356 & $\overline{16,086}$ & $-5,610$ \\
\hline \multirow[t]{4}{*}{9} & $5 R 43 \mathrm{~N}$ & 3,190 & 230 & 9.96 & 2.460 & 1.9 & 12,002 & 9,450 & \\
\hline & Robinaon & 1.820 & 1.820 & 9.96 & - & $\cdot$ & 18,127 & 3,926 & \\
\hline & 5alisbury & 1,240 & 1.240 & 9.96 & - & . & 12,350 & 7,350 & \\
\hline & & $\overline{6,250}$ & & & & & $\overline{42.479}$ & $\overline{20,620}$ & 21,609 \\
\hline ... & & & & & & & $=\ldots+\infty$ & $n+\cdots$ & 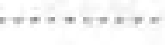 \\
\hline \multirow[t]{5}{*}{10} & Solisbury & 1.240 & 1.240 & 8. 98 & - & - & 11,135 & 7,550 & \\
\hline & Grant & 1.580 & 1.580 & 8. 98 & - & • & 14,188 & 6,500 & \\
\hline & & $\overline{2,820}$ & & & & & 25,323 & T4, 065 & \\
\hline & & & & & & & Robinson & 3, 9010 & \\
\hline & & & & & & & & 1\%, पेकी & 7,353 \\
\hline 12 & Northwestern & 5,500 & 2,300 & 7,96 & 3,200 & 1.6 & 23,428 & 14,500 & 8.930 \\
\hline \multirow{4}{*}{13} & & & & & & & & (2) & $\cdots+\ldots$ \\
\hline & State & 10,000 & 8,500 & 3.18 & 1,500 & 1.9 & 29,850 & 16,500 & \\
\hline & Stadium & $\frac{5,580}{15,580}$ & 5,580 & 3.18 & - & & $\frac{17,744}{47.624}$ & $\frac{10,400}{24.0060}$ & \\
\hline & & & . & & & d. $\mathrm{H}$ & rison, Will & $\frac{n s 9.5,60}{36.500}$ & 9.124 \\
\hline
\end{tabular}

Average Existing Volume Per Corridor $=16,352$.

Average Estimated Volume Per Corridor $=21,521$.

$$
\begin{aligned}
\text { Difference } & =5,169 \\
\text { Errot Nerstreel } & =3,100
\end{aligned}
$$

Note: Removal of West Lafayelte, Corridurs 9, 10, 12 Reduces Corridor Error to 2, 700 A.D. I. . and Per Street Erzot to 1,700 A, D. 1. 
Table 4 Radial Corfidors - Lafayette - Midpoint of Corridor

\begin{tabular}{|c|c|c|c|c|c|c|c|c|c|}
\hline \multirow[t]{2}{*}{ Corridor } & \multirow[t]{2}{*}{ Streets } & \multirow{2}{*}{$\begin{array}{c}1952 \\
\text { Volume }\end{array}$} & \multicolumn{2}{|c|}{ Internat } & \multicolumn{2}{|c|}{ External } & \multirow{2}{*}{$\begin{array}{c}\text { Estimated } \\
1970 \\
\text { Volume }\end{array}$} & \multirow{2}{*}{$\begin{array}{c}\text { Actual } \\
1970 \\
\text { Volume }\end{array}$} & \multirow{2}{*}{$\begin{array}{c}\text { Corridor } \\
\text { Error }\end{array}$} \\
\hline & & & Volume & Factor & Vofunie & ractar & & & \\
\hline 1 & $\begin{array}{l}\text { Wabash } \\
\text { Third \& Fourth }\end{array}$ & $\begin{array}{l}3,200 \\
7,100\end{array}$ & $\begin{array}{l}3,200 \\
3,800\end{array}$ & $\begin{array}{l}2.22 \\
2.22\end{array}$ & 3,300 & 1.9 & $\begin{array}{r}7,104 \\
\frac{14.706}{21,810}\end{array}$ & $\begin{array}{r}4,421 \\
16,000 \\
20,421\end{array}$ & 1,369 \\
\hline 2 & Ninth & 3,640 & 3,640 & 2,53 & - & . & 9.209 & 7,000 & $2,20 \%$ \\
\hline 3 & Eighteenth & 1.930 & 1,910 & 3.57 & 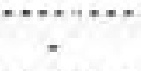 & . & 6.890 & 8,700 & 1.810 \\
\hline 4 & Main & 6,360 & 4,360 & 1.96 & 2,000 & 1.9 & 12,346 & 10,400 & 1. 946 \\
\hline 5 & Soath & 7,370 & 5,870 & 2.03 & 1,500 & 1.9 & 14,766 & 11.000 & 3.766 \\
\hline 6 & $\begin{array}{l}\text { Union } \\
\text { Elmwood }\end{array}$ & $\begin{array}{r}3,630 \\
640\end{array}$ & $\begin{array}{r}3.630 \\
640\end{array}$ & $\begin{array}{l}3.97 \\
3.97\end{array}$ & . & 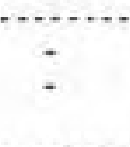 & $\begin{array}{r}14,411 \\
2,541 \\
16,952\end{array}$ & $\begin{array}{r}6,200 \\
\frac{6,600}{13,000}\end{array}$ & 3.952 \\
\hline 7 & $\begin{array}{l}\text { Eighteenth } \\
\text { Fourteenth }\end{array}$ & $\begin{array}{l}1,630 \\
5,830\end{array}$ & $\begin{array}{l}1,130 \\
4.330\end{array}$ & $\begin{array}{l}1.09 \\
1.09\end{array}$ & $\begin{array}{r}500 \\
1,500\end{array}$ & $\begin{array}{l}1.9 \\
1.9\end{array}$ & $\begin{array}{l}2.182 \\
\frac{7.370}{9.752}\end{array}$ & $\frac{4,804}{6.700}$ & 3,052 \\
\hline B & Canal Road & 3,620 & 2,620 & 1.50 & 1,000 & 1.9 & 5,830 & 4. 400 & 1.430 \\
\hline 9 & $\begin{array}{l}5 R 43 \text { N } \\
\text { Happy Hollow } \\
\text { Salisbury }\end{array}$ & $\begin{array}{l}2.590 \\
1.000 \\
1,000\end{array}$ & $\begin{array}{l}1,000 \\
1,000\end{array}$ & $\begin{array}{l}9.96 \\
9.96\end{array}$ & 2,590 & $\begin{array}{c}1.9 \\
:\end{array}$ & $\begin{array}{r}4.921 \\
9.960 \\
9.960 \\
27.951\end{array}$ & $\begin{array}{r}5.200 \\
4.000 \\
11.0606 \\
20.200\end{array}$ & 4,641 \\
\hline 10 & Salisbury & 1,000 & 1,000 & 8,98 & $\cdots$ & . & 6. 990 & 11,060 & $, 2,020$ \\
\hline 12 & Northwestern & 4,020 & 820 & 7.96 & 3,200 & 1.6 & 11,650 & 13.000 & -1.350 \\
\hline 13 & $\begin{array}{l}\text { State } \\
\text { Stadium }\end{array}$ & $\begin{array}{l}5.540 \\
1,200\end{array}$ & $\begin{array}{l}4,040 \\
1,200\end{array}$ & $\begin{array}{l}3.18 \\
3.18\end{array}$ & 1,500 & 1.9 & $\begin{array}{r}15,697 \\
3.816 \\
14.513\end{array}$ & $\begin{array}{r}13,000 \\
2,000 \\
15,000\end{array}$ & 4,513 \\
\hline
\end{tabular}




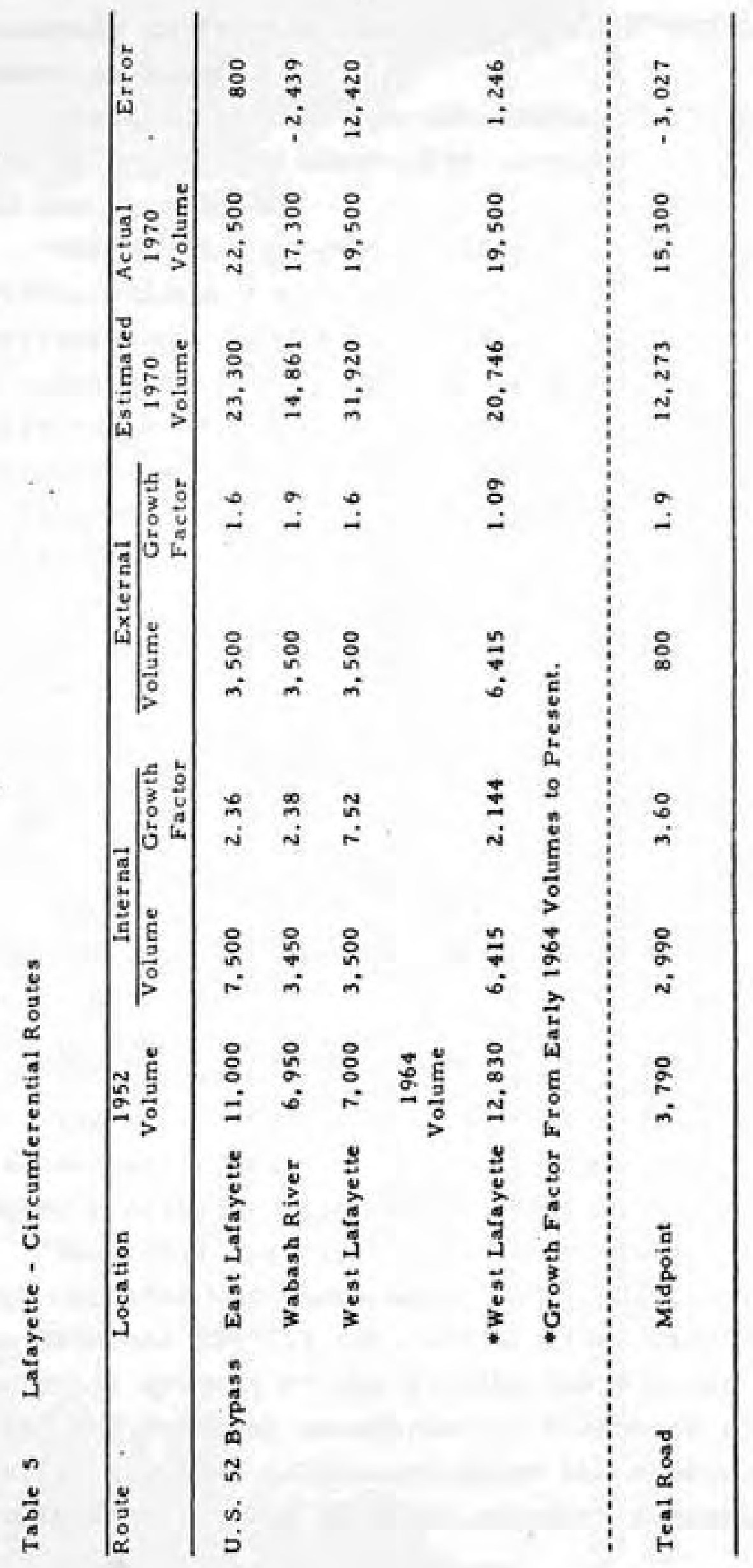


presented on figures and tables are ADT values unless otherwise noted.

Table 6 presents the comparison of the West Lafayette 1964-1970 corridor check with corridors nine, ten, eleven, and twelve combined.

Table 7 was prepared indicating the comparison of traffic volumes for the Lafayette-West Lafayette radial corridors near the central area utilizing the percentages of total traffic to be represented by the dwelling unit parameter as fifty percent, with that portion to be represented by the total number of employees as thirty-five percent and that part to be represented by the number of retail employees as fifteen percent.

The comparison of the forecasted Lafaycte exterial station volume counts to the existing counts, using granth factors based on vehicle registration, are presented in Table 8 . The only forecasts varying substantially from observed counts are those at locations where the original cordon line did not include the 1970 developed area. Thesc stations are on S.R. 26 West and S.R. 26 East.

The growth factor applied to U.S. 52 Bypass through traffic was based on the Indiana vehicle registration increase over the forecast period as follows:

$$
\frac{1970 \text { vehicle registration }}{1952 \text { vehicle registration }}=\frac{52,582}{27,613}=1.90
$$

The maximum error of four thousand five hundred nineteen daily vehicles on State Road 26 East would not have caused a design change in the arterial streets involved.

The total forecasted versus existing volume within each corridor was compared and not individual street volumes. The external traffic for each corridor was subtracted from the total volumes of the streets and forecasted separately using the external growth factor discussed above. Internal traffic was then forecasted using the developed corridor growth factor. The original research suggested that the 
Table 7 Radial Corridors - Lafayette - Near Central Area

\begin{tabular}{|c|c|c|c|c|c|c|c|c|c|}
\hline Cotridor & Sireets & $\begin{array}{c}1952 \\
\text { Volume }\end{array}$ & $\frac{\text { Inter }}{\text { Volume }}$ & $\begin{array}{l}\frac{\text { nal }}{\text { Growth }} \\
\text { Factor }\end{array}$ & $\frac{\text { Extern }}{\text { Volume }}$ & $\begin{array}{l}\text { Growth } \\
\text { Factor }\end{array}$ & $\begin{array}{c}\text { Estumated } \\
1970 \\
\text { Volume }\end{array}$ & $\begin{array}{c}\text { Actual } \\
1970 \\
\text { Volume }\end{array}$ & $\begin{array}{c}\text { Corridar } \\
\text { Errur }\end{array}$ \\
\hline 1 & $\begin{array}{l}\text { Wabash } \\
\text { Rhird } L \text { Fourth }\end{array}$ & $\begin{array}{r}3.530 \\
8.710 \\
12.270\end{array}$ & $\begin{array}{l}3,530 \\
5,440\end{array}$ & $\begin{array}{l}2.14 \\
2.14\end{array}$ & 3,300 & 1. 9 & $\begin{array}{r}7,554 \\
17,911 \\
25,465\end{array}$ & $\begin{array}{r}6,000 \\
18.400 \\
24,406\end{array}$ & 1,406 \\
\hline 2 & Nisth & 3,760 & 3,760 & 2. 48 & - & - & 9,325 & 10,100 & $=7 m$ \\
\hline 3 & Eighteenth & 2.850 & 2,850 & 3.53 & . & . & 10,060 & 14,100 & -1.040 \\
\hline 4 & Main & 7,690 & 5,690 & 1.97 & 2,000 & 1. 9 & 15,010 & 10.500 & 4.516 \\
\hline 5 & South & 7,370 & 5,870 & 1.93 & 1,500 & 1.9 & 14,180 & 12,000 & 2,1 ho \\
\hline 6 & $\begin{array}{l}\text { Union } \\
\text { Elmweod }\end{array}$ & $\begin{array}{l}3,630 \\
1.660 \\
3,290\end{array}$ & $\begin{array}{l}3,630 \\
1,660\end{array}$ & $\begin{array}{l}3.90 \\
3.90\end{array}$ & $\therefore$ & $\dot{*}$ & $\begin{array}{r}14,156 \\
6,474 \\
20,6,30\end{array}$ & $\begin{array}{l}16,560 \\
12,000 \\
22,500 \\
\ldots \ldots \ldots\end{array}$ & $\begin{array}{l}-1, k 20 \\
\ldots \ldots \ldots\end{array}$ \\
\hline 7 & $\begin{array}{l}\text { Eighteenth } \\
\text { Fourteenth }\end{array}$ & $\begin{array}{l}2.950 \\
6,950 \\
9.900\end{array}$ & $\begin{array}{l}2,450 \\
5,450\end{array}$ & $\begin{array}{l}1.11 \\
1.11\end{array}$ & $\begin{array}{r}500 \\
1,500\end{array}$ & $\begin{array}{l}1.9 \\
1.9\end{array}$ & $\begin{array}{r}3,670 \\
8,900 \\
12,570\end{array}$ & $\begin{array}{l}6.500 \\
5.500 \\
12,500\end{array}$ & 270 \\
\hline 8 & $\begin{array}{l}\text { Ninth } \\
\text { Canal }\end{array}$ & $\begin{array}{l}3,010 \\
3,650 \\
6,660\end{array}$ & $\begin{array}{l}2,710 \\
2,950\end{array}$ & $\begin{array}{l}1.54 \\
1.54\end{array}$ & $\begin{array}{l}300 \\
700\end{array}$ & $\begin{array}{l}1.9 \\
1.9\end{array}$ & $\begin{array}{r}4.745 \\
5.875 \\
10,620\end{array}$ & $\begin{array}{r}\text { 1.,000 } \\
9,050 \\
12, \text { जet }\end{array}$ & $-9,340$ \\
\hline 9 & $\begin{array}{l}\text { SR } 43 \mathrm{~N} \\
\text { Robinson } \\
\text { Salisbury }\end{array}$ & $\begin{array}{l}3,190 \\
1,820 \\
1,240 \\
6,250\end{array}$ & $\begin{array}{r}730 \\
1,820 \\
1,240\end{array}$ & $\begin{array}{l}9.63 \\
9.63 \\
9.63\end{array}$ & $\begin{array}{c}2,460 \\
- \\
-\end{array}$ & $\begin{array}{c}1.9 \\
- \\
-\end{array}$ & $\begin{array}{l}11,703 \\
17,526 \\
11,941 \\
41,174\end{array}$ & $\begin{array}{r}4,406 \\
3,420 \\
7,+50 \\
70,0,07\end{array}$ & 20. $16 \mathrm{al}$ \\
\hline 10 & $\begin{array}{l}\text { Salisbury } \\
\text { Grant }\end{array}$ & $\begin{array}{l}1,240 \\
1,580 \\
\frac{2,620}{260}\end{array}$ & $\begin{array}{l}1,240 \\
1,580\end{array}$ & $\begin{array}{l}8,58 \\
\text { B. } 58\end{array}$ & $\dot{-}$ & 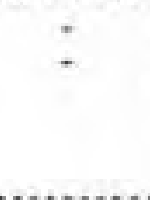 & $\begin{array}{l}10,640 \\
13,555 \\
24,195\end{array}$ & 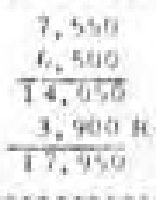 & $\begin{array}{l}\text { thitistelt } \\
t, 0 s\end{array}$ \\
\hline 12 & Northwestern & 5,500 & 2,300 & 7,27 & 3,200 & 1,6 & 21,840 & 14,500 & 7,340 \\
\hline 13 & $\begin{array}{l}\text { State } \\
\text { Stadium }\end{array}$ & $\begin{array}{r}10,000 \\
5,580 \\
15,580\end{array}$ & $\begin{array}{l}8,500 \\
5,580\end{array}$ & $\begin{array}{l}\text { 3. } 18 \\
\text { 3. } 18\end{array}$ & 1,500 & od, Harris & $\begin{array}{l}29,880 \\
17,744 \\
47,624 \\
\text { on, Williams }\end{array}$ & $\begin{array}{l}16,500 \\
\frac{10,5000}{2} 9.000 \\
\frac{9.500}{38,500}\end{array}$ & 9.124 \\
\hline
\end{tabular}

Average Existing Volume Per Corridor $=16,352$

Average Estimated Volume Per Corridor $=21,050$

Difference $\quad=\quad 4,698$

Error Per Street $=2,800$

Note: Removal of West Lafayette Corriders 9, 10, 12 Reduced Corridor Error to 2, 450 A, D. T. and per Street Error to 1,700 A. D. T. 
Table 8 Lafayette External Cordon Stations

\begin{tabular}{lccrrr}
\hline Route & $\begin{array}{c}1952 \\
\text { Volume }\end{array}$ & $\begin{array}{c}\text { Growth } \\
\text { Factor }\end{array}$ & $\begin{array}{c}\text { Estimated } \\
1970 \\
\text { Volume }\end{array}$ & $\begin{array}{c}\text { Actual } \\
1970 \\
\text { Volume }\end{array}$ & Error \\
\hline SR 25 S & 3,080 & 1.9 & 5,852 & 5,220 & 630 \\
SR 43 S & 3,600 & 1.9 & 6,840 & 6,977 & 137 \\
US 52 S & 3,620 & 1.9 & 6,878 & & \\
& 3,500 & 1.64 & 5,740 & & \\
SR 38 & 2,590 & 1.9 & 4,921 & 3,817 & 1,104 \\
SR 26E & 2,000 & 1.9 & 3,800 & 8,319 & $-4,519$ \\
SR 25 N & 4,400 & 1.9 & 8,360 & 10,715 & $-2,355$ \\
Canal Road & 1,450 & 1.9 & 2,755 & 4,160 & $-1,405$ \\
SR 43 N & 2,590 & 1.9 & 4,921 & 4,212 & 709 \\
US 52 N & 5,590 & 1.9 & 10,621 & & \\
& 3,500 & 1.64 & 5,740 & & \\
SR 26 W & 1,530 & 1.9 & 2,907 & 5,945 & $-3,038$
\end{tabular}


university area (corridor thirteen) required the addition of existing traffic volumes on Wood, Harrison and Williams Street to the state and stadium street volumes to provide a valid comparison. Including the existing 1970 volunes on these streets provided an excellent check with the basic reasoning being that these streets were not used in 1952 because state street was operating below capacity, but in 1970 they serve as overflow arterial routes with state street operating at or near capacity. In addition, there is substantially increased parking adjacent to the cirant strect screenline on the CBD side with traffic that was autombile. traffic entering purdue University in 1951 now using the parking and converting to pedestrian traffic before crosising the screenline in 1970. The corridor volumes check within the accuracy desired with the above modifications.

The West Lafayette area, specifically from West of Northwestern Avenue to the Wabash River, corridor nine, ten, eleven and twelve and including state Road 43 morth, Robinson Street, Salisbury Street, Grant street and Northwestern Avenue, was reviewed in considerable detail. Using the same corridor identification as used in the earlier research, the total traffic volume was overforecasted by twenty-one thousand six hundred ADT in corridor nine. Northwestern Avenue, corridor twelve, traffic volumes were overforecasted by nine thousand ADT and corridor ten was overforecasted by seven thousand three hundred fifty ADT. Since the area had experienced higher then normal growth, which for our purposes we shall define at greater then six percent per year, and since employment, non-existant in 1952, was present in substantial amounts in these corridors in 1970, it was considered probable that this corridor growth factor technique would exhibit the same problem that has been inherent in all growth factor techniques. If an area, with zero or low trip qeneration in 
the base year, experiences substantial growth by the target year then the growth factor is no longer dependable for estimation of trip generation rates and requires modification. To check this assumption, the dwelling units and employment figures for these corridors for late 1963 and early 1964 were obtained. This provided data for calibration of a growth factor over a period of approximately seven instead of eighteen years and encompasses a period when the growth was more typical. Utilizing this procedure and also combining corridors nine, ten, eleven and twelve the total corridor error was approximately five thousand vehicles, which is considered well within the limits for design. This also substantiates the assumption concernirig the growth factor limitation.

In one other corridor, corridor eight, the traffic volumes were under predicted by five thousand six hundred cars; however, assuming the error to be evenly distributed over the two thoroughfares serving the corridor the error is insignificant.

\section{Conclusions on the Lafayette Check.}

The growth factor corridor technique, as indicated by the above comparisons, gives results sufficiently accurate to determine major improvements needed, the location and the number of lanes for which a facility should be designed and necessary information for establishing construction priorities. It can also be concluded from the comparisons that an eighteen to twenty year forecast is probably taxing the procedure to its useful limit. As shown in check of the West Lafayette area, using a seven year period instead of eighteen year period, the difference was reduced to a point of insignificance from a design viewpoint overcoming the weakness of any growth factor technique by reducing the forecast period. 
MODEL DEVELOPMENT

One of the basic parts of this project was the development of methods and/or models to synthetically dcrive external traffic information normally obtained by conducting an external cordon survey in a city. Several approaches to the problem were considered. Use of models developed using regression tochniques is an accepted procedure for traffic forecasting. One of the advantarges of regression models developed with data fron many sourcrs is that application of the models can then be with new data that falls within the range of the original data limits.

The alternate procedure developed simple models based on historical information. This procedure thus automatically considers any special localized factors and it is also pos:tible that information developed in this manner wowld be flore acceptable to the local people because they could better understand the procedure.

The discussion of the model development for this project will therefore be divided into two parts, regression models and what will be called direct models. These two types will be discussed separately.

\section{Regression Mode1s}

Regression analysis assumes the general form of the equation to be as follows:

$$
\mathrm{x}=\mathrm{a}+\mathrm{b}_{1} \mathrm{x}_{1}+\mathrm{b}_{2} \mathrm{x}_{2}+\cdots-\cdots \mathrm{b}_{n} \mathrm{x}_{n}
$$

Where:

$\mathrm{Y}=$ Response or dependent variable

$\mathrm{a}=\mathrm{A}$ constant 
$b=$ Coefficient for the independent variable

$\mathrm{X}=$ Independent variable

Three basic assumptions necessary for regression analysis are as follows:

1. The independent variables are fixed and measured without error.

2. For a set of independent variables, the dependent variable is normally and independently distributed.

3. For any set of independent variables the variances of the dependent variables are homogeneous.

The BuD2R library program is generally referred to as a stepwise or buildup regression program. The program first develops the simple correlation matrix for the variables and enters the independent variable at each step having the highest partial correlation with the response variable. This continues until all variables are entercd or until a specified level of significance is reached.

Criteria for selection of the "best" model must also be established. The multiple correlation coefficient or $R^{2}$ is one measure of the quality of the equation. The $R^{2}$ statistic indicates the amount of the total variation cxplained by the calculated regression line. This statistic is expressed as a decimal and may assume values frot 0 to 1.00. An $\mathrm{R}^{2}$ of 1.00 denotes a perfect fit with all the observations lying on the calculated regression line.

The standard error of the estimate indicates the scatter of the observed data around the calculated regression line. It is expressed in the same units as the response variable. With a normal distribution, approximately two-thirds of the observations will be in a band formed by lines within one standard error on each side of the regression line. In order that the developed nodrs Is be stable over a time period, the prerequisite for allowing a variable to enter the model was a hypothesized causal relationship rather than a mere correlation. The assuription 
is that the relationship will remain the same over time. Also, in keeping with a desire for simplicity and because of the difficulty of interpretation three factor interactions were not considered.

In stepwise regression, a test is needed at each step to check if the increase in $\mathrm{R}^{2}$ contributed by each added independent variable in the equation is significantly different than zero. This is called the partial F test. The following F statistic tests that the contribution of the $k$ independent variables is significantly greater than zero.

$$
\text { - } \mathrm{F}_{\mathrm{k}, \mathrm{n}-\mathrm{k}-1}=\frac{\mathrm{R}^{2} \mathrm{k} / \mathrm{k}}{\left(1-\mathrm{R}_{\mathrm{k}}{ }_{\mathrm{k}}\right) /(\mathrm{n}-\mathrm{k}-1)}
$$

Where :

$\mathrm{n}=\mathrm{N}$ umber of observations

$\mathrm{k}=\mathrm{N}$ umber of independent variables

$\mathrm{R}^{2}=$ Coefficient of multiple determination of a model with $k$ independent variables

The blind use of the $\mathrm{F}$ tost and the stepwise regression can result in developing a regression model with more independent variables than are of practical significance. Care must be taken in the selection of variables, using criteria other than simply the relying on the coaputer program.

The choice of independent variables to be exanined was based primarily on the results of previous research in the subject area. Additional selection criteria for inclusion of independent variables was as follows:

1. Readily obtainable

2. Can be obtained economically

3. A logical relationship with the dependent variable

4. Readily forecastable

5. Reasonable reason to believe future relationship will be the same as today 
Regression analysis, using cross products of certain combinations of the variables, determined from plots, was employed as a means of investigating the interactions. A statistical plot program, BMD5D, was used to individually plot possible combinations of independent variables versus each of the response variables. Those combinations of variables indicating an intersection within the limits of the response variable being investigated if they met the additional criteria stated above, were then entered into the stepwise regression program by use of the transgeneration option.

External survey reports from seventy-seven cities in nineteen different states were obtained for the original data set. The reports were made available by the state highways departments in each of the states. Ohio provided external survey data for cities listed in Table 1 ; however, formal reports were not available. Initially, data from a Federal Ilighway Administration Data hook was included for cities that conducted transportation planning studies under the Federal Aid Highway Act of 1962 and during the course of the research each of these cities was: contacted to ensure use of proper data in the investigation.

During the development of the regression models several data sets of different sizes were used. This was necessary because, as the addition of new variables was determined to be necessary, the additional information was not available from some of the reports.

A total of twenty independent variables, both quantitative and qualitative, were available in the development of the final regression models for this study. Of these twenty, three were dummy variables usedto reprosent qualitative factors. Utilizing the same independent variablos, two models were developed regressing on two different response variables during the model development. The response variables were the total external and total 
external-external cordon crossing for a city per day.

The information for the independent variables was taken primarily from external survey reports for the citics included in the data set (listed in Table 1). It was necessary to supplement the report information from other sources. The Bureau of the Census population reports (1960) were used for completion of employment data in those cases where the reports did not contain the data. Information furnished by the Federal Highway Administration was used to complete county vehicle registration data. The variables used in the development of the model are listed below.

\section{Variables for Model Development}

Variable Number

1

2

3

4

5

6

7

8

9

10
Variable Name and Code

Study area population

Study area population density

Population of cities smaller than

subject city within 25 miles

Population of cities larger than

subject city within 25 riles

population of cities larger than

subject city within 50 miles

University if present (coded: yes 1 ,

no 0$)$

City is county seat (coded: yes 1, no 0$)$

Interstate route through study area (coded: present 1 , not present 0 )

County population density outside study cordon, persons per square mile $\mathrm{P}_{1} \cdot \mathrm{P}_{2} / \mathrm{D}^{2} ; \mathrm{P}_{1}$ in population of city $\mathrm{P}_{2}=$ Sum of population of cities larger than subject city within 50 miles 
$D^{2}=$ Sum of distances from $P_{1}$ to $P_{2}$ squared

11

$\mathrm{P}_{1} \cdot \mathrm{P}_{2} / \mathrm{D}^{2} ; \mathrm{P}_{1}=$ population of city

$\mathrm{P}_{2}=$ Sun of population of cities larger than subject city within 25 miles

$D^{2}=$ Sun of distance from $P_{1}$ to $P_{2}$ squared

County population density, persons per square milc

$\mathrm{P}_{1} \cdot \mathrm{P}_{2} / \mathrm{D}^{0.5} ; \mathrm{P}_{1}=$ population of city

$\mathrm{P}_{2}=$ Sum of population of surrounding counties

$D=$ Sum of distances from city to county seat of county

$\mathrm{P}_{1} \cdot \mathrm{P}_{2} / \mathrm{D}^{1 \cdot 0} ; \mathrm{P}_{1}=$ Population of city

$\mathrm{P}_{2}=$ Sum of population of surrounaing counties

$D=$ Sum of distanees from eity to county seat of county

$\mathrm{P}_{1} \cdot \mathrm{P}_{2} / \mathrm{D}^{1.5} ; \mathrm{P}_{1}=$ population of city $\mathrm{P}_{2}=$ Sum of population of surrounding counties

$D=$ Sum of distances from city to county seat of county

$\mathrm{P}_{1} \cdot \mathrm{P}_{2} / \mathrm{D}^{2 \cdot 0} ; \mathrm{P}_{1}=$ Population of city $\mathrm{P}_{2}$ =Sum of population of surrounding counties

$\mathrm{D}^{2}=$ Sum of distances from city to county seat of county squared County population County area, squares miles Total employment in study area County vehicle registration 


\section{Stepwise Regression}

The Statistical Program BMD2R, Stepwise Regression (a library program) was used throughout the model development. The summary table option was used during model development to evaluate the contribution of each new variable to the model at each step and also to determine the order of entry.

From review of many past research projects involving traffic forecasting it was noted that several forms of transformations seemed to be repeated as significant variables in regression models in the projects. These transformations included the logarithms and the reciprocel of population variables, ratios formed by population over study employment, population over study area, county population over county area, etc. In a few cases the quadratic terms, $x^{2}$, or cubic terms, $x^{3}$, of the various independent variables were found to contribute significantly to the models.

The initial phase of the regression analysis used a data set consisting of seventy-seven cities and cighteon independent variables. In this phase of the analysis cross-product terms and various transformations of the original variables including the quadratic and cubic form of the quantitative variables, the logs of quantitative variables and the reciprocal of those variables involving population were investigated. Using this procedure the maximum $\mathrm{R}^{2}$ obtained was .53 with four variables in the model using the total external traffic as a response variable. For simplicity, a model was not considered to be satisfactory if more than four variables were necessary to increase the ratio of the residual sum of squares to the total sum of squares $\left(\mathrm{R}^{2}\right)$ to an acceptable level (predetermined as approximately seventy percent). 
At this point in the research possible additional variables were considered, evaluating each variable with respect to the selection criteria established initially. Employment data was selected as the best candidate for an additional variable. Each of the cities used in the original seventy-seven city data set were contacted by letter (Chamber of Commerce) asking for employment data by location within the city. A fifty-four city data set was assembled adding the employment thus obtained as an indupendent variable. A regression analysis at this stage developed a model with an $\mathrm{R}^{2}$ of .57 utilizing four independent variables and total external-external as the response variable.

Some of the employment data collected by contact with each of the cities was considered suspect and the decision was made to substitute the 1960 Bureau of Census data giving employment for cities of over ten thousand population although this introduced a slight error because the traffic data and other information from the survey reports was collected primarily in the early $1960^{\prime} \mathrm{s}$. This difference was considered insignificant. The 1960 census data did not include cities of less than ten thousand population thus restricting the inference space for the developed models.

In the final phase in the regression analysis, total study area employment data obtained from the original study reports were added and supplemented by Bureau of Census data where necessary. County vehicle registration data was also included. This final data set contained thirty-six cities that are listed in Table 1. This set provided sufficient degrees of freedom for error when the number of independent variables was 1 imited to three and four in the two models.

Several additional variations on the general procedure were tested during the course of analysis. The substitution 
of city population for the study population was investigated due to the ease of data collection from current publications without modification. In all analysis using city population a slightly less satisfactory modol, using $\mathrm{R}^{2}$ as the criteria, was produced. An estimate of the study area population can be obtained using the number of dwelling units already obtained for the internal traffic forecast, and is a simple, satisfactory procedure.

The final adopted predicting models for the two separate response or dependent variables for an inference space of $10,000-100,000$ population are as follows:

$\mathrm{Y}_{1}=28.55162+0.0681\left(\mathrm{x}_{1}\right)+0.00009\left(\mathrm{x}_{2}\right)-369.81395\left(\mathrm{x}_{3}\right)$

$+78.32657\left(\mathrm{x}_{4}\right)$

Where :

$\mathrm{y}_{1}=$ Total external cordon crossings

$x_{1}=$ County population density

$\mathrm{x}_{2}=$ County area multiplied by population of the cities larger than subject city within a 25 mile radius of the city center

$\mathrm{x}_{3}=$ Reciprocal of the total study area population

$\mathrm{x}_{4}$ =Reciprocal of the total study area employment

The summary table is as follows:

$\begin{array}{ccccc}\text { Variable } & \mathrm{R} & \mathrm{R}^{2} & \begin{array}{c}\text { Increase } \\ \text { in } \mathrm{R}^{2}\end{array} & \begin{array}{c}\mathrm{F} \text { value to enter } \\ \text { or remove }\end{array} \\ \mathrm{X}_{1} & .66 & .43 & .43 & 25.68 \\ \mathrm{x}_{2} & .75 & .57 & .14 & 10.47 \\ \mathrm{x}_{3} & .81 & .65 & .08 & 7.39 \\ \mathrm{x}_{4} & .85 & .72 & .07 & 8.13\end{array}$

ANOVA

$\begin{array}{lclrl}\text { Source } & \text { d.f. } & \text { SS } & \text { MS } & \text { F Value } \\ \text { Regression } & 4 & 4519.11 & 1129.78 & 20.10 \\ \text { Residual } & 31 & 1742.47 & 56.21 & \\ \text { Total } & 35 & 6261.58 & & \end{array}$


The standard error of the estimate $=7.50$

The second model is as follows:

$\mathrm{Y}_{2}=4.27784+0.03465\left(\mathrm{x}_{1}\right)+0.06629\left(\mathrm{x}_{2}\right)-0.06410\left(\mathrm{x}_{3}\right)$

Where:

$\mathrm{Y}_{2}=$ Total external-external cordon crossings

$x_{1}=$ Population of the cities larger than subject city within a 25 mile radius of the city center

$\mathrm{x}_{2}=$ County population density

$\mathrm{x}_{3}=$ Population of the cities smaller than subject city within a 25 mile radius of the city center

The summary table is as follows:

$\begin{array}{ccccc}\text { Variable } & \mathrm{R} & \mathrm{R}^{2} & \begin{array}{c}\text { Increase on } \\ \mathrm{R}^{2}\end{array} & \begin{array}{c}\mathrm{F} \text { value to } \\ \text { enter or remove }\end{array} \\ \mathrm{x}_{1} & .73 & .53 & .53 & 37.96 \\ \mathrm{x}_{2} & .82 & .68 & .15 & 15.27 \\ \mathrm{x}_{3} & .86 & .74 & .06 & 7.10\end{array}$

ANOVA

Source d.f. SS MS F value

$\begin{array}{lllll}\text { Regression } & 3 & 1339.08 & 446.36 & 29.69\end{array}$

$\begin{array}{llll}\text { Residual } & 32 & 481.16 & 15.04\end{array}$

Total $35 \quad 1820.24$

The standard error of the estimate $=3.88$ under the assumption that no correction is necessary due to correlation of independent variables.

To test for the significance of the multiple regression equation, the $\mathrm{F}$ distribution was used for the test in the following manner.

$F_{k}, \mathrm{n}-\mathrm{k}-1=\frac{\text { Mean square due to regression }}{\text { Mean square deviation from regrossion }}$

The value obtained from the above computation appears in the $F$ value Column and is compared to tabulated $F$ values for the $\alpha$ level selected and the number of degrees of freedom, thus the significance of the regression is determined. 
Residuals for each model were plotted versus the response variable. No recognizable pattern in the plots was discernible giving no reason to doubt the assumptions that the errors are independently distributed with 0 mean and variance of $\sigma^{2}$ (NID $\left(0, \sigma^{2}\right)$ ).

A frequency plot of the residuals does not show any indication of skewness. The " $W$ " test, developed by Shapiro and Wilk, could have been used to test for normality but it was not considered necessary.

\section{Direct Models}

It was determined that there were five different items in external traffic information requiring procedures to be developed for application in the planning. These were as follows :

1. Method of distributing total external traffic to each external cordon crossing

2. Method of distributing external-internal traffic volumes to each external corcion station

3. Method of forecasting total external traffic volumes

4. Method of determining the amount of the forecasted total external traffic that is total externalinternal traffic volumes

5. Method of determining the amount of the total external-internal traffic volume that is the external-internal traffic destined to the central area

Each of the above will be discussed separately.

For the direct models 1 isted under $1,2,3$, and 5 , the basic data were analyzed using a simple regression with one dependent and one independent variable. The procedure involved assigning values at one point in time as the dependent variables and data at another point in time as the independent variables. The values for $\mathrm{R}^{2}$, standard error of the estimate, intercept and regression coefficient 
were examined to evaluate the comparison. 'Two null hypothesis were tested in each model as follows:

1. $\mathrm{H}: \mathrm{B}_{\mathrm{O}}=0$

2. $\mathrm{H}: \mathrm{B}_{1}=1.00$

The first hypothesis tests that the intercept value is equal to zero while the second hypothesis tests that the regression coefficient is equal to 1.00 . If the intercept is 0 , the regression coefficient is equal to 1.00 , and a $\mathrm{R}^{2}$ of 1.00 is obtained, then the fit would be perfect. For this use of regression it is not necessary that the normal assumptions for regression be met. In al1 models neither hypothesis could be rejected at the $\alpha=.05$ level.

\section{Distribution of Total External, Volumes hmon't}

\section{Extornal Stations}

To develop a model to distribute total external traffic among stations, eight cities with external survey reports available for two points in time were used for the investigation. Data from a total of seventy-two external cordon crossings in the eight cities were utilized in a simple regression procedure. This technique for estabilishing the correlation between the variables was selected because of simplicity while at the same time being adequate. The fact to be established statistically was that the percent of the total traffic crossing at an external cordon station remains constant over time. As a test, the percentages of total traffic crossing at each station from the base year reports were used for the dependent or response variable and the percentages of total traffic crossing at each station in the later reports were used for the indepondent variable. The multiple regression program BMD3R was used for this analysis. Values for stations in each city were computed in addition to a regression on a combined sample of all seventy-two crossings in the eight cities. The results of the analysis 
are presented in Table 9 and Figure 9. The assumption, that the percent of total traffic crossing the external cordon at each station remains constant over time, was considered correct. The $\mathrm{R}^{2}$ was .94 and the standard error of the estimate was 2.70 percent for the combined set. The values for the $\mathrm{R}^{2}$, the regression coefficient or slope of the regression line, the standard error of the estinate and the intercept value for each subset and the combined set are presented in Table 9. The plot of the combined set and the computed regression line is shown in Figure 9.

\section{Distribution of External-Internal Volumes to Stations}

If an external survey report for a past period is available for the city being studied, the percentages of the total external-internal cordon crossings at each station as presented in the report is probably the best estimate of the percentage of the total external-internal cordon crosnings for the study year; however, a procedure to provione this information where a report is not available was developed using the same regression technique as outlined above on available data. The assumption was that the percentage of the external-internal traffic crossing the external cordon at each cordon station was the same as the percentage of the total external traffic crossing at that same station. Twenty-seven survey reports were used for this phase of the investigation consisting of two hundred and thirty-two independent cordon crossing stations. Values were computed for data for each city in addition to the regression on the combined sample. For this regression analysis the percentage of the total external cordon crossings at each cozdon station was used as the dependent or response variable. The percent of the total external-internal traffic at each cordon crossing was used as the indepencient variable. The values for the $R^{2}$, the regression coefficient or slope of the 


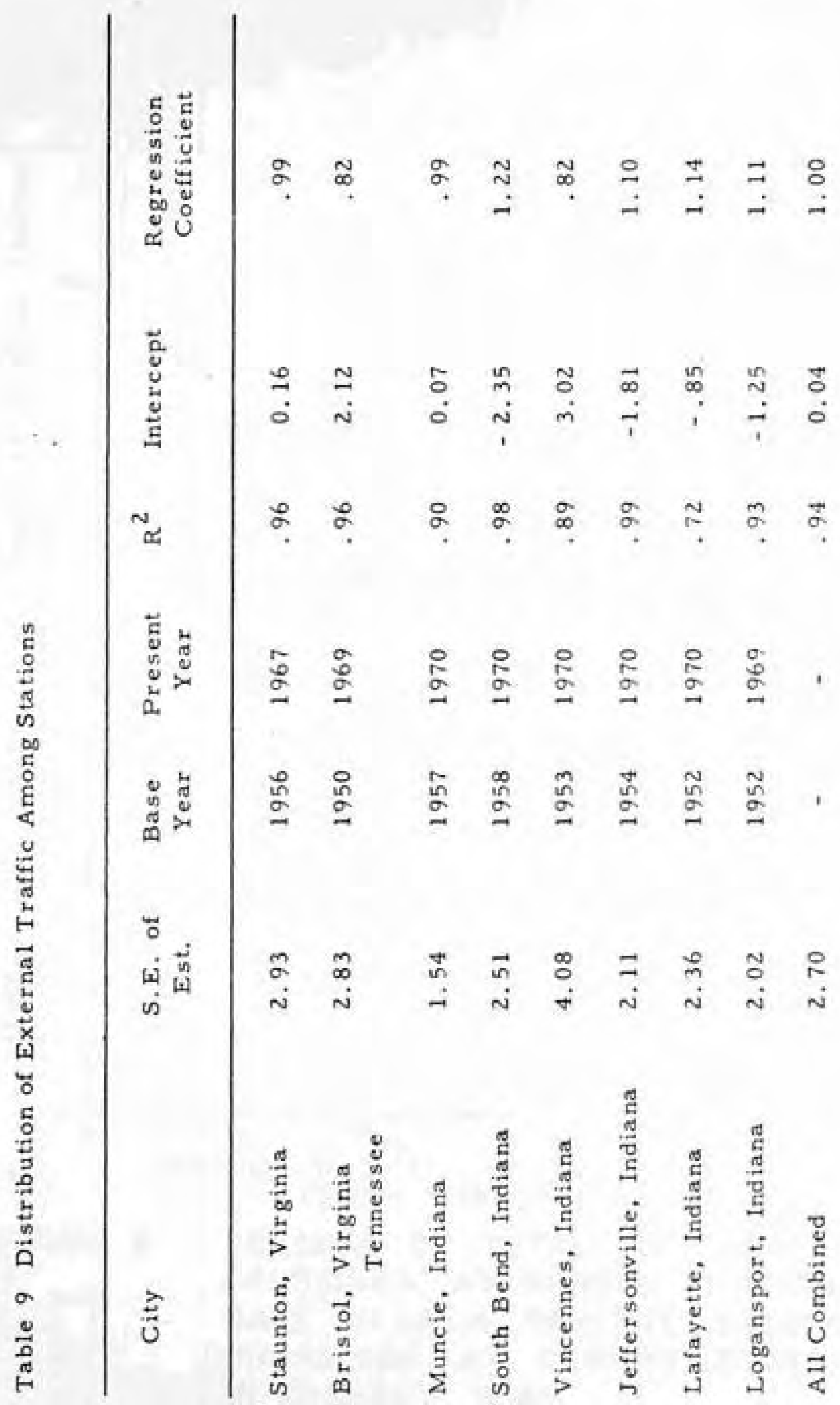




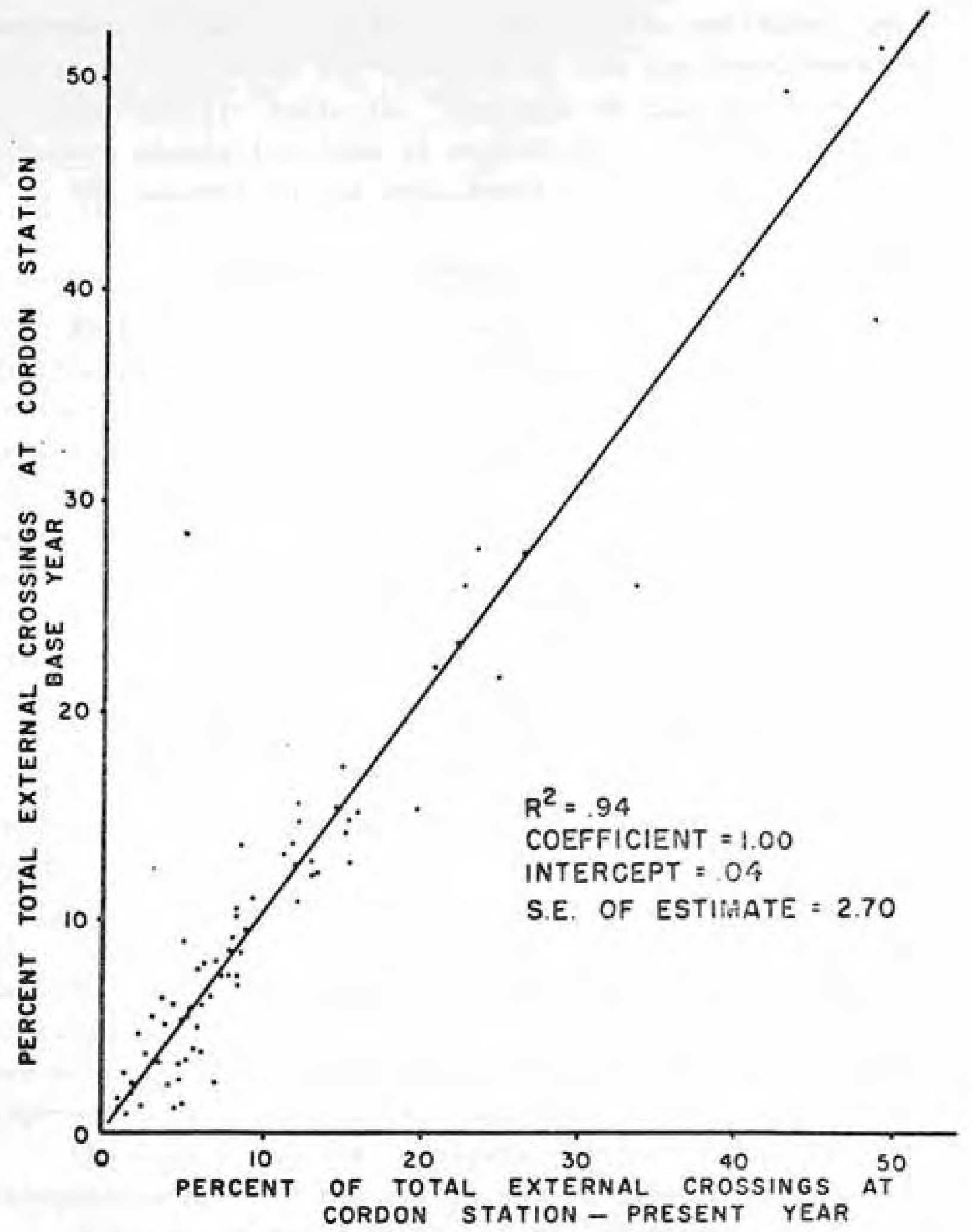

FIGURE 9. PERCENT OF TOTAL EXTERNAL CROSSINGS AT CORDON STATION IN BASE YEAR vs. PERCENT EXTERNAL CROSSINGS AT CORDON STATION IN PRESENT YEAR 
regression line, the standard error of the estimate, and the intercept value for each subset and the total combined set are shown in Table 10. The plot of the data and the computed regression line is presented in Figure 10.

The assumption was considered correct.

\section{Forecasting External Volumes}

As discussed in the conceptualization of the forecasting procedures, an external traffic growth factor based on increased county vehicle registration should be adequate to expand existing external volumes in small urban areas. To test this assumption, fifteen cities in Indiana were selected for a data set. Traffic volumes on an external cordon around each city were obtained for two points in time which were a minimum of five and preferably ten to twenty years apart. The dates and interim period were determined by availability of information from the Indiana State Highway Comission. The cordon line was established at a point that included the urban area for both years and where an Indiana count station was located. The regression procedure in this case used the base year total external traffic volumes multiplied by a growth factor representing the increase in county vehicle registration for the period between the two points as the independent variable. The observed total external traffic volume for the later year was used as the dependent variable. The results of the regression are presented in Figure 11.

The assumption was considered correct. The cities and information used in the analysis are presented in Table 11.

The possibility that the above assumption might not be true if the city in question were not the primary city in the county was considered. Goshen, Indiana, in the same county as Elkhart, was added to the sample to check this factor. The results indicate that in this case the 
Table 10 External Volume Vs. External-Internal Volume Model

\begin{tabular}{|c|c|c|c|c|c|c|}
\hline City & \multicolumn{2}{|c|}{$\begin{array}{l}\text { Sample Intercept } \\
\text { Size }\end{array}$} & $\begin{array}{l}\text { Reg. } \\
\text { Coeff. }\end{array}$ & $\begin{array}{l}\text { S. E. of } \\
\text { Est. }\end{array}$ & F Value & $R^{2}$ \\
\hline Independence, Kansas & 10 & .02 & 1.00 & 1.14 & 719.54 & .99 \\
\hline Big Rapids, Mich. & 6 & -4.36 & 1.26 & 2.42 & 206.11 & .98 \\
\hline Richmond, Ky. & 7 & -5.28 & 1. 38 & 3.27 & 90,08 & .95 \\
\hline Campbellsville, Ky. & 8 & -.81 & 1.07 & .92 & 274.06 & .98 \\
\hline Bonham, Texas & 6 & -1.23 & 1.07 & 3.60 & 36.7 & .90 \\
\hline Center, Texas & 8 & .48 & .96 & 1.83 & 21.54 & .78 \\
\hline New Castle, Penna. & 12 & -.00 & 1.00 & 1.57 & 87.72 & .90 \\
\hline Vincennes, Indiana & 13 & -.03 & 1.01 & 2. 54 & 113.44 & .91 \\
\hline Bay City, Mich. & 6 & -3.54 & 1.21 & 5.14 & 9.71 & .71 \\
\hline Ann Arbor, Mich. & 5 & 2.65 & .87 & 4.71 & 32. 74 & .92 \\
\hline Bowling Green, Ky. & 10 & -2.20 & 1.22 & 2.48 & 140.91 & .95 \\
\hline Junction City, Kansas & 11 & 1. 48 & .84 & 3.76 & 134.93 & .94 \\
\hline Brownwood, Texas & 9 & -98 & 1.09 & 1.27 & 510.60 & .99 \\
\hline Somerset, Ky. & 9 & -1.35 & 1. 12 & .91 & 947.01 & .99 \\
\hline Childress, Texas & 7 & -3.92 & 1.27 & 2.68 & 165.96 & .97 \\
\hline Bay City, Texas & 7 & -.21 & 1.02 & 1.27 & 651.34 & .99 \\
\hline Athens, Texas & 9 & -.60 & 1.05 & 1.00 & 380.05 & .98 \\
\hline Caruthersville, Missour & ri 4 & 2. 56 & .90 & 2.63 & 138.59 & .99 \\
\hline Hannibal, Missouri & 9 & -.68 & 1.06 & 1. 36 & 440.44 & .98 \\
\hline Commerce, Texas & 6 & -.88 & 1.05 & 2.19 & 113.80 & .97 \\
\hline Blytheville, Ark. & 8 & -.09 & 1.01 & .39 & 4507.47 & 1. 00 \\
\hline Borger, Texas & 6 & 1.53 & .91 & 1.18 & 347.64 & .99 \\
\hline Cynthiana, Ky. & 6 & -.69 & 1.04 & 3.09 & 80.51 & .95 \\
\hline Kinston, N. C. & 13 & -.05 & 1.01 & 1.93 & 85.50 & .89 \\
\hline Charlotteville, Vir. & 11 & -.58 & 1.06 & 1.21 & 391.43 & .98 \\
\hline Pulaski, Vir. & 10 & -.00 & 1.00 & .44 & 5408.23 & 1. 00 \\
\hline Martinsville, Vir. & 16 & .02 , & 1.00 & 2.37 & 73.98 & .84 \\
\hline Combined Set & 232 & -.16 & 1.01 & 2.33 & 4193.07 & .95 \\
\hline
\end{tabular}




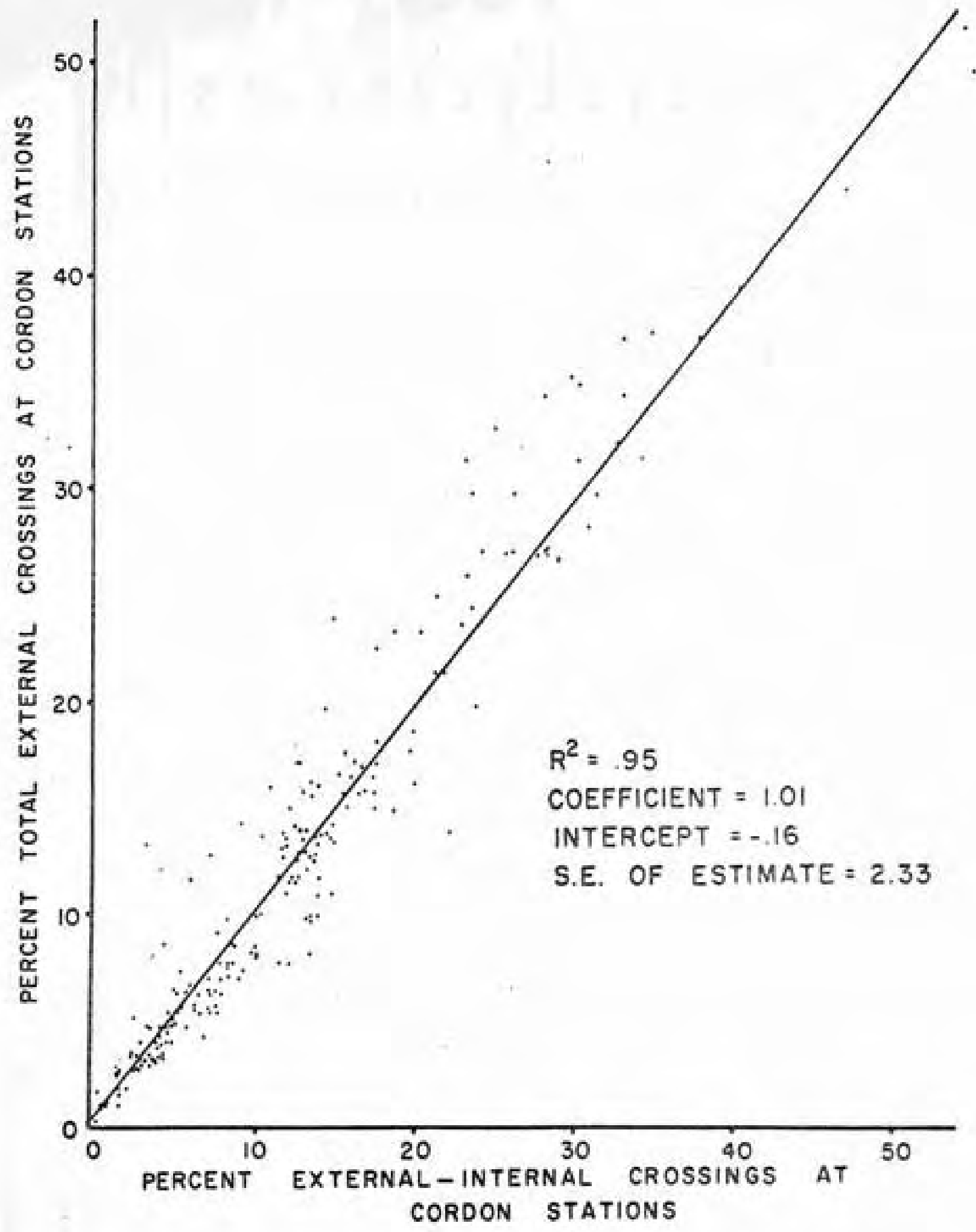

FIGURE 1O. PERCENT OF TOTAL EXTERNAL CROSSINGS AT CORDON STATION vs. PERCENT EXTERNAL- INTERNAL CROSSING AT CORDON STATION 


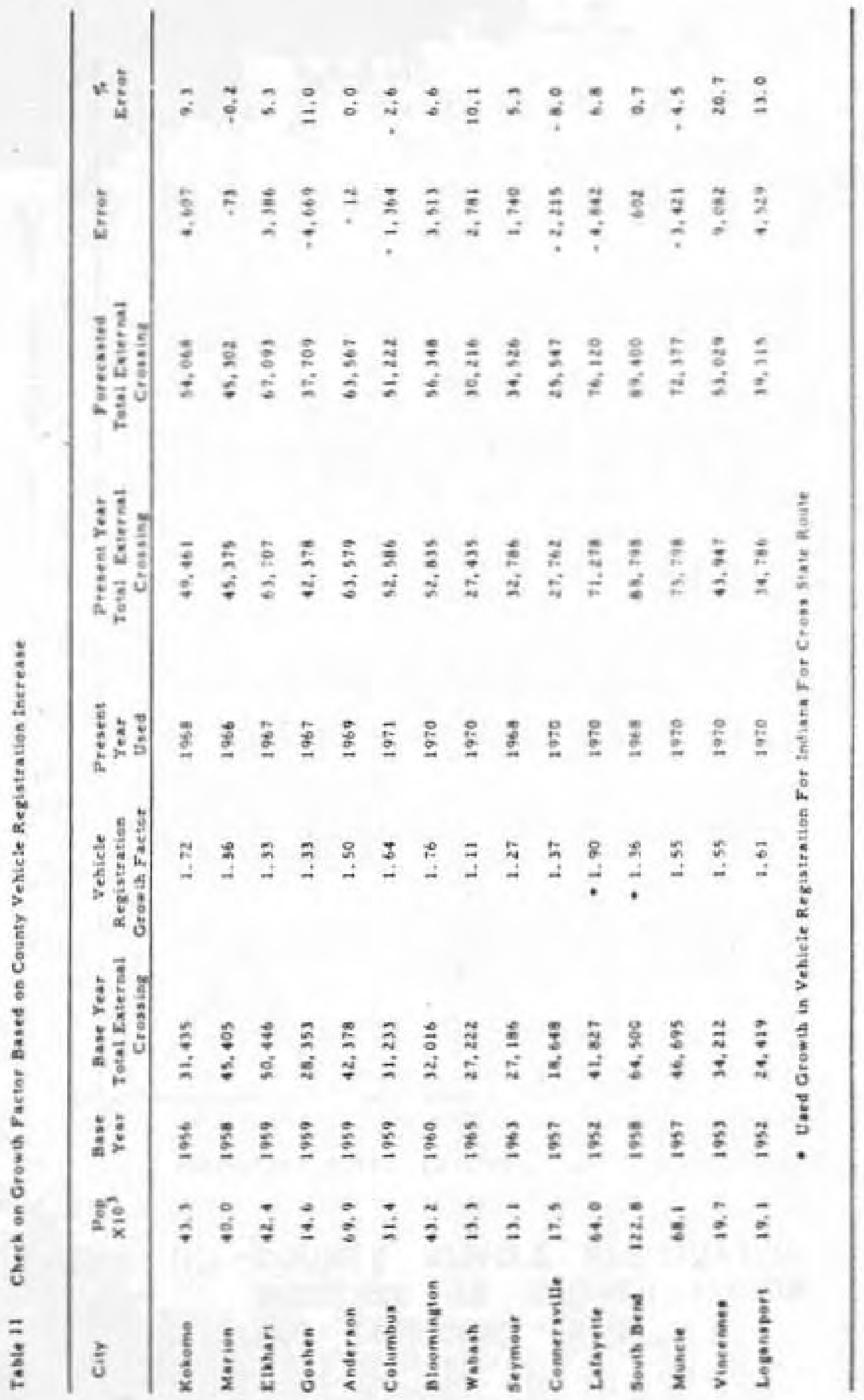




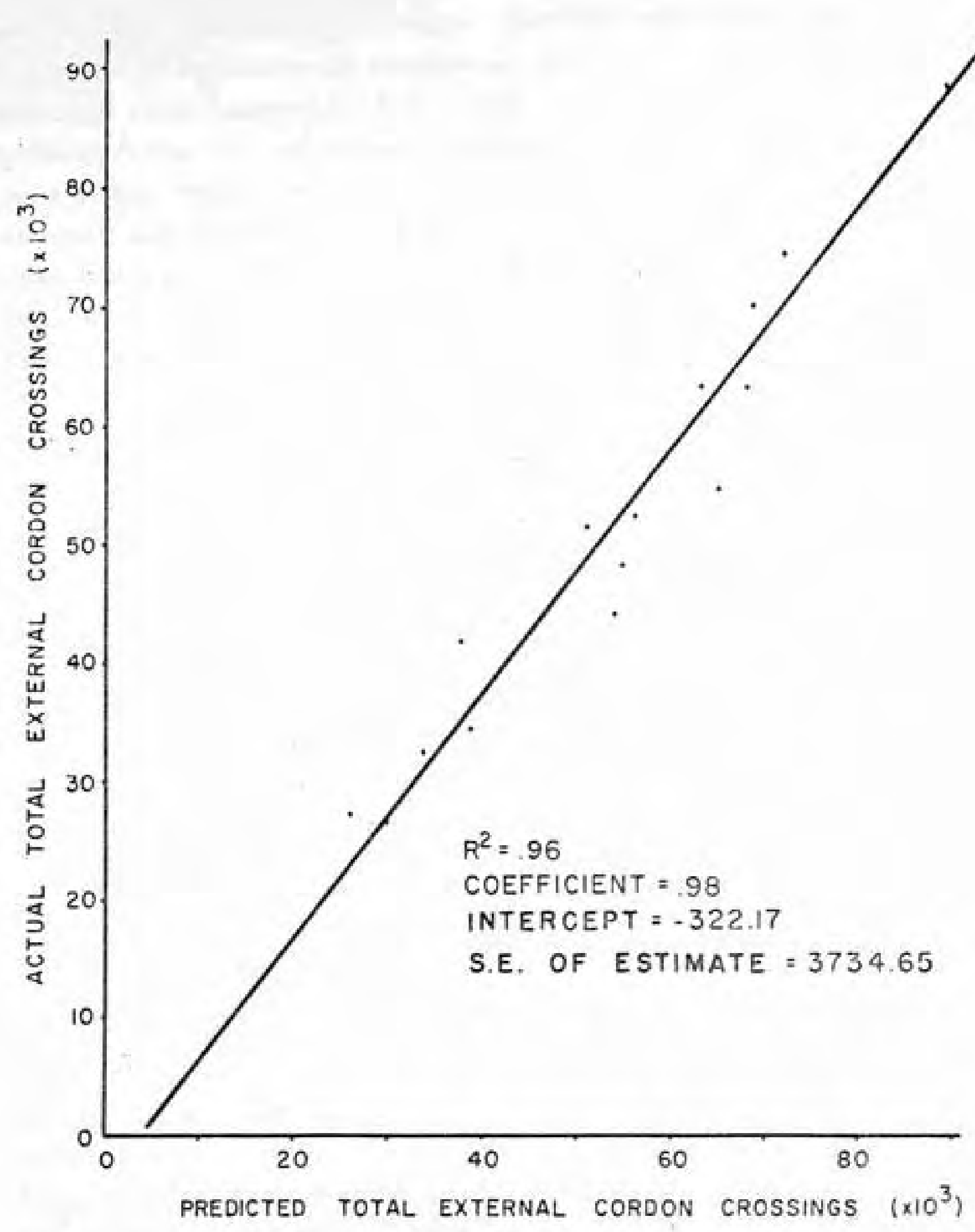

FIGURE II. COUNTY VEHICLE REGISTRATION INCREASE AS GROWTH FACTOR FOR EXTERNAL TRIPS 
assumption was still correct. Further observation indicates that the percentage of cities of over five thousand population (the lower limit for the study) that are not the primary city in the county is very small. The basic assumption that the study city must exist as a separate entity, not a suburb of a larger city, also reduces the probability of the study city being the secondary city in the county. The growth factor check using two points in time for the study city, recommended as a part of the simplified planning procedure, would disclose any unusual factors and indicate the necessity of using rograstion models.

\section{Deterinining External-External Volumes}

The split of the total external traffic volume into the two components, external-external and extornal-internal traffic volumes, is required for the simplified planning procedure. If a previous external cordon survay has bech completed, the percentage split at each station then provides the best estimate of the present split. If a report is not available, the regression model discussed in the first part of this chapter is used to estimate the total external-external traffic volume. The procelure discussed under the previous sub-heading entitled "Distribution of Total External Volumes Among External Stations" also provides the means of allocating the external-external volumes among the external stations. It is also considered probable that forecasting the smaller component of the total traffic should be a conscrvative approach when distributing the external-intexnal component to the central area.

\section{External-Internal Traffic to CBD}

The final step necessary to provide a completc package for the simplified planning procedure is to determine a 
means of establishing the percentage of the externalinternal trips at each external cordon station destined to the central area or to the screenline where the radial corridors merge and lose identity. Employment has been shown to be a very strong trip indicator in other studies and a simplified distribution method using employment, not requiring computer iterations for application was investigated.

Eleven study reports containing detailed employment data and trip information by traffic zones were utilized as the data source for this phase of the investigation. Identification of a central area was initially required. For this study the central area was defined as the Central Business District and contiguous traffic zones where the total employment exceeded the number of residents. The area thus defined compares to the central area defined in both Lafayette and Columbus established where traffic corridors merge. The area is also very close to being the area defined by the Bureau of Public Roads publication (12). The regression procedure was again utilized. The response variable was the percent of external-internal trips destined to the Central Area. The independont variable was: the percent of the total employment in the Central Area. The $\mathrm{R}^{2}$ was .75 , the regression coefficient was .95 , the standard error of the estimate was 4.60 percent, and the intercept value is 1.11. The assumption, that the percent of the total external-internal trips with origins and destinations in the Central Area is the same as the percent of the total study area employment employed in the Central Area, was considered correct. Table 12 and Figure 12 present this information.

An additional informative piece of information, although not directly utilized, was computed during this project. External survey reports from thirty cities ranging in population from 5,400 to 49,100 were reviewed determining 


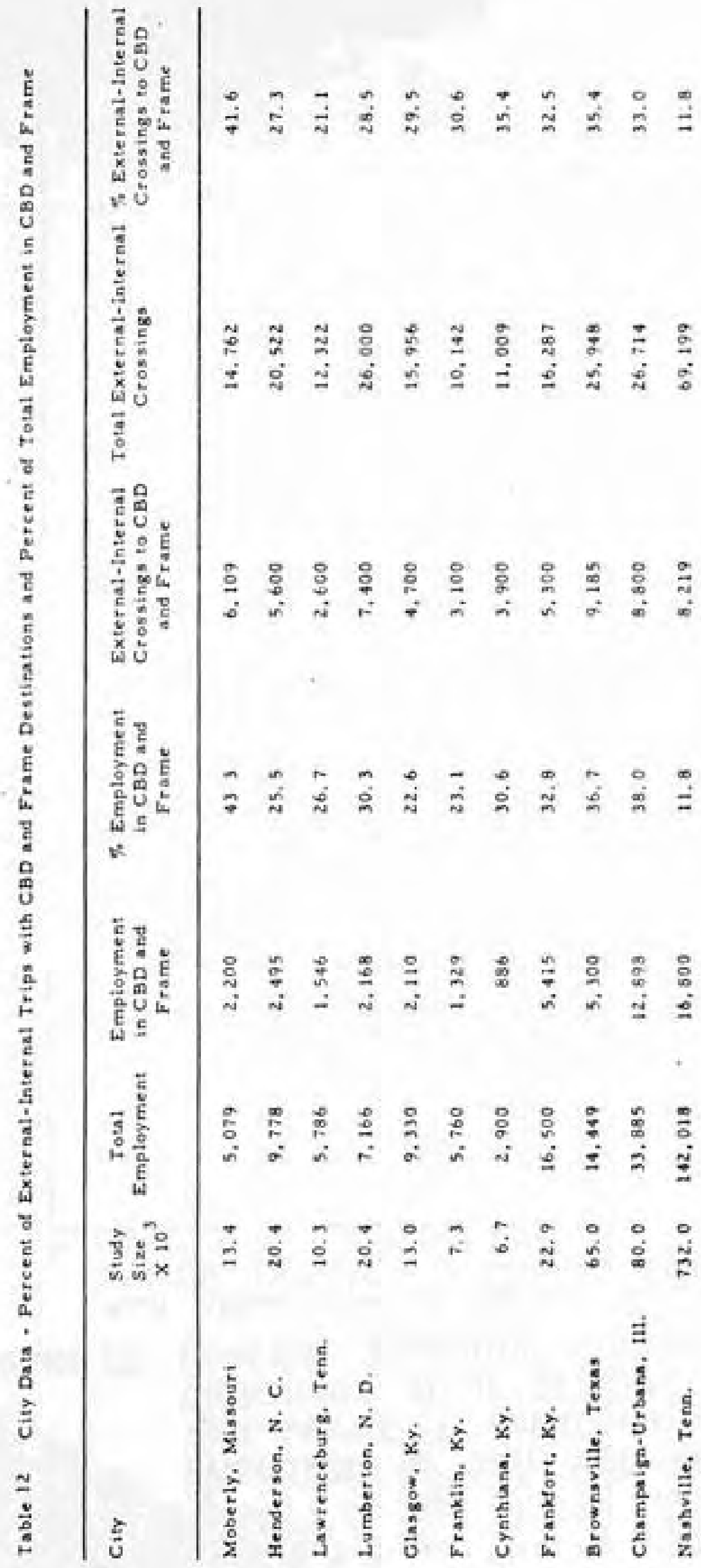




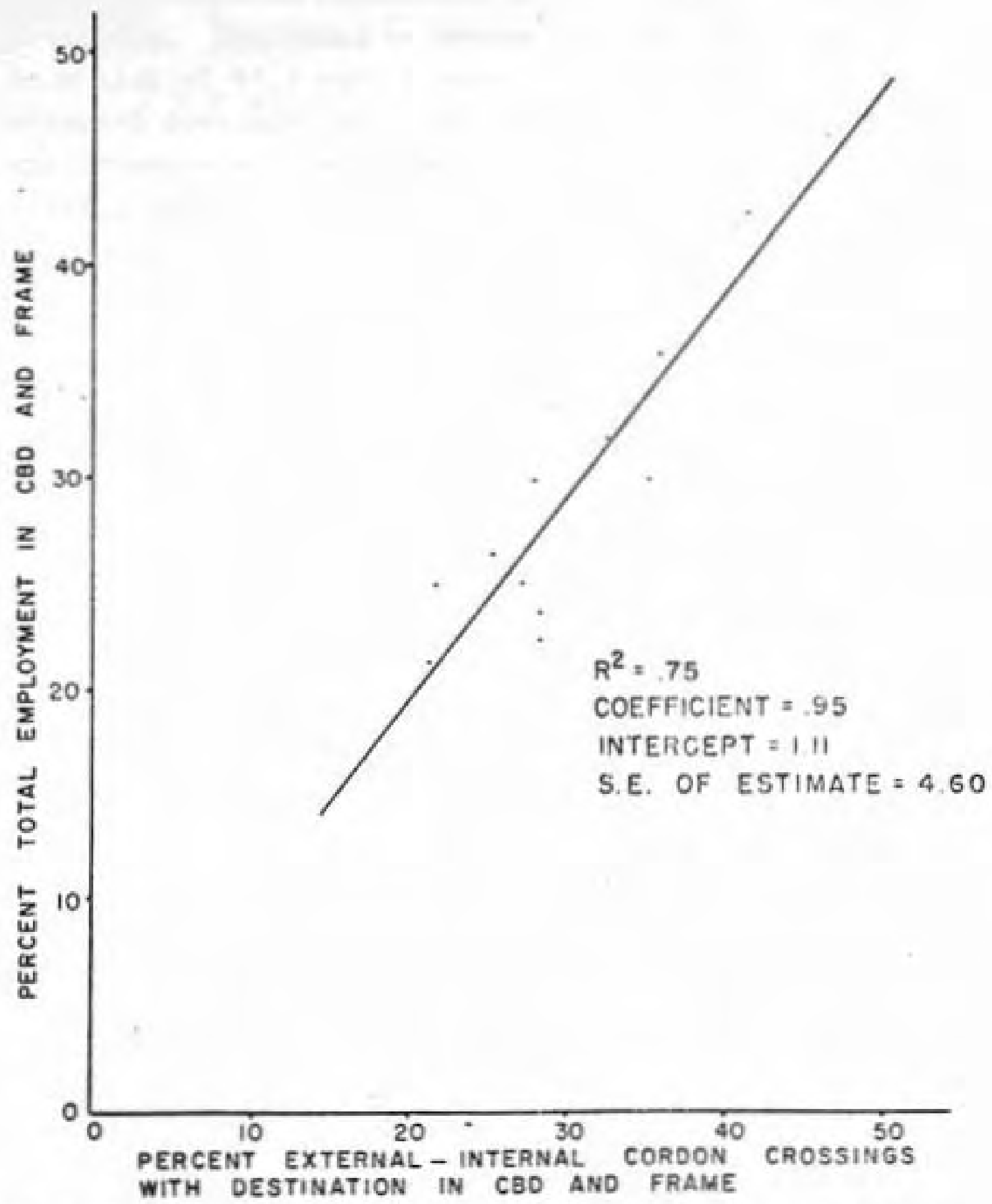

FIGURE I2. PERCENT EXTERNAL - INTERNAL CORDON CROSSINGS WITH DESTINATIONS IN CBD AND FRAME vs. PERCENT TOTAL EMPLOYED IN CBD AND FRAME 
the percent the external cordon crossings on U.S. and State numbered highways represents of the total external cordon crossings. The range of percentages was from a low of 68.1 to a high of 97.9 with a mean of 88.2 percent. The standard deviation was 6.6 percent. These data attests to the importance of state and U.S. numbered highways to a sma11 community. 
COLUMBUS FEASIBILITY DEMONSTRATION

The city of Columbus, Indiana was selected as the site to demonstrate the feasibility of the entire packacte comprising the simplified procedure for major thoroughfare planning in small urban areas.

\section{Study Area}

Columbus is a city of approximately 27,000 population. The city is a typical small city that has experienced a steady growth through the years. Because of the location at the junction point of severai rivers and other small streams the growth has been primarily in the north and east portions of the city rather than concentrically as in pany conmunties:

The completion of Interstate 65 , providing a connecting route from Indianapolis to Louisville, Kentucky and also on the route from Chicágo to Florida and other southern states, is the only major change in the highway systen in the area during the last twenty years.

A number of major industrial plants such as Cummins Engine and Arvin Industries are located in the city. The city has a higher than average ratio of employment to population due to the heavy industrialization. This effect on trip generation characteristics of the community is to produce a higher percentage of external-internal trips than other comparable sized communities. The city administration and the citizens have long recognized the necessity for sound planning of the future. 'This progressive attitude is positively indicated by numerous studies and resulting reports on all phases of community development. This abundance of basic 
material to use for data sources may indicate that the estimated cost for the study should be increased when estimating the cost of application in communities with less basic data.

\section{External Cordon}

The study area external cordon was established to include the area expected to become developed by 1990. The Interstate 65 route was utilized as the west cordon 1 imit because of the natural screenline it provides.

clifty Creek was established as the east boundary. The location of the cordon throughout the study area permitted using the Indiana State Highway Commission count station locations.

\section{Level of Service}

The ranges of service volumes for a thoroughfare were computed for columbus. The ranges were derived assuning the following:

1.

A level of service - "C"

2. Population of city - 75,000

3. Peak hour factor - .85

4. Directional split - 60-40

5. Peak hour volune - Ten percent of ADT

6. $\mathrm{G} / \mathrm{C}-.45$

7. Lane width $-10-12$ feet

8. No parking

9. Twenty percent turns

The calculated capacity ranges for major thoroughfares are as follows:

4 lane major thoroughfare $-12,000-15,000$ vehicles per day

4 lanes with left turn lanes - 15,000-19,000 vehicles per day 
6 lane major thoroughfare - 19,000 - 23,000 vehicles per day

The minimum major thoroughfare facility is assumed to be four lanes as recommended by the National Cosmittee on Urban Transportation.

The study area location is shown on Figure 13 .

\section{Corridors and Major Thoroughfares}

The arterial street plan prepared by Deleuw Cather and Associates (9), presently being used as a guide for Columbus, was used to assist in initial street inventory traffic volume counts and corridor identification.

The identification of corridors for columbus was accomplished by utilizing the arterial strect plan, the existing traffic volume flow map, existing land use map and information from personnel familiar with the area.

Seven basically radial corridors were established as shown in Figures 14 and 15. Two of these corricors overlap due to the configuration of the streets. State Highway 46 is considered a radial route; however, it effects a ninety degree route change to approach the central area screenline, disbursing traffic over five closely spaced strects crossing the screenline. This alignment crossed corridor 4, Central Avenue. As shown in Lafaycte this does not create a double count because the procedure uses a growth factor not trip productions.

u. S. 31 Bypass traific was forecasted using a growth factor based on the growth of the entire area frotu the Tenth Street corridor on the east to the Flatrock River on the west. 


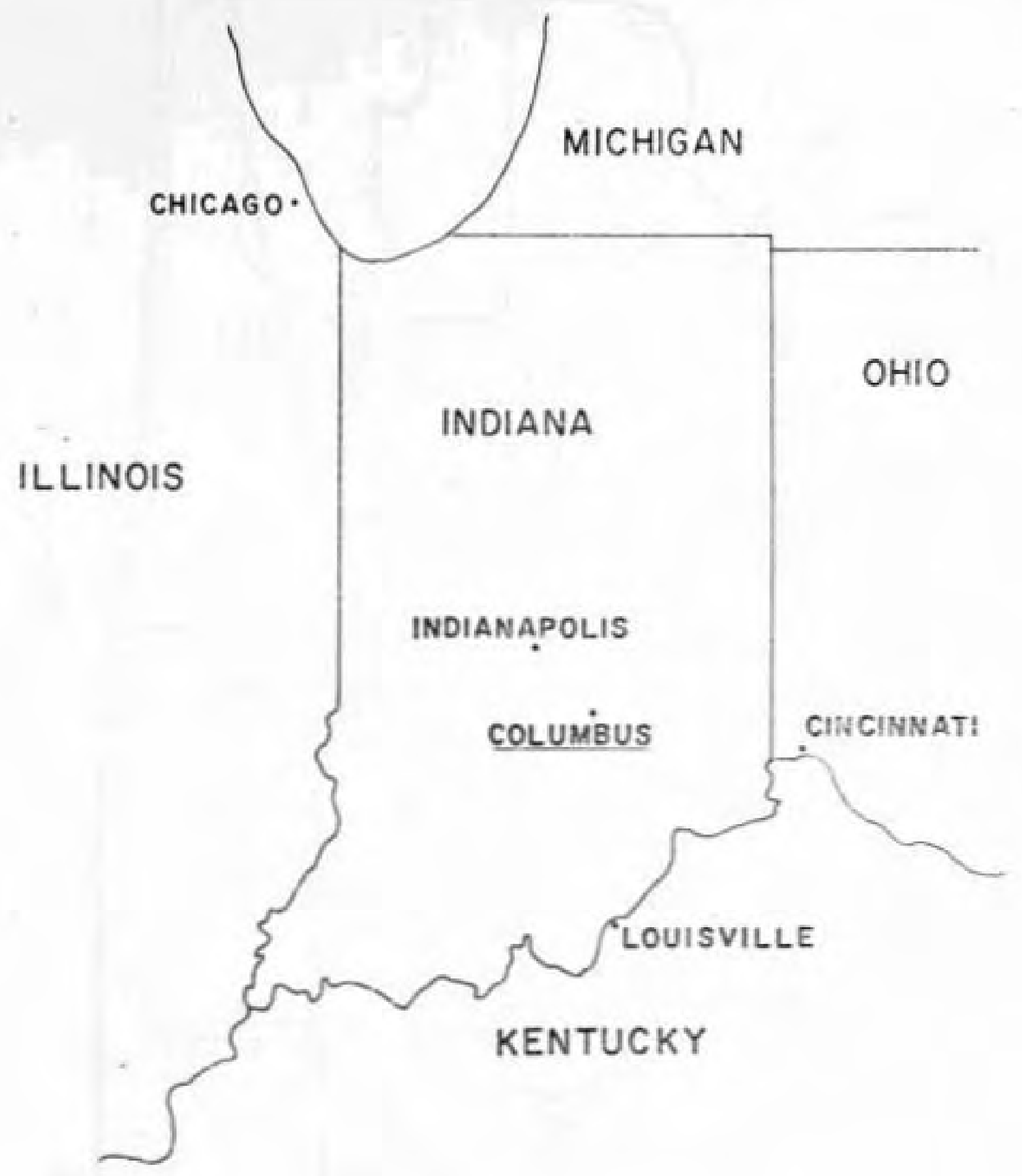

FIGURE 13. GREATER COLUMBUS URBAN AREA LOCATION IN INDIANA 


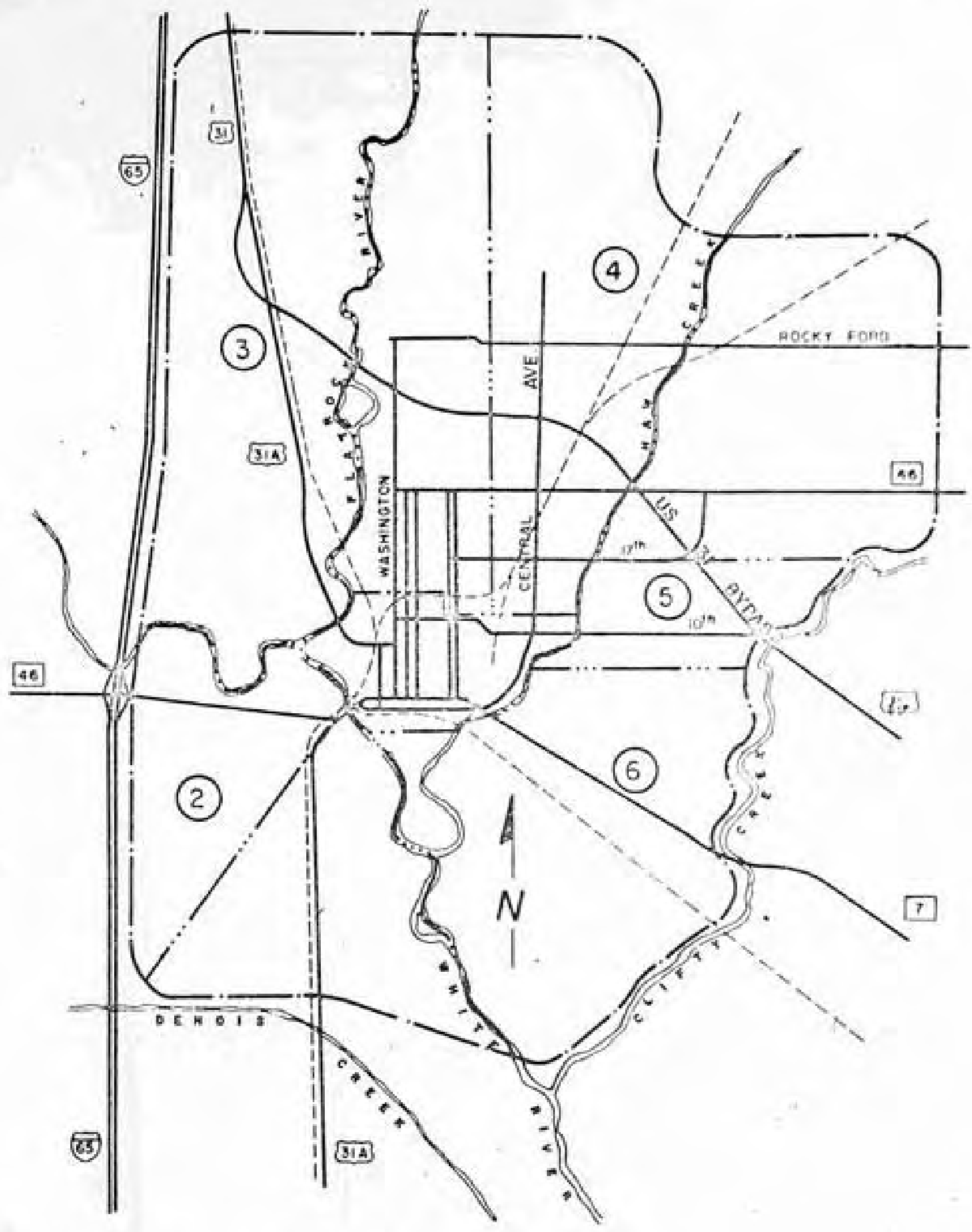

FIGURE 14. CORRIDORS - COLUMBUS 


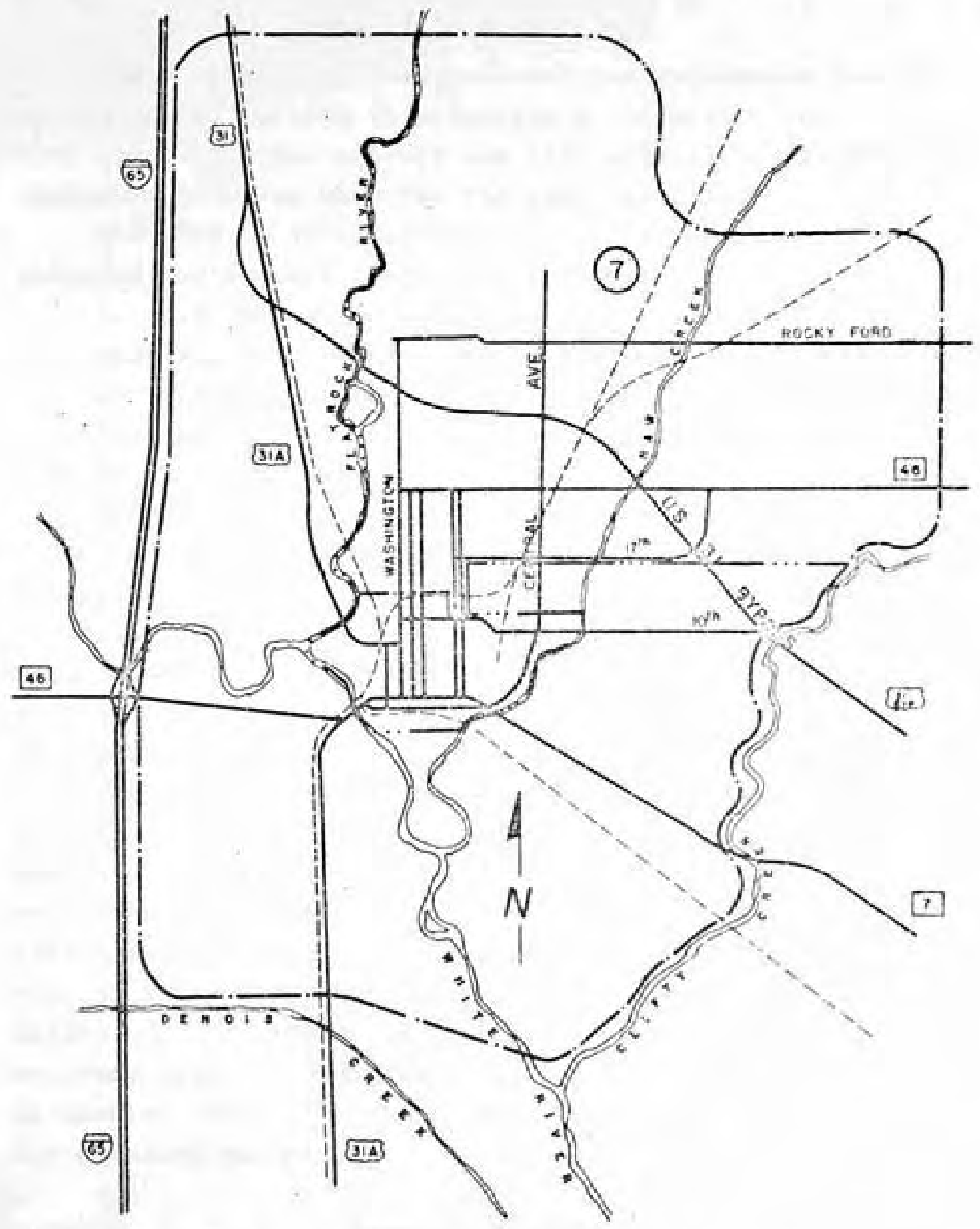

FIGURE I5. CORRIDORS - COLUMBUS 


\section{Calibration Procedure}

The simplified procedure developed recommends the use of two points in time to establish a calibration for the city involved. The project was initiated early in 1971, therefore 1970 was used for the study year data.

The 1960 to 1970 calibration period for Columbus was selected for several reasons as follows:

1. U.S. Bureau of Census data was available to check dwelling unit counts from aerial photography.

2. Traffic volume counts were available from the

Indiana State Highway Comission.

3. The ten year period provided a reasonable test of the capabilities of the overall procedure.

A complicating or confounding factor that occurred during this period was the construction and opening to traffic of Interstate 65 immediately west of Columbus. The 1963 Columbus Arterial plan (9) presented before and after volumes throughout the city providing sufficient information to assess the effect of opening of Interstate 65 .

The actual calibration procedure was as follows. 1960 was used as a base year and growth factors for the external and internal traffic based on the corridors established were computed. After applying the growth factors to the 1960 existing volumes, the resulting forecasted 1970 volumes were compared to the observed 1970 volunies. Conparison of the central area screenline volumes within the accuracy necessary for design was considered reasonable assurance that the corridors established are satisfactory for planning purposes.

\section{External Traffic}

An external traffic growth factor was computed using the increase in total vehicle registration for Bartholomew County for the period $1960-1970$. The completion and 
opening to traffic of Interstate 65 just west of the city in late 1962 make direct comparison of 1960 to 1970 external volumes impossible; however, adjustment of the 1960 volumes on U. S. 31 by thirty percent to adjust for the Interstate provides comparable figures. The adjustment factor was provided by information presented in the Arterial street Plan report ( 9 ).

Table 13 presents the comparison of forecasted 1970 traffic volumes at external cordon stations (developod by applying a growth factor based on the increaso in total vehicle registration in the county from 1960 to 1970 , to the 1960 traffic volumes at each station) to the olsterved 1970 traffic volumes. The 1960 traffic volume at the U.S. 31 external station north of the city and 11.5. 31 Bypass at clifty creek were reduced thirty percent is: indicated by the Deleuw Cather Study (9) to adjust for the opening of Interstate 65. The total 1970 forecasted external volume was 46,614 vehicles per day as compared to the observed 1970 external volume of 48,683 vehicles per day at the stations. The total error is 2,069 crossings and by distributing this to the individual stations based on the existing percentages of total external traffic the maximum error would be 500 crossings. Individual cxpansions at each station indicate maximum errors of 3,301 vehicles per day at U.S. 31 Bypass at Clifty Creek ancl 2,790 vehicles per day at U.S. 31 Alternate at Donois creek. These differences can be attributed to a slight change in traffic patterns occuring subsequent to the opening of Interstate 65 . None of the differences were of sufficient magnitude to cause a design change if they were used for a design. However, the future forccast will be based on the 1970 patterns and therefore will not reflect these differences due to a slight change in traffic patterns. The growth factor for all external stations was based on the Bartholonew County total vehicle rogistration 
Table 13 Columbus - External Cordon Station Check

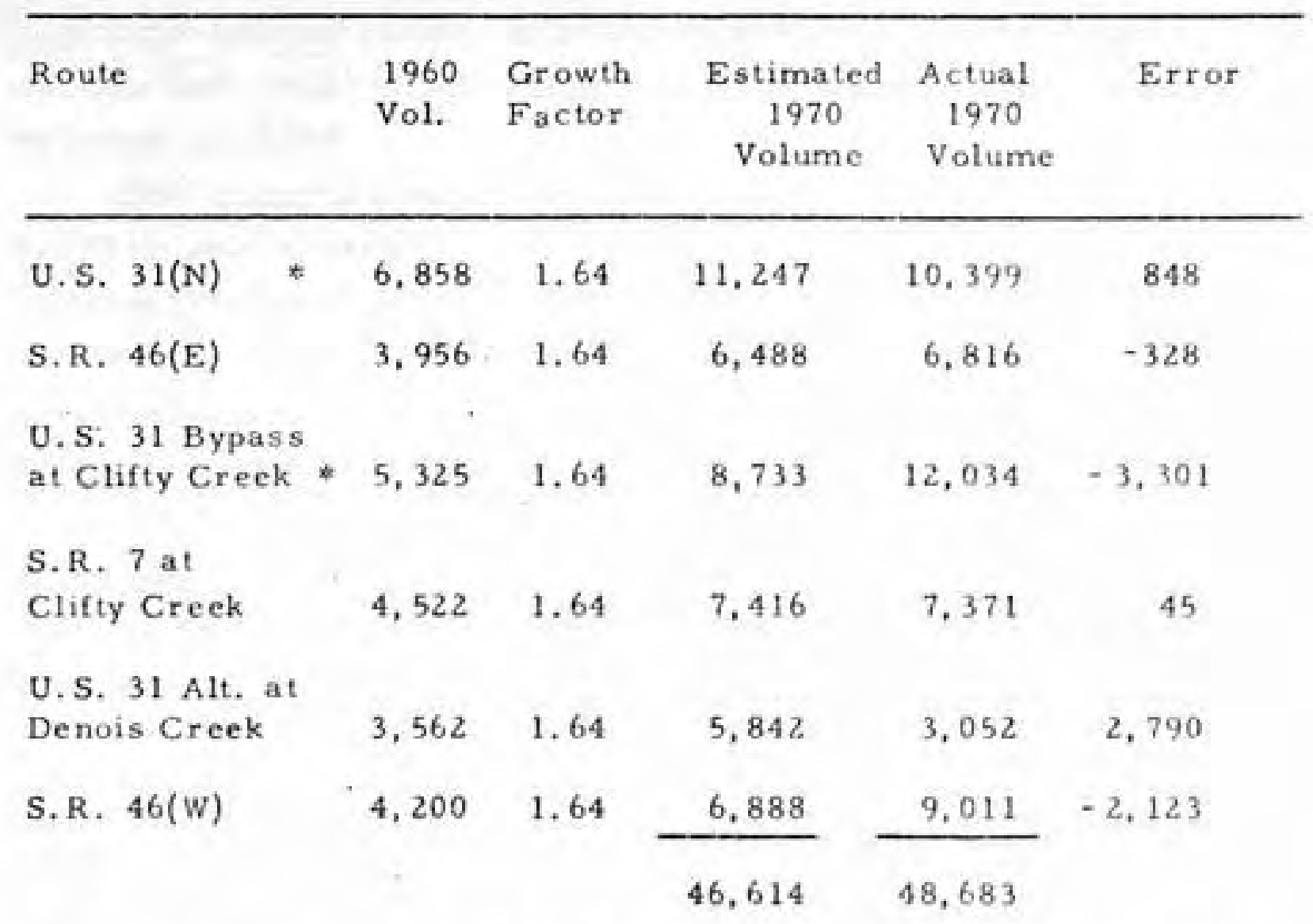

* Existing volumes reduced $30 \%$ to adjust for opening of 1.65 as per Arterial Street Plan for Columbus, Indiana (9). 
increase because Interstate 65 (outside cordon) was considered to be the route selected by cross state traffic. The comparison thus obtained was considered acceptable and a growth factor based on county vehicle registration increase was considered acceptable for forecasting external volumes to 1990 .

The external-external component of the total external traffic was determined by regression model. The externalexternal volume thus computed was 9,500 vehicles in 1960 and 10,800 in 1970. This volume was distributed to the external stations using the same percentage as existed for the total external volume.

The percentage of the external-internal traffic to be distributed to the central area was detormined by the percentage of total study arca employees etiploycd in the central area in 1970. This amounted to 44.3 percent.

\section{Internal Traffic}

The internal traffic volume growth factors were computed using the growth of three parameters of dwelling units, total employment and retail employment in each of the seven established corridors.

The percentage of the total internal trips to be represented by each of the three parameters of dwelling units, total employment and retail employment are 50, 35, and 15 respectively. Dwelling unit data by corridor was obtained from $1^{\prime \prime}=400^{\prime}$ aerial photography enlargements for both years. Employment data for both years were from information assimilated and tabulated by the Indiana Employment Securities Division. The base year traffic volumes were basically from counts made by the Indiana State Highway Commission in 1959, supplemented by information from city files and the Arterial street Plan Report (9). The 1970 counts were from the I.S.H.C. and City Engineer's Office. 
Additional counts were provided by city personnel to complete the required information.

Using the corridor growth factor procedure the existing 1960 traffic volumes were expanded to 1970 and compared to the actual observed traffic volumes. The forccasted and observed volumes at the central area screenline were compared for each corridor and additional point volumes were compared on S.R. 46 (Twenty-fifth Street) at U.S. 31 Bypass and Washington Street intersections. Table 14 presents the results of this comparison and gives the growth factors used.

The maximum difference between 1970 forecasted traffic volumes and 1970 observed volumes was 2,361 in Corridor 3, U.S. $31(\mathrm{~N})$. This is probably due to a slight change in traffic patterns occuring after completion of Interstate 65; however, the difference would not affect the thoroughtare design.

Differences in all other corridors are of such magnitude that designs would have been unaffected. Corricior 7 is one. of the major corridors with respect to total traffic magnitude; however, the one-way pairs of Franklin and Lafayette, California and Chestnut, in addition to Washington street serve the traffic desiring to enter the central area. Seventeenth Street was not included as an east-west route because of its configuration terminating at U.S. 31 Bypass on the east and at a cemetery on the west. It does effectively serve as a overflow or alternate route for S.R. 46 and Twenty-fifth Street for short trips as shown by the existing volumes. The calibration or check period as described herein substantiates the corridor identifications and the overall feasibility of the entire procedure with respect to providing adequate accurate design information. Tables $3 \mathrm{~A}$ and $4 \mathrm{~A}$ present the tabulations of the parameter data for the corridors for 1960 and 1970 . 


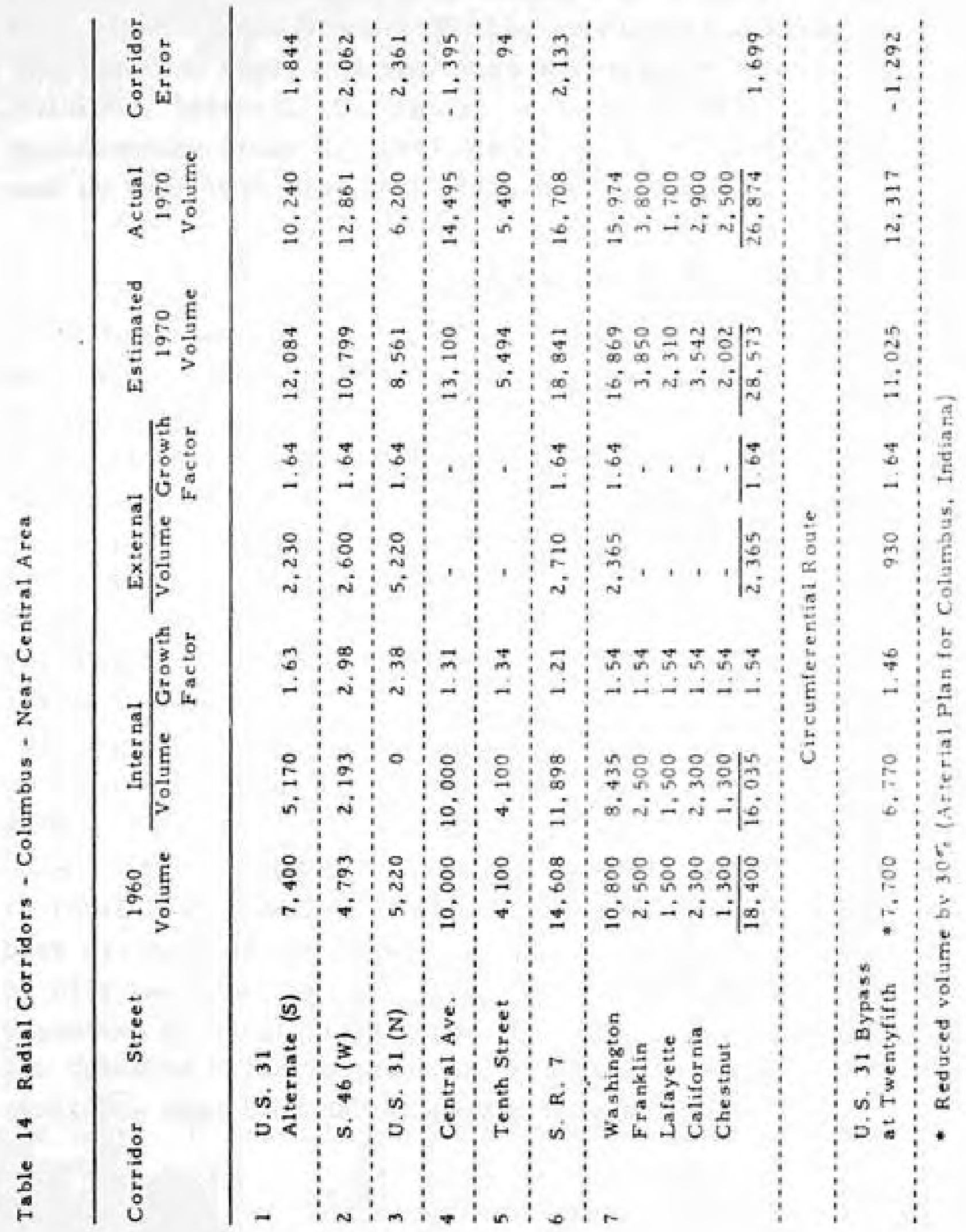


Finally, the feasibility of the entire package for providing the information necessary for major thoroughfare planning was demonstrated by completing a major thoroughfare study and preparing a thoroughfare plan for Columbus, Indiana. The report is entitled "Major Thoroughfare Study and 1990 Plan for Columbus, Indiana" and is available from JHRP at Purdue University.

\section{Conclusions}

The completed package for a simplified planning procedure for major thoroughfare planning for small uriban areas, utilizing the corridor growth factor technigue with synthetically developed external data, provides: traffic volumes sufficiently accurate to develop thajor thoroughfare plans. The methodology fits satisfactorily into the overall planning process utilizing output from other studies as input to the process. The cost of conpleting this type of study is a fraction of that reguired for the home interview, computer oriented procedures although the resulting information produced satisfies the same reguirements, i.e., design volumes. Detailed cost and time figures were compiled during the feasibility demonstration discussed above. After making upward adjustments in these costs to convert from a research environment, the best estimate of the total cost if the study is conducted by city personnel is $\$ 15,389.00$. The cost estimate is presented in detail in a report entitled " study Design for Columbus Major Thoroughfare and Plan Development Study", available from the JHRP at Purdue University. 
SUMMARY AND CONCLUSIONS

The completed package for the simplified procedure for major thoroughfare planning in small urban areas was first re-tested and refined in Lafayette utilizing 1970 data available from the GLTADS study and then the feasibility of the completed package for major thoroughfare planning was demonstrated in columbus, Indiana. The use of Columbus for the final application of the methodology was considered especially appropriate for several reasons as follows :

1. The city growth patterns, while uniform with respect to rates of growth, have been erratic with respect to direction due to flood plain barriers. This factor presented a problem slightly different from Lafayette.

2. One of the major traffic corridors traverses the north east quadrant in an east-west direction and then effects a ninety degree directional change to enter the central area rather than radiating in a straight line.

- 3. The completion and opening to traffic of Interstate 65 during the calibration period added an extraneous effect to the normal calibration factors.

The capability of handling these somewhat atypical aspects of a community without special techniques demonstrated the wide applicability and flexibility of the developed procedure.

The development of models and/or procedures to synthetically produce external traffic information and the 
demonstration of the feasibility of the alternative procedure of using previously determined external information substantially reduces the cost and time requirements of a thoroughfare planning study and further enhances the possibility of a community systematically and regularly updating the planning and maintaining a continuing planning process.

Specifically the following conclusions can be drawn from the research.

1. The corridor growth factor procedure, in combination with synthetically produced external information, can be used as a complete package to determine future traffic demand within the accuracy necessary for major thoroughfare planning in small urban areas. Tests in Lafayette and columbus substantiated this fact.

2. The three parameters used for the corridor growth factors determination are adequate to indicate corridor traffic volume growth. The data are easy to obtain and easy to forccast. Aerial photography can be used satisfactorily to obtain dwelling unit information, discern growth patterns, etc., for use with the simplified procedure.

3. The research indicates that the following conclusions may be drawn concerning external traffic in small urban areas:

a. The existing distribution of total external cordon traffic volumes between stations may be used as the best estimate of future distribution of the forecasted total external volumes.

b. For small urban areas, a growth factor developed using the county total vehicle registration increase is sufficiently accurate for thoroughfare planning. 
c. Regression modeling can be used to provide the total external-external traffic volumes in a small urban area within sufficient accuracy for thoroughfare planning.

d. The best estimate for distribution of external-external traffic volumes among external cordon stations is the existing percentages of total external volumes.

Some precautions are necessary to use the completed procedure as follows:

1. In corridors where the rate of growth of the parameters for the forecast period exceeds a rate of approximately six percent per year, a shorter forecast period should be used.

2. Although the analysis should be by corridor, the location of a specific major generator on an arterial should be considered in the determination of future improvernent priorities.

3. When traffic on one arterial in a corridor nears the capacity of the street, traffic will use parallel arterials in the corridor. This fact should be considered in evaluation of deficiencies.

4. The addition of new generators in the outer portion of the corridors do not effect the central area traffic volumes significantly.

5. The procedure has a slight tendency toward over estimating traffic volumes. This is considered a positive factor in the procedure. A slight over design in essence slightly extends the derign life of the facility.

6. If regression modeling is utilized for forecasting total external-external traffic volumes, the external cordon must be outside all 
development. The only problem this incurs is a slightly larger area within which to count the parameters.

It should be recognized that columbus, Indiana is fortunate to have had capable staff personnel and progressive administrations interested in proper planning through the years. This factor should be considered when planning similar studies in other communities and where necessary adjusting the cost upward if the same positive attributes have not existed in the past city government.

Finally, the simplified procedure for major thoroughfare planning as outlined herein can provide estimates of future traffic sufficiently accurate for the planning. Comparison of the forecasted volumes to the capacities of the existing streets provide for the identification of both the location and magnitude of the deficiency. In a small urban area the application of sound traffic engineering will provide the necessary relief for many of the problem areas. If further remedial action is required the simplicity of the thoroughfare system in small urban areas usually dictates the feasible alternative. Extensive, detailed studies are usually not necessary.

The application of the methodology developed and outlined will substantially reduce the cost, time and personnel requirements for thoroughfare planning. A city. using existing personnel, can reasonably expect to be able to complete a major thoroughfare plan in less than one year assuming that the personncl contribute only a portion of their time to the study. The personnel can then maintain a continuing planning process with the devotion of only approximately ten percent of their time to the study. This will provide the means of accomplishing major thoroughfare planning in small urban areas within the capabilitics of all such areas, thus ultimately providing a better thoroughfare system at the most economical cost. 
RECOMMENDATIONS FOR FURTHER RESEARCH

To ensure that the inference space for the completed procedure includes the nation as a whole it is recommended that the external growth factor method of forecasting be thoroughly investigated for regional areas where the urbanization patterns of the communities were different, such as the west and southwest.

Additional research is also necessary to evaluato completely the effect that the location of an interstate Highway through a study area has on the traffic patterns of small urban areas of different population ranges.

The full range of applicability of the completed package for corridor growth factor method of traffic lozecasting in small urban areas should be determined. The completed project indicated complete acequacy of the package through a population range of 65,000 (LafayetteWest Lafayette). The upper population limit beyond this point would have to be determined by successive applications in various sizes of urban areas. 


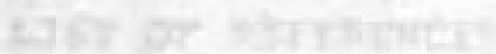

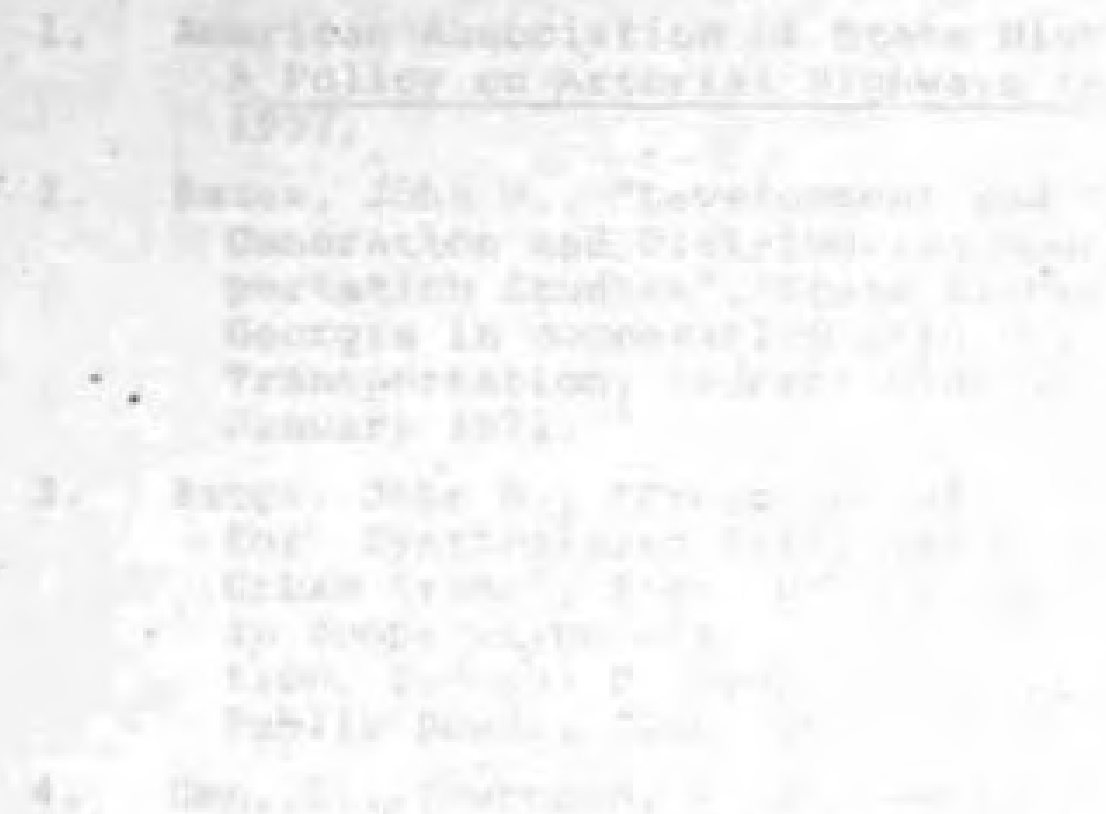

\section{LIST OF REFERENCES}

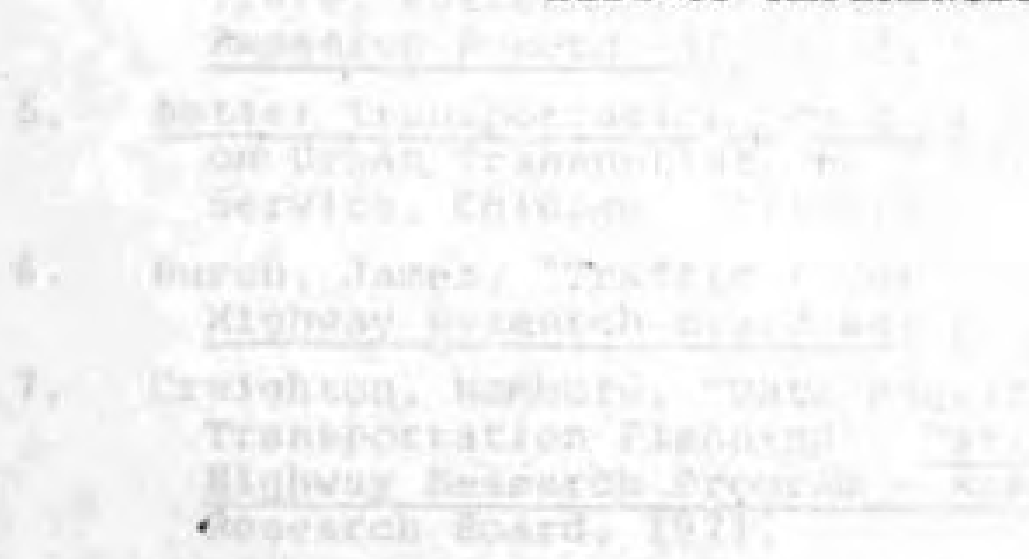

415.

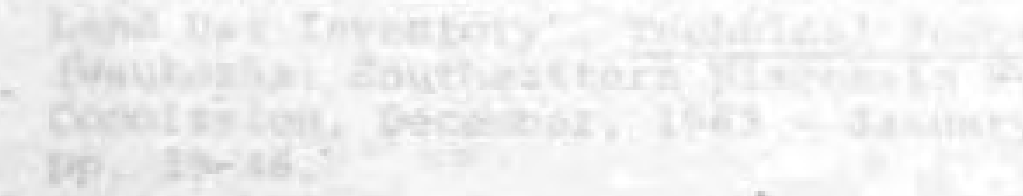




\section{LIST OF REPERENCES}

1. American Association of State llighway officials, A Policy on Arterial Highways in Urban Arcas, 1957.

2. Bates, John W., "Development and Testing of Synthetic Generation and Distribution Models for Urban Transportation Studies", State Highway Department of Georgia in cooperation with U.S. Department of Transportation, Federal Highway Administration, January 1971 .

3. Bates, John W., "Experimental Development of a Method for Synthesizing Internal-Internal Trips in Small Urban Areas", State llighway Department of Georyia in cooperation with U.S. Department of Transportation, Federal llighway Administration, Bureas of Public Roads, June, 1970.

4. Len, C., Bouchard, R. J., Sweet, C. E., Jr., "An Evaluation of Simplified Procedurcs for Determining Travel Patterns in a Small Urban Arca, Hiqhway Research Record, 88, 1965, Pp. 137-170.

5. Better Transportation for Your City, Wational Comittee on Urban Transportation, Public Administration Service, Chicago, Illinois, 1958.

6. Burch, James, "Traffic Interactance Between Cities", Highway Research Board Bulletin, No. 297, pp. 14-21.

7. Creighton, Hamburg, "Data Requirements for Metropolitan Transportation Planning", National Coonerative Highway Research Program - Report 120, Highway Research Board, 1971.

8. Clinkenbeard, Harland E., "Aerial Photographs in Land Use Inventory", Technical Record, Vol. 1, No.2 (Waukesha: Southeastern Wisconsin Regional Planning Commission, December, 1963 - January, 1964), PP. 39-46.

9. DeLeuw, Cather and Company, Arterial Strect Plan for Columbus, Indiana, Chicago, I11inois, April 1963.

10. French, D.K., "A Simplified Procedure for Major Thoroughfare Planning in Small Urban Areas", Joint Highway Rescarch Project, Report No. 29, Novenber, 1967. 
11. Golenburg, Marvin, "An Evaluation of Methods for Updating Origin and Destination Studies", Joint Highway Research Project No. 9, June, 1966.

12. Lansen, Walter G., "Traffic Approaching Cities", Public Roads, Vol. 31, No. 7, April 1961.

13. Harland Bartholonew and Associates, Procedural Outline for Major Thoroughiare planning, Memphis, Tennessce, 1964 .

14. Highway Research Board, Hiqhway Capacity Manual, Special Report No. 87,1965 .

15. Howlett, Bruce E., "Determining Urban Growth and Change from Aerial Photograph Comparisons", Highway Research Record, No. 19, Washington: Highway Research Board, 1963, pp. 1-16.

16. Jeffries, W. R., Carter, E. D., Simplified Technirues for Developing Transportation Plans - Trip Coneriation in Small Urban Areas, Technical bulletin No. 84, Engineering Experiment Station, West Virginia University, Morgantown, West Virginia, December, 1966.

17. Jones, Andrew D., "The Uses of Aerial Photography in Urban Transportation Studies" Masters Thesis, University of Texas, Austin, Texas, January 1965.

18. Newspaper Enterprise Association, Inc., Wor J Alamante1970, New York, N.Y., 1970.

19. North Caroline Ilighway Department, Transportation Planning Data, March 1965.

20. Pollard, William S. Ir., Guyton, Joseph W., A Modified Growth Factor, Trip Distribution Procchura, Prejared for presentation at lighway kesearch Hoard, January, 1964 .

21. Ricks, S. W., "A Synthesis of Urban Travel Patterns in Metropolitan Lafayette, Indiana", Jojnt Highway Research Project No. 28, Gctober 1965.

22. Rude, Ronald Gregory, "Formulation of a Technique for Evaluating Urban Highway Needs", Masters Thesis, Purclue University, January 1966.

23. Schuster, J.J., "Development of Travel Patterns in Major Urban Áreas", Joint Highway Research project, Report No. 10, June 1964.

24. Sexton, B. J., "Kentucky's Transportation Planning Program for Small Urban Areas", Traffic Quarterly, Vol. XXIII, No. 4, October 1969. 
25. Shunk, G. A., "The Journey to Work: A Singular Basis for Travel Pattern Surveys", Joint Highway Research Project, Report No. 29, November 1967.

26. Texas Highway Department, Corpus Christi Transportation Plan, Austin, Texas, 1964 .

27. Texas Highway Department, Urban Transportation Planning Manual, October 1963.

28. U.S. Department of Commerce, Bureau of Public Roads, Calibrating and Testing a Gravity Model for any Size Urban Area, Washington, D.C., July 1963.

29. Vogt, Sage and Pflum, Technical Memorandum: Traffic Models Winchester Urban Transportation tudy, Prepared for N.E. Kentucky Department of III hivays, in cooperation with U.S. Department of Transportation Federal Highway Administration, Cincinnati, Ohio, January 1971.

30. Wiant, Rex H., " $\mathrm{A}$ Simplified Method for Forecasting Urban Traffic", Highway Research Board Bulletin No. $297,1961, \mathrm{pp} \cdot 129-138$. 


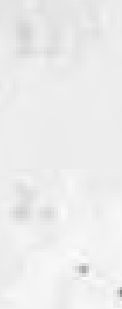

GENERAL REPERENCES

\section{ChIFA}

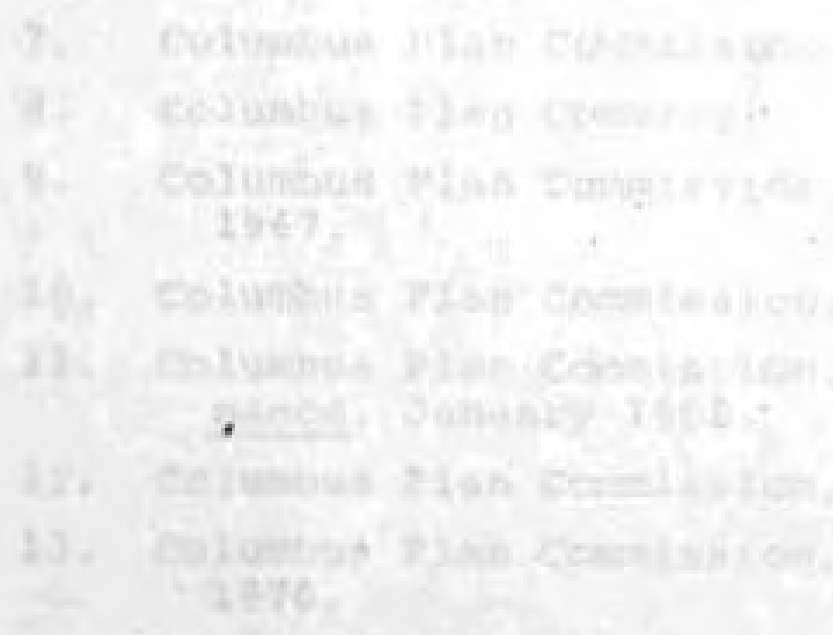

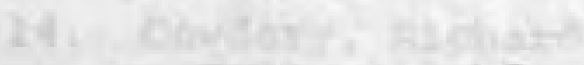

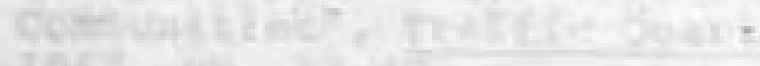

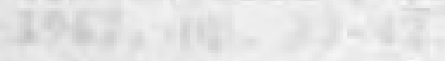

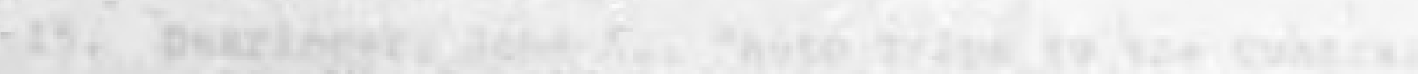

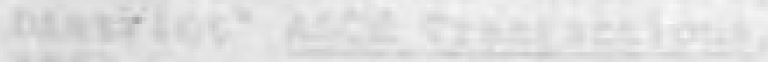

14tata 
GENERAL REFERENCES

1. Barnes, Charles F., "Integrating Land Use and Traffic Forecasting", Highway Research Board Bulletin, No. 297, 1961, pp. 1-14.

2. Barr, Dunlop and Associates, Inc., "Technical Memorandum on Travel Model Developrient - Bowling Green, Kentucky", 1971.

3. Barton-Aschman Associates, Inc., Columbus Central Arca Traffic Volumes, December 1970.

4. Barton Aschman Associates, Inc., A Sugqested Circulation Plan and Illustrative Parking promram, January 1969.

5. Bather-Ringrose-Wolsfeld, Inc., Technical Memorandur: Development of Internal Travel, St. Clour iksopolitan Arca Transportation and Planning study, Roseville, Minnesota, August, 1971.

6. Chapin, F. Stuart, Urban Land Use Planning, University of Illinois Press, Urbana, Illinois, 1965.

7. Columbus Plan Commission, Columbus Master Plan, 1949.

8. Columbus Plan Comnission, Columbus Master plan, 1951.

9. Columbus Plan Commission, Comprehensive Plan - 1985, 1967.

10. Columbus Plan Commission, Proposed Genoral Plan, 1966.

11. Columbus Plan Coumission, Thoroughfare Plan - Ordinance, January 1968.

12. Columbus Plan Comission, Zoning Ordinance, 1971.

13. Columbus Plan Commission, Annual Reports, 1968, 1969, 1970.

14. Cowdery, Richard C., "Transportation Planning in Smal1 Communities", Traffic Quarterly, Vol. 16, January 1962, pp. 13-42.

15. Dearinger, John A., "Auto Trips to the Central Business District" ASCE Transactions, Vol. 128, Part IV, 1963. 
16. DeLeuw, Cather and Company of Canada Linited, A New Procedure for Urban Transportation Planning, Chicago, Illinois, September 1969.

17. DeLeuw, Cather and Company, Parking Needs and Feasibility Study: Bartholomew County Indiana, January 1966.

18. Draper, N.R., Smith H., Applied Regression Analysis, John Wiley and Sons, Inc., New York, 1966.

19. Gakenheimer, Ralph A., "Planning, Transportation and the Small City", Traffic Quarterly, Vol. 16, January 1962, pp. 31-42.

20. Grecco, W. L., "The Continuing Transportation Study for the Small City", Proceeding of the 49 th Annual Road School, Purdue University, Lafayette, Indiana, 1963 .

21. Guyton, J. W. and Pollard, W. S., Jr., "Corridor Analysis of Travel Desires as Utilized in Major Street Planning", Highway Research Board BulloLin $347,1962, \mathrm{pp} .222=253$.

22. Hammer, Greene, Siler Associates, The Housing Crisis in Bartholomew County, Indiana, 1970 .

23. Lafayette - West Lafayette, Indiana Traffic Survey Report, Indiana State Highway Commission, 1964 .

24. Martin, Brian V., Memmott, Frederick W., III., Bone, Alexander J., Principles and Techniques of frodicting Future Demand for Urban Arca Transportation, Massachusetts institute of Technology, Cambriage, Massachusetts, 1970 .

25. Missouri State Highway Department, Travel Sinulution Procedures for Small Cities.

26. Nakkash, T.z., "Activity - Accessibility Models of Trip Generation", Joint Highway Research Project No. 10, May 1969.

27. Ostle, Bernard, Statistics in Research, Iowa State University Press, Ames, Iowa, 1963.

28. Smith, Bob L., "Gravity Model Theory Applied to a Small City Using a Small Sample of Origin-Destination Data", Highway Research Record 88, 1965, pp. 85-115.

29. Smith, Wilbur and Associates, Patterns of Car Ownership, Trip Generation and Trip Sharing in Urbanized Areas, Prepared for U.S. Department of Transportation, Bureau of Public Roads, New Haven, Connecticut, June 1968. 
. . * ' '

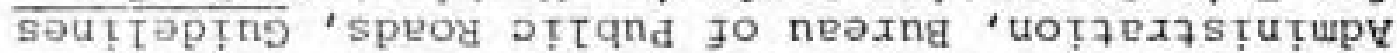

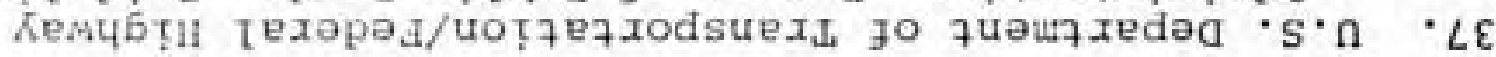

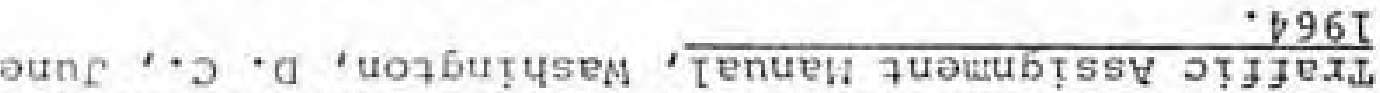

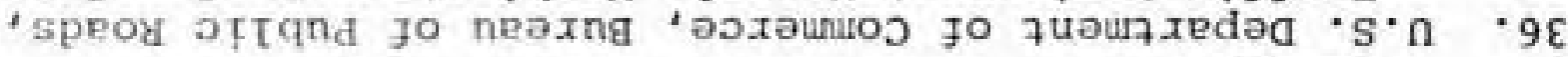

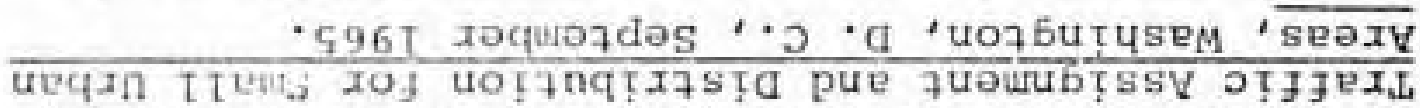

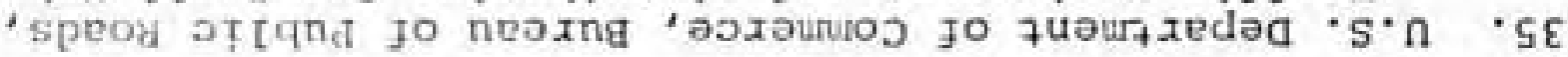

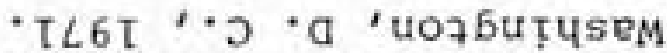

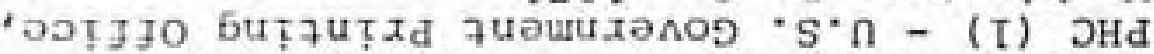

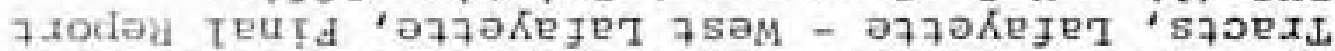

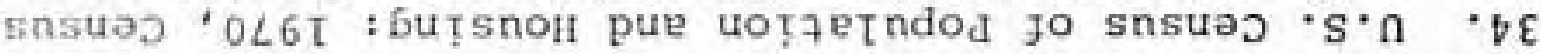

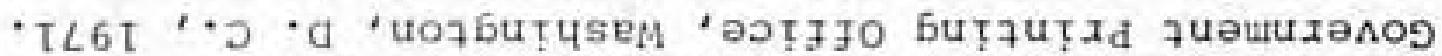

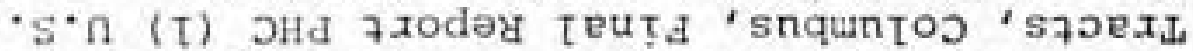

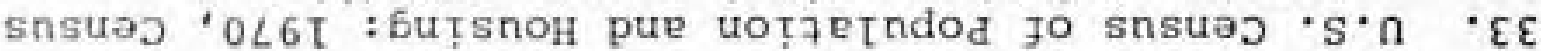

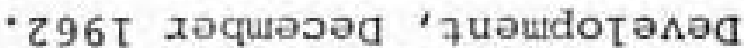

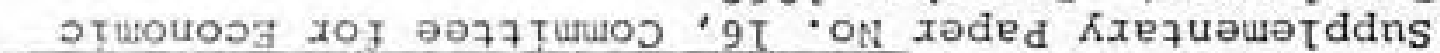

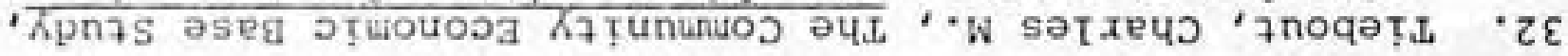

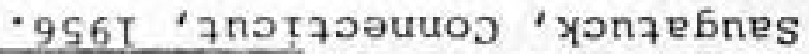

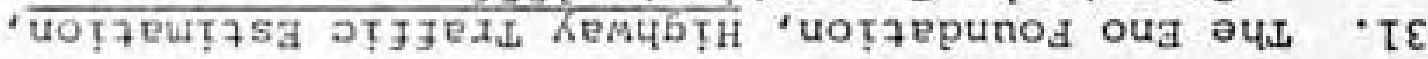

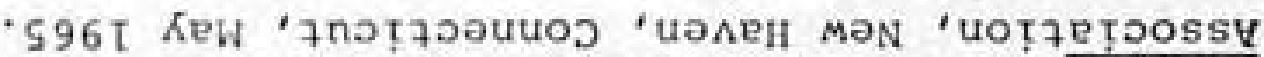

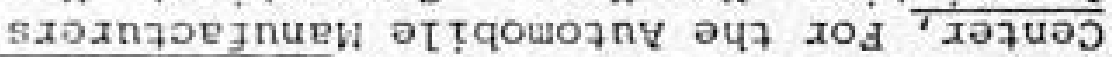

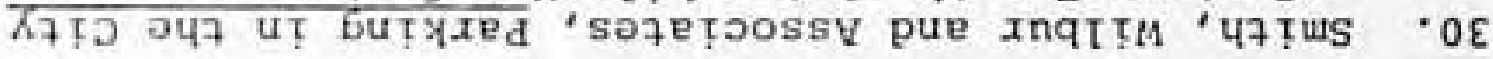





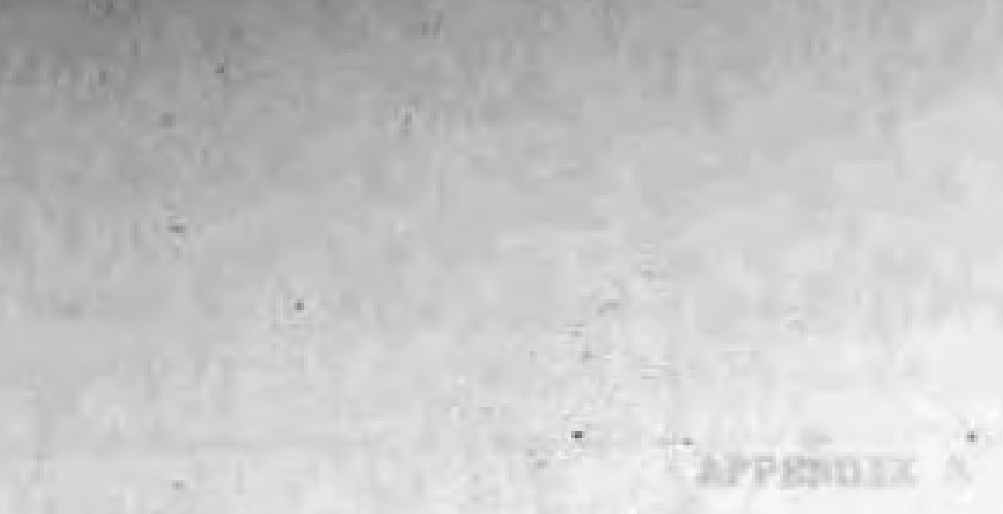

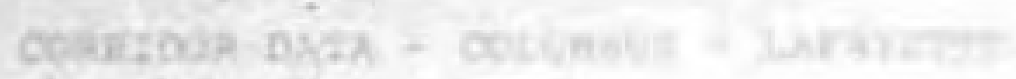

the Ial foung taides or

numbes of givetiset andes

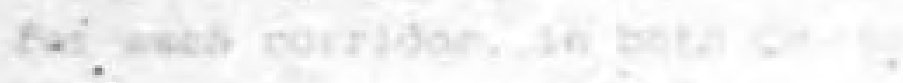

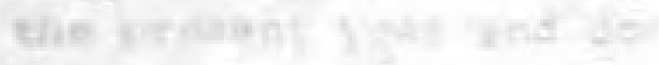

\section{APPENDIX A}


APPENDIX $A$

CORRIDOR DATA - COLUMBUS - LAFAYETTE

The following tables in Appendix A present the total number of dwelling units, employces and retail crployees for each corridor, in both colunbus and Lafayette, for the present year and design year. 
Table IA 1952 Lafayette Corridor Data

\begin{tabular}{|c|c|c|c|}
\hline Corridor & $\begin{array}{c}\text { Dwelling } \\
\text { Units }\end{array}$ & Employees & $\begin{array}{c}\text { Retail } \\
\text { Employees }\end{array}$ \\
\hline Central Area & 4,044 & 5,063 & 1,708 \\
\hline 1 & 1,144 & 546 & 18 \\
\hline 2 & 788 & 55 & 30 \\
\hline 3 & 1,045 & 122 & 8 \\
\hline$\cdot 4$ & 931 & 3,651 & 125 \\
\hline 5 & 1,126 & 864 & 39 \\
\hline 6 & 906 & 743 & 12 \\
\hline 7 & 2,010 & 1,576 & 73 \\
\hline 8 & 88 & 1,790 & 0 \\
\hline 9 & 337 & 61 & 0 \\
\hline 10 & 355 & 29 & 0 \\
\hline 11 & 854 & 3,599 & 79 \\
\hline 12 & 315 & 26 & 26 \\
\hline 13 & 0 & 2,066 & 0 \\
\hline \multirow[t]{2}{*}{14} & 378 & 64 & 46 \\
\hline & 12,889 & 16,817 & 2.039 \\
\hline
\end{tabular}


Table 2A 1970 Lafayette Corridor Data

\begin{tabular}{lrrr} 
Corridor & $\begin{array}{c}\text { Dwelling } \\
\text { Units }\end{array}$ & Employees & $\begin{array}{c}\text { Retail } \\
\text { Employees }\end{array}$ \\
\hline Central Area & 8,228 & 3,972 & 1,413 \\
1 & 1,862 & 1,909 & 139 \\
2 & 1,673 & 377 & 153 \\
3 & 3,332 & 489 & 199 \\
$4^{*}$ & 841 & 6,249 & 516 \\
5 & 1,444 & 2,735 & 162 \\
6 & 2,169 & 2,404 & 903 \\
7 & 2,391 & 1,255 & 139 \\
8 & 301 & 2,320 & 35 \\
$9 *$ & 472 & 153 & 0 \\
$10 *$ & 1,929 & 733 & 0 \\
11 & 172 & 0 & 016 \\
12 & 1,195 & 1,857 & 100 \\
13 & - & 6,464 & 81 \\
$14 *$ & 535 & 102 & 4,451 \\
& & 31,019 &
\end{tabular}

* 9 and $10-4$ and 14 were combined for growth factor calculation. 
Table 341964 West Lafayette Data

\begin{tabular}{cccc}
\hline Corridor & Dwelling Units & Employees & $\begin{array}{c}\text { Retail } \\
\text { Employees }\end{array}$ \\
\hline $9 \& 10$ & 1,103 & 686 & 136 \\
11 & 163 & 0 & 0 \\
12 & 422 & 784 & 117
\end{tabular}


Table 4A 1960 Corridor Data - Columbus

\begin{tabular}{|c|c|c|c|}
\hline Corridor & $\begin{array}{c}\text { Dwelling } \\
\text { Units }\end{array}$ & Employees & $\begin{array}{c}\text { Retail } \\
\text { Employees }\end{array}$ \\
\hline Central Area & 460 & 6,360 & 467 \\
\hline 1 & 259 & 25 & 4 \\
\hline 2 & 69 & - & - \\
\hline 3 & 239 & 92 & 21 \\
\hline 4 & 1,533 & 3,686 & 188 \\
\hline 5 & 167 & 262 & - \\
\hline 6 & 1,657 & 2,420 & 66 \\
\hline 7 & 4,780 & 2,988 & 325 \\
\hline $\begin{array}{l}\text { N. E. Quadrant } \\
\text { (U.S. } 31 \\
\text { Bypass) }\end{array}$ & 5,663 & 4,752 & 325 \\
\hline
\end{tabular}


Table 5A 1970 Corridor Data - Columbus

\begin{tabular}{cccc}
\hline Corridor & $\begin{array}{c}\text { Dwelling } \\
\text { Units }\end{array}$ & Employees & $\begin{array}{c}\text { Retail } \\
\text { Employees }\end{array}$ \\
\hline Central Area & 460 & 9,415 & 666 \\
1 & 409 & 67 & 9 \\
2 & 131 & 126 & 23 \\
3 & 614 & 147 & 35 \\
4 & 1,619 & 4,739 & 536 \\
5 & 170 & 499 & 3 \\
6 & 1,863 & 2,844 & 194 \\
7 & 5,732 & 6,486 & 1,190 \\
N. E. Quadrant & 6,618 & 8,573 & 1,236 \\
(U.S. 31 \\
Bypass)
\end{tabular}





\section{VITA}

Andrew Delaney Jones was born February 23, 1930 in Camp Verde, Texas. He is married to the former Norene Beard and has two children, Kathy Sue and Randal Delaney.

He graduated from Schreiner Institute in Kerrville, Texas in June 1950 with an Associate of Arts Degree.

He attended the University of Houston, graduating with a Bachelor of Science in Civil Engineering in June 1953.

Mr. Jones was employed by the Texas Highway Departmont for approximately nineteen years. The first nine years he was engaged in planning, design and construction of freeways within the city of llouston, Texas. The next five years were spent in the Urban Planning Section in the department's Austin office as a Supervising Planning Engineer, serving on the technical comnittees for the Galveston and Houston Transportation Studies and serving as the liaison-coordinator between the Austin office and the Transportation Study offices in the Dallas-Ft. Worth, Corpus Christi and San Antonio Urban Transportation Studies.

He attended the University of Texas at Austin receiving a Master of Science in Civil Engineering in January 1965.

Mr. Jones held the position of District Construction Engineer in the E1 Paso Texas Highway Department District from 1965 until submitting his resignation to enter Purdue University in September 1970.

He attended the University of Texas at El Paso part time during 1968 and 1969. He also held the position of part-time lecturer at the university during the fall of 1969 . 
$\mathrm{Mr}$. Jones is a Registered Professional Engineer in Texas and is a member of Texas and National Society of Professional Engineers and an Associate Member of the Institute of Traffic Engineers.

He is a member of Tau Beta Pi, Chi Epsilon and an Associate nember of the Society of Sigma Xi.

$\mathrm{Mr}$. Jones has participated as a speaker in several Urban Transportation Planning Seminars in Texas and also participated in the preparation of an Urban Transportation Planning Manual that is used as a guide for the Texas Studies conducted in accordance with the Federal Aid Highway Act of 1962 . 